\title{
C. ESKALATION: BIS ZUM AUSBRUCH DES BÜRGERKRIEGES
}

In diesem Kapitel untersuche ich die Zeit zwischen Vertragsspaltung und Ausbruch des Krieges. Zunächst stelle ich die irische Presselandschaft vor und zeige, wie die Propagandisten während des Unabhängigkeitskrieges die öffentliche Meinung beeinflussten. Dann erkläre ich die Organisation der Propagandabehörden von Vertragsbefürwortern und -gegnern und warum die freistaatlichen Propagandisten ihren Gegnern - zumindest organisatorisch - deutlich überlegen waren.

Danach wende ich mich den unterschiedlichen Handlungs- und Legitimationsstrategien zu. Ich zeige, wie das dogmatische Festhalten an „the Republic" schnell die Handlungsmöglichkeiten der Vertragsgegner einengte. Wie versuchten die Republikaner, sich aus dieser Handlungskrise zu befreien - und versuchten sie es überhaupt? Auf der anderen Seite gerieten die Befürworter des Vertrages in eine Legitimationskrise: Als „Kompromißler“ konnten sie nicht mehr ungebrochen auf das republikanische Geschichtsgesetz, die nationale Martyrologie und das britische Feindbild zurückgreifen. Wie gelang es ihnen, sich eine neue, möglichst eine nationale Legitimationsstrategie zu erfinden?

Im letzten Teilkapitel zeige ich: Obwohl der Bürgerkrieg vielen Zeitgenossen bald unvermeidlich erschien, war der Weg in die Konfrontation keine Einbahnstraße. Die Aktivisten auf beiden Seiten bemühten sich um eine neue "national unity“, auch wenn sie damit scheiterten.

\section{RAHMENBEDINGUNGEN UND ORGANISATION VON PROPAGANDA}

\section{DIE PRESSE IRLANDS UM 1922}

Was die Bevölkerung oder einzelne soziale Gruppen vom Vertrag hielten, läßt sich, wie ich gezeigt habe, nur grob abschätzen. Leichter läßt sich bestimmen, was diejenigen dachten, deren Beruf es war, eine Meinung zu haben und diese zu veröffentlichen: Journalisten, Redakteure und Propagandisten.

Zeitungen und Propagandablätter spiegelten nicht einfach „die öffentliche Meinung" wider. Zwar mußte jedes Blatt Rücksicht auf seine Klientel nehmen, um nicht am Markt vorbei zu produzieren. Genauso versuchte es 
aber, seine Leser zu beeinflussen und seinen politischen Standpunkt durchzusetzen. Als politische Tendenzpresse schwankten die Blätter daher zwischen der „Reinheit der Lehre“ und den Interessen ihres Publikums. Die Auflagen der Blätter geben dabei einen groben Hinweise darauf, wie groß diese Klientel war, sie sind jedoch nur in wenigen Fällen eindeutig zu ermitteln. ${ }^{1}$

In den 1920ern erreichten die Dubliner Tages- und Wochenzeitschriften über Lkws und Eisenbahnen alle irischen Grafschaften. Dazu existierte in jeder größeren Ortschaft mindestens eine lokale Provinzzeitschrift. Zeitungen waren längst kein Luxusgut mehr: 1920 kostete eine Zeitung nur noch ein Achtel des Preises von 1850. Seit 1914 hatte sich der durchschnittliche Zeitungspreis trotz Kriegsinflation halbiert. Auch Analphabetismus schloß 1920 nur noch wenige von der Lektüre aus. ${ }^{2}$

Den Einfluß der Presse sollte man dennoch nicht überschätzen. Wie ich gezeigt habe, gab es im frühen zwanzigsten Jahrhundert effizientere Umschlagsorte von politischer Meinung: die katholische Kirche, deren Priester fast die gesamte katholische Bevölkerung erreichten, die Institutionen des „Local Government“, Pubs und Läden. ${ }^{3}$ Weniger wichtig als zuvor waren während des Bürgerkrieges die politischen Vereine: Sie wurden im Bürgerkrieg selbst Opfer der Vertragsspaltung, die Gaelic League schrumpfte zusammen, Sinn Fein kollabierte. ${ }^{4}$ Doch während diese anderen Einflüsse quellentechnisch viel schwerer zu greifen sind, läßt sich über die Argumentation in Presse und Propaganda auch abschätzen, mit welchen Argumenten Pfarrer, Pubbesitzer oder Sinn Fein-Aktivisten die Bevölkerung polarisierten.

Auch wenn Presse und Propaganda die politische Meinung nicht monopolisieren konnten, so hatten sie doch fast ein Monopol für politische Informationen. Dieses Informationsmonopol wirkte viel restriktiver, als die Pluralität der irischen Presselandschaft zunächst vortäuscht. Alle Provinzzeitungen bezogen ihre überregionalen Nachrichten aus den drei Dubliner

1 Noch 1937 war der IRISH INDEPENDENT das einzige Blatt, das unabhängig zertifizierte Auflagezahlen veröffentlichte: STEPHEN J. BROWN, The Press in Ireland. A Survey and a Guide. Dublin 1937, S. 171.

2 Louis Michael Cullen, Eason and Son. A History. Dublin 1989, hier: S. 167 f.; ders., Establishing a Communications System: News, Post and Transport, in: Farrell (Hrsg.), Communications, S. 18-29, hier: S. 29; FOSTER, Modern Ireland, S. 385: 1851 war noch knapp die Hälfte der irischen Bevölkerung Analphabeten, 1911 nurmehr elf Prozent; LEE, Ireland 1912-1985, S. 76, geht für die zwanziger Jahre von einer an Null grenzenden Analphabetismusrate aus.

3 FITZPATRICK, Politics, S. 86-107.

4 Hopkinson, Green, S. 57, 100, 131 f.; FITZPATRICK, Politics, S. 164. 
Tageszeitungen, manchmal auch aus der britischen Tagespresse oder dem Cork Examiner. Nur Propagandablätter verfügten über zusätzliche Informationen aus ihrem Lager.

Die drei Dubliner Tageszeitungen dominierten damit die irische Presselandschaft: Das Freeman's Journal, der Irish Independent und die Irish Times waren neben dem Cork Examiner die einzigen modernen Tageszeitungen außerhalb Nordirlands. Sie veröffentlichten jeweils eine Wochenzeitung. Freeman's Journal und Irish Independent gaben dazu eine tägliches Abendblatt, die Irish Times und das Freeman's Journal ein wöchentliches Sportblatt heraus. ${ }^{5}$ Die Dubliner Tageszeitungen hatten ein eigenständiges Korrespondentennetz, Niederlassungen in der Londoner Fleet Street, besaBen eigene Druckereien und Verlage und organisierten zum Teil auch den irlandweiten Handel mit ihren Zeitungen selbst. Sie waren professionelle journalistische Großbetriebe und in Dublin ein wichtiger Arbeitgeber; für den Irish Independent arbeiteten rund 500 Mitarbeiter. $^{6}$

Der Freeman war 1763 gegründet worden und damit Irlands älteste Zeitung. Spätestens ab 1916 war sie offizielles Sprachrohr der niedergehenden Irish Parliamentary Party gewesen, zu der Patrick J. Hooper, ab August 1916 Chefredakteur des Freeman, enge Kontakte gehabt hatte. Doch seine redaktionelle Politik eines konstitutionellen Nationalismus fand in den folgenden Jahren immer weniger Leser. Nach dem Waffenstillstand stellte sich der Freeman auf die Seite der erfolgreichen Revolutionäre, unterstützte nach der Vertragsspaltung dezidiert die Vertragsbefürworter.

Die Auflage der frühen zwanziger Jahre läßt sich, da der Freeman unter der erdrückenden Konkurrenz des Irish Independent die Auflage verheimlichte, nur schätzen, vermutlich weniger als 30000 Stück pro Tag. Doch durch den damit verbundenen finanziellen Mißerfolg steigerte sich das politische Engagement des Blattes und seines neuen Besitzers, des Weinhändlers Martin FitzGerald nur noch mehr. Hatte er die Übernahme des Blattes im Oktober 1919 zunächst als lukrative Investition betrachtet, hielt er jetzt erst recht an Chefredakteur Patrick J. Hooper, der alten Redaktion und ihrer gemäßigten Politik fest - bis das Blatt Ende 1924 endgültig bankrott ging. ${ }^{7}$

5 Das Freeman's Journal den Evening Telegraph, den WeEkly FreEman AND NATIONALIST PRESS und SPORT; Der IRISH INDEPENDENT den EVENING HERALD, den SUNDAY INDEPENDENT und den WEEKLY INDEPENDENT; die IRISH TIMES die WeEKLY IRISH TIMES und IRISH FIELD.

6 The Newspaper Press Directory And Advertisers Guide. London 1921, S. 203, 210 f.; NeWsPaper Press Directory, 1922, S. 205, 547, 581; NeWsPAPER Press DireCTORY, 1923, S. 205, 549, 582; IRISH INDEPENDENT, 22. Dezember 1919, S. 2.

7 FELIX M. LARKAN, Editorial Comment in the Freeman's Journal 1916-1918, (Master The- 
Seit 1859 war die Irish Times aus nationalistischer Sicht „the organ of the alien garrison"8, also Stimme der irischen Protestanten außerhalb Ulsters gewesen. 1922 wurde sie zum Sprachrohr der Unionisten, die sich mit dem Vertrag abgefunden hatten. Entsprechend deutete die Irish Times den Vertrag als Integration Irlands in das Commonwealth und als Ende eines Bürgerkrieges. ${ }^{9}$ Als Zeitung einer Minderheit war die Auflage der Irish Times deutlich kleiner als die des nationalistischen Massenblattes Irish Independent, vermutlich um die 30000 pro Tag. ${ }^{10}$

Der 1905 von Dublins „premier capitalist“11 William Martin Murphy gegründete Irish Independent war die jüngste und modernste der drei Dubliner Tageszeitungen. Seine redaktionelle Politik orientierte sich nicht primär an politischen Überzeugungen, sondern an der Auflage. Obwohl der Irish Independent nationalistisch ausgerichtet war, legte er sich auf keine Parteilinie fest. Im Unabhängigkeitskrieg lavierte er zwischen konstitutionellem und radikalem Nationalismus, verfolgte eine Politik, die zwischen den Zeilen Sympathie für Sinn Fein spüren ließ, aber keine drastischen Maßnahmen der britischen Verwaltung provozierte. Auch der Irish Independent unterstützte den Vertrag, machte sich aber, anders als der Freeman, nicht zum inoffiziellen Regierungsblatt. Er folgte in seinen Leitartikeln einer ausgesprochenen Stammtischlogik, argumentierte in einem populistischen, mitunter auch regierungskritischen Ton. ${ }^{12}$ Der Irish Independent traf damit den Nerv einer großen Leserschaft, seine Auflage lag kurz vor dem Ausbruch des Bürgerkrieges bei knapp 130000 Stück pro Tag, dazu kamen noch einmal gut 65000 Exemplare für das Abendblatt Evening Herald..$^{13}$

Außerhalb Dublins erschien in den sechsundzwanzig südirischen Grafschaften nur eine Tageszeitung: der 1841 gegründete Cork Examiner. Mit einer Auflage von schätzungsweise 30000-50000 war er die in Munster am

sis). Dublin 1972, S. 92-104; ebd., S. 115 f. Larkan hat für Juni 191840000 Stück ermittelt. Während der Revolution verlor der FREEMAN jedoch einen Teil seiner Klientel, während die Auflage des IRISH INDEPENDENT um 20000 Stück stieg.

8 CATHOlic Bulletin, Februar 1922, S. 68.

9 Geraldine Newcomen, Reactions of Southern Irish Unionists to the Birth of the Irish Free State, 1922-23. Dublin (Thesis, University College Dublin [UCD]) 1983, S. 1-4.

$10 \mathrm{Vgl}$. LARKAN, Freeman's Journal, S. $116 \mathrm{f}$.

11 So: FosTER, Modern Ireland, S. $442 \mathrm{f}$.

12 IRISH INDEPENDENT, 14. Januar 1922, S. 5; Donal MCCARTNEY, William Martin Murphy: An Irish Pressbaron and the Rise of the Popular Press, in: FARrell (Hrsg.), Communications, S. 30-8, hier: S. 33 f.

13 IRISH INDEPENDENT, 28. Februar 1923, S. 4 (zertifiziert von der unabhängigen Agentur „Craig Gardener \& Co.“); NEWSPAPER PRESS DiRECTORY, 1923, S. 220: für 1922 trotz Bürgerkrieg durchschnittlich über 130000 . 
weitesten verbreitete Zeitung. Auch der Cork Examiner unterstützte den Vertrag. ${ }^{14}$ Neben dieser Tagespresse, die in ganz Irland zirkulierte, gab es in jedem größeren Ort mindestens eine Provinzzeitung. Diese Blätter erschienen ein- bis dreimal pro Woche, waren häufig Einmann-Unternehmen, ${ }^{15}$ aber auch professionelle Kleinbetriebe. ${ }^{16}$ Die Provinzpresse repräsentierte ein breiteres Meinungsspektrum: Es gab einige unionistische Blätter, wie Skibbereen Eagle, Limerick Chronicle oder Cork Constitution. Daneben existierten viele Blätter, die nach wie vor einen gemäßigten Nationalismus vertraten, etwa Drogheda Independent, Galway Observer, Dundalk Democrat oder Roscommon Messenger. Die meisten Blätter radikalisierten sich während des Unabhängigkeitskrieges. Ihre Sympathien für Sinn Fein, zum Teil auch für die IRA, ließen sich zwischen den Zeilen herauslesen, wenn man die offizielle Sprachregelung kannte. Bereits im August 1919 registrierte die britische Verwaltung 45 Provinzblätter mit Sinn Fein-Sympathien gegenüber 59 Blättern, die noch zu Home Rule standen. Viele Zeitungen testeten während des Unabhängigkeitskrieges, wie weit sie gehen konnten, und kamen dabei häufig mit der britischen Verwaltung in Konflikt. ${ }^{17}$ Im ganzen gesehen war die Provinzpresse nationalistischer als die Dubliner und Corker Tagespresse und repräsentierte so auch den diffusen Republikanismus der Bevölkerung besser.

Im Dezember 1921 begrüßten auch alle irischen Provinzblätter den Vertrag. Einzige Ausnahme war der radikal nationalistische Connanghtman in Sligo. Doch nach der Vertragsspaltung äußerten viele Zeitungen Skepsis und Widerwillen. Zahlreiche Blätter waren bereit, für „national unity“ den Vertrag aufs Spiel zu setzen. ${ }^{18}$ Einige nahmen langsam eine neutrale Haltung an. ${ }^{19}$ Der Donegal Vindicator war jedoch das einzige Blatt, das offen ins vertragsablehnende Lager überlief.

Neben der Tages- und Provinzpresse erschienen in Irland eine Reihe politischer Wochenzeitungen und Zeitschriften. Diese Blätter hatten meist kleine Auflagen, aber eine oft sehr spannende politische Programmatik. Relativ weit verbreitet war das vom prominenten Labour-Politiker Cathal Shannon herausgegebene offizielle Organ der ITGWU, die Voice of La-

CORK EXAMINER, 23. März 1922, S. 4.

Z.B.: DONEGAL VINDICATOR, KERRY PEOPLE.

Z.B.: NATIONALiST, WATERFORD NEWS, Sligo CHAMPION, LiMERiCK LEADER.

FITZPATRICK, Politics, S. 90 f., 118-23.

18 Z. B.: Kerry PeOple, Munster News, Limerick Leader, Western PeOPle, WeXford PEOPLE.

19 Clare Champion, Waterford News, Mayo News. 
bour, ${ }^{20}$ sowie die Zeitschrift der Gaelic League Fine an Lae. ${ }^{21}$ Eine noch kleinere Reichweite hatte das Catholic Bulletin. Es war eine gleichermaßen nationalistische wie religiöse monatliche Zeitschrift, die der vertragsablehnende Abgeordnete J.J. O’Kelly und ab Ende 1922 Father Timothy Corcoran herausgab. Auf der anderen Seite des politischen Spektrums veröffentlichte der protestantische Intellektuelle George Russle seit 1904 die Irish Homestead. Als dieser im September 1923 das Geld ausging, gründete er mit Hilfe amerikanischer Spender den Irish Statesman.22

Zusätzlich zu Tageszeitungen, Provinzpresse und politischen Zeitschriften konnte man in den sechsundzwanzig Grafschaften auch alle nordirischen und britischen Zeitungen und Zeitschriften kaufen. Intransigente Unionisten, die den Vertrag nicht als Chance, sondern als Verrat werteten, fanden sich in der kompromißlosen Morning Post bestätigt. Die liberale Daily Mail war mit schätzungsweise 40000-50000 täglichen Exemplaren die in Irland am weitesten verbreitete britische Zeitung und auch bei Nationalisten beliebt: Sie hatte im Unabhängigkeitskrieg die britische Konfrontationspolitik kritisiert und der revolutionären Bewegung Publicity gegeben, ohne dabei der britischen Pressekontrolle in Irland zu unterliegen. ${ }^{23}$ Neben anderen Tageszeitungen wie der London Times oder dem Daily Telegraph überschwemmte eine Vielzahl unpolitischer Zeitschriften den irischen Markt: Allein zwanzig Sportzeitschriften und Rennmagazine, dazu Abenteuerheftchen für Jungen, Mädchenhefte, Hausfrauenmagazine, Klatschzeitungen, Fachzeitschriften. Bei diesen unpolitischen Titeln dominierten britische Importe den Markt. ${ }^{24}$

In dieser vielfältigen Presselandschaft machten die von Sinn Fein-Propagandisten während des Unabhängigkeitskrieges hergestellten Untergrundblätter nur einen kleinen Bruchteil aus.

20 Glandone, Advanced Nationalist Press, S. 211, meint die VoICE of LABOUR sei 1919 Irlands zweitgrößte Wochenzeitung gewesen. Vgl. dagegen die Selbsteinschätzung der VOICE OF LABOUR, 21. Juli 1922, S. 1, während des Bürgerkrieges: „Only a small proportion of the OBU [One Big Union, gemeint hier ITGWU] read it.“"Vgl. EMMET O’CONNOR, Syndicalism, S. 127.

21 Fine an Lae: mythische keltische Kriegerhorde um Fionn Mac Cumhaill.

22 IRISH HOMESTEAD, 14. Oktober 1922, S. 605; vgl. O'CALlaghan, Language, S. 237-40.

23 STEPHEN BRown, Press, S. 174 nennt für 1936 eine (vermutlich zu hoch angesetzte) Auflagenzahl von $70000-100000$.

24 NLI, BP, box 28a, Heft mit Auflistung der aufgehaltenen britischen Zeitungen (Zensurliste), 5. Juli 1922, 6. Juli 1922; NLI, BP, box 6, H.E. Gray an Beaslai, 7. Juli 1922. 


\section{Das PRopaganda DePartment im UNABHÄNGIGKEITSKRIEG}

Die IRA terrorisierte im Unabhängigkeitskrieg die Krontruppen, während die Untergrundorganisation Dail Eireanns die britische Verwaltung unterhöhlte. Damit konnte die revolutionäre Bewegung die britische Herrschaft in Irland erschweren, aber nicht beseitigen. Gefährlich wurden Guerillakrieg und republikanische Untergrundverwaltung für die britische Regierung erst, wenn von ihnen erzählt wurde. Der Tod Kevin Barrys, Thomas MacCurtains und Terence MacSwineys, die Guerillaerfolge von Cross Barry und Kilmichael, das Massaker vom Croke Park, auch die Dekrete Dail Eireanns: als isolierte Ereignisse waren sie alles andere als kriegsentscheidend. Erst als Geschichte delegitimierten sie die britische Herrschaft, emotionalisierten und radikalisierten sie eine breite Öffentlichkeit in Inund Ausland. Erst so wurden aus den Toten Märtyrer, aus den Guerilleros Freiheitshelden, aus einflußlosen Untergrundpolitikern eine republikanische Regierung. Geschichten wurden damit der Schlüssel zum Erfolg der Revolution.

Über den Guerillakrieg und Dail Eireanns Politik Geschichten zu erzählen, war die Aufgabe der republikanischen Propagandabehörden. In Irland selbst war Propaganda schwer zu verbreiten: Die Propagandablätter wie Griffiths Young Ireland oder Nationality hatten eine kleine Auflage und wurden von der britischen Behörden verfolgt oder unterdrückt. Die britische Pressekontrolle machte es den Zeitungen unmöglich, republikanische Gegendarstellungen zu veröffentlichen. Die republikanischen Pressemitteilungen konnten aber immerhin die Redakteure mit Informationen versorgen, die das Vertrauen in die offizielle britische Version der Ereignisse untergruben.

Die republikanische Propaganda richtete sich vorwiegend an das Ausland, vor allem an die USA, aber auch an Großbritannien, das europäische Ausland und an die übrigen Staaten des Empire. Ihr gelang es dabei sehr effizient, der britischen Version der "armed revolt“ die republikanische Version eines nationalen Freiheitskampfes gegenüberzustellen. In Amerika mobilisierten die Propagandisten die große Volksgruppe der irischstämmigen Amerikaner, um Druck auf die amerikanische Regierung auszuüben. Dabei verließ sich die revolutionäre Bewegung nicht allein auf Pamphlete und Propagandablätter. Die Amerikapropaganda war ihnen so wichtig, daß prominente Republikaner persönlich auf Propagandatour durch Amerika gingen, darunter Präsident de Valera, Mary MacSwiney und Harry Boland. So demontierte republikanische Propaganda das internationale Ansehen der 
britischen Regierung und setzte sie damit unter Druck, mit den Revolutionären zu verhandeln. ${ }^{25}$

Propaganda war im Unabhängigkeitskrieg die Aufgabe, die Dail Eireann am effizientesten improvisierte. Da Titel und Bezeichnungen häufig wechselten und keine klare Verwaltungsstruktur existierte, hing vieles von den Personen ab, die die Propaganda organisierten. Am wichtigsten waren die schon oben vorgestellten Propagandisten FitzGerald und Beaslai, sowie Robert Brennan, Erskine Childers und Frank Gallagher.

$\mathrm{Da}$ war zunächst Robert Brennan. 1881 in Wexford geboren, begann er gleich, nachdem er die örtliche Schule besucht hatte, als Journalist zu arbeiten. 1913 trat er den Irish Volunteers bei und nahm 1916 am Osteraufstand teil. Brennan wurde wie so viele Aktivisten zum Tode verurteilt, dann jedoch begnadigt und bald entlassen. Ab April 1918 leitete er das Sinn Fein Propaganda Department und koordinierte den Wahlkampf Sinn Feins. Im Unabhängigkeitskrieg war er einer der fähigsten Propagandisten. Er versorgte hauptsächlich ausländische Journalisten mit republikanisch selektierten Informationen. Brennan verbreitete Daten, Statistiken und Fakten, die republikanische Schlußfolgerungen nahelegten. Die Schlußfolgerungen selbst verbreitete er nicht. Nach dem Bürgerkrieg arbeitete er als Journalist für das Enniscorthy Echo, bis er 1931 Manager der neu gegründeten republikanischen Irish Press wurde. 1938 bis 1947 war er Diplomat in den USA. Danach leitete er ein Jahr den irischen Rundfunk, Radio Eireann. 1964 starb Brennan in Dublin. ${ }^{26}$

Neben der Parteipropaganda Sinn Feins gab es ab 1919 ein Ministerium für Publicity, das eng mit Brennans Behörde kooperierte und sich hauptsächlich auf Auslandspropaganda spezialisierte. FitzGerald, den ich oben als nachdenklichen Kritiker seines jugendlichen Idealismus vorgestellt habe, leitete diese Behörde. Auch er versorgte die Presse mit selektiven Informationen, organisierte geheime Treffen zwischen den Führern der revolutionären Bewegung und ausländischen Journalisten, bis ihn die Krontruppen im Februar 1921 verhafteten.

Das Herzstück der republikanischen Propaganda war das Irish Bulletin, das Frank Gallagher herausgab und für das er auch selbst die meisten Beiträge schrieb. Der 1898 in Cork geborene Gallagher begann wie Brennan

25 MCCRACKen, Representative Government, S. 24, 37f.; Richard Davis, Griffith, S. 30 f.; Alan Ward, Anglo-American Relations, S. 216-36; MCCARTNeY, Mission, S. 311-9; LYONS, Three Essays, S. 252; ders., War of Independence, S. 249 f.; KEOGH, Ireland and Europe, S. 5-9.

26 Zusammengefaßt nach: BOYLAN, Dictionary, S. 32; Zu Brennan siehe auch seine bis Mitte 1922 führende Autobiographie, Allegiance, passim. 
nach der Schule eine Karriere als Journalist, arbeitete zunächst bei der Cork Free Press. Gallaghers Irish Bulletin war während des Unabhängigkeitskrieges ein durchschlagender Erfolg. Das Irish Bulletin war keine aus dem Untergrund heraus verkaufte Zeitung, sondern die offizielle tägliche Pressemitteilung der revolutionären Untergrundregierung. Obwohl die Krontruppen das Irish Bulletin verfolgten, Mitarbeiter verhafteten und einmal sogar die Druckanlagen beschlagnahmten, erschien es lückenlos bis Ende 1921. Es versorgte in- und ausländische Zeitungen mit Berichten über britische „acts of aggression“,27 später auch über die offizielle Politik Dail Eireanns. Das Irish Bulletin war in einem bewußt nüchternem Ton geschrieben, stützte sich für Berichte zu britischen Übergriffen ausschließlich auf die britisch zensierte Tagespresse und genoß deshalb eine hohe Glaubwürdigkeit. 28

Auch nach dem Bürgerkrieg arbeitete Gallagher weiter als Propagandist für die republikanische Seite, wurde 1931 erster Chefredakteur der republikanischen Tageszeitung Irish Press. 1939 bis 1948 und 1951 bis 1954 leitete Gallagher das Government Information Bureau. Er starb 1962 in Dublin. ${ }^{29}$

Die Propaganda der IRA organisierte Beaslai, jener euphorische Beobachter der „national unity“ von 1921. Damit übernahm er eine Schlüsselstelle im Dubliner Hauptquartier. Seine Aufgabe war es, über seine Armeezeitung An tOglach die inhomogene IRA als einheitliche Armee darzustellen: nach außen, um aus den dezentral organisierten „gunmen“ eine legitime staatliche Armee zu machen, nach innen, um der IRA eine gemeinsame offizielle Identität zu verleihen und um neuen Mitgliedern der IRA den Glauben von „the Republic“ zu vermitteln. Das heißt nicht, daß Beaslai die Strategie oder Politik der IRA auch prägte. Im Gegenteil: Als Chefpropagandist der IRA integrierte Beaslai im nachhinein militärische Initiativen der radikalen IRA in der Provinz in das revolutionäre Programm und verschleierte so die Brüche zwischen aktiven und inaktiven Gebieten. ${ }^{30}$

Diese Propagandaprofis des Unabhängigkeitskrieges waren auch im Bürgerkrieg die entscheidenden Propagandisten: Beaslai und FitzGerald auf der vertragsbefürwortenden Seite, Erskine Childers, Brennan und Gallagher bei den Vertragsgegnern.

Exemplarisch: IRISH BULLETIN, 12. Juli 1919, S. 1.

MCCRACKEN, Representative Government, S. 37f.; KEOGH, Ireland and Europe, S. 5-7.

Zusammengefaßt nach: BOYLAN, Dictionary, S. 125.

AN tOglaCH, 15. August 1918, S. 1 f.; HoPKINSON, Green, S. 12. 


\section{Die Organisation der Propaganda ANFANg 1922}

Fast alle Propagandablätter Sinn Feins hatten bis Ende 1921 aufgehört zu erscheinen. Während der Friedensverhandlungen mit England war die bisher wichtigste Aufgabe der republikanischen Publicity so gut wie überflüssig: Sie mußte und konnte kaum mehr über britische Übergriffe berichten. $\mathrm{Da}$ alle Blätter bis auf die unionistische Presse sich hinter Sinn Fein stellten, schien nationale Propaganda auch nicht mehr so wichtig. Unter dem Schock der sich abzeichnenden Vertragsspaltung stellte schließlich auch noch das Irish Bulletin Mitte Dezember sein Erscheinen ein, um das Ende von „national unity" nicht noch weiter zu thematisieren. So waren Ende 1921 New Ireland und An tOglach die einzigen ehemaligen Untergrundblätter auf dem Markt. ${ }^{31}$ Das hieß: Nach der Vertragsspaltung mußten beide Seiten ihre Propaganda weitgehend neu organisieren. Um die Mehrheit der Bevölkerung von ihrer Version zu überzeugen, mußten beide Seiten ihre Propaganda auch verbreiten können. Die organisatorischen Möglichkeiten entschieden mit über Erfolg und Mißerfolg der Propaganda.

Die vertragsablehnenden Propagandisten waren den Vertragsbefürwortern von Anfang an hoffnungslos unterlegen. Gegen das erdrückende Übergewicht der vertragsbefürwortenden Leitartikel in Tages- und Provinzpresse waren sie machtlos. ${ }^{32}$ Abgesehen von meist kritischen Interviews und suggestiv verkürzten Reden, bekamen die Republikaner im redaktionellen Teil der Zeitungen wenig Publicity. Allein die Stellungnahmen, Reden und Interviews mit de Valera erschienen nach wie vor fast lückenlos in der Dubliner Presse. Weniger prominenten Republikanern und der offiziellen Propaganda blieben Leserbriefe, oder sie mußten Anzeigen schalten, und das war für die finanzschwachen Republikaner auf Dauer zu teuer. ${ }^{33}$

Ungehindert konnten die Republikaner ihre Thesen nur in Pamphleten, Flugblättern, auf Plakaten und vor allem in der am 3. Januar 1922 gegründe-

31 National Archive of Ireland, Dail Eireann Correspondence, (NAI, DE Correspondence), DE 2/10, Report on Publicity Department, ca. Februar 1922; KeIKO InNOUE, Propaganda of Dail Eireann: From Truce to Treaty, in: Eire/Ireland, XXXII, 2 \& 3, (1997), S. 154-72, hier: S. 160 f., 172 f.; Seit dem 22. Oktober 1921 erschienen wieder die sozialistische vertragsbefürwortende VOICE OF LABOUR und seit 18. Oktober 1921 die kommunistische vertragsablehnende WORKER'S REPUBLIC.

32 So auch: Graham Walker, Propaganda, S. 97; Neeson, Civil War, S. 73, 86; falsch: GLANDONE, Advanced Nationalist Press, S. 224.

33 FLK, DeV, 250, registriert für die Zeit zwischen Januar und Juni 192274 Interviews, Reden oder Statements von de Valera, die in der Provinzpresse, vor allem aber in den Dubliner Tageszeitungen erschienen; AN POBLACHT, 28. Februar 1922, S. 7; LONGFORD und O’NEILL, De Valera, S. 168; IRISH INDEPENDENT, 8. März 1922, S. 6; exemplarisch für eine Anzeige: Evening Herald, 8. April 1922, S. 3. 
ten wöchentlich erscheinenden $A n$ Poblacht ${ }^{34}$ veröffentlichen. Sie war das wichtigste Medium der republikanischen Propaganda vor und während des Bürgerkrieges. Das „commitee of direction“ der Poblacht liest sich wie ein „who's who“ des politischen Flügels der Vertragsgegner. Bis auf den „assistant editor" der Poblacht, den ehemaligen Herausgeber des Irish Bulletins, Gallagher, waren sie alle bekannte Mitglieder des revolutionären Parlaments: Mary MacSwiney, Constanze de Markievicz, J.J. O’Kelly, Austin Stack, Sean Etchingham, Joseph McDonagh, Kathleen O'Callaghan, Sean T.O'Kelly, Sinn Feins ehemaliger Propagandachef Brennan, daneben auch prominente Militärs wie Cathal Brugha und Liam Mellows. Auch de Valera besuchte die wichtigeren Treffen der Poblacht-Spitze. Chefredakteur der Poblacht war Erskine Childers, die wichtigste Schlüsselfigur der vertragsablehnenden Propaganda: Fahrtensegler, Abenteurer, britischer Geheimdienstoffizier, Schriftsteller, Waffenschmuggler, zunächst Imperialist, dann Aktivist der Home Rule-Bewegung und schließlich republikanischer Märtyrer. 35

Childers Biographie ist voller Brüche und so ungewöhnlich wie die keines zweiten irischen Revolutionärs. 1870 in London als zweiter Sohn eines englischen Vaters und einer protestantischen anglo-irischen Mutter geboren, wuchs er nach dem frühen Tod seiner Eltern in Glendalough, in der Grafschaft Wicklow, auf. Er machte zunächst die für einen Sprößling der administrativen Elite Englands typische Karriere. 1893 schloß er sein Jurastudium im Trinity College Cambridge ab, arbeitete zwischen 1895 und 1910 als Clerk des britischen Unterhauses. Zu dieser Zeit überzeugter Imperialist, meldete er sich 1899 freiwillig für den Burenkrieg. Er veröffentlichte mehrere Bücher. Sein Bestseller The Riddle of the Sands - eine antideutsche Spionagegeschichte - machte ihn $1903 \mathrm{zu}$ einem landesweit bekannten Schriftsteller. Beeinflußt von Sir Horace Plunkett, wurde er 1908 zum Anhänger der Home Rule-Bewegung, widmete sich ab 1910 ganz der irischen Politik.

1914 organisierte Childers den größten Waffenschmuggel der Irish Volunteers, das spektakuläre Howth gun running. Die Waffen transportierte er auf seiner Privatyacht aus Deutschland nach Irland. Während des Ersten Weltkrieges arbeitete er als Geheimdienstoffizier, wurde mit dem „Distin-

\footnotetext{
An Poblacht na hEireann: Die irische Republik, The Irish Republic.

35 Trinity College Dublin, Frank Gallagher Papers (TCD, GP), 10050/491, „Republic of Ireland“, Committee of Direction; TCD, GP, 10050/493, report on meeting, 14. März 1922; TCD, GP, 10050/491, Minutes of meeting, 11. Januar 1922; TCD, GP, 10050/492, Minutes of meeting, 14. März 1922; TCD, CP, 7815, Childers Diary, 9. Februar 1922 - 13. Februar 1922.
} 
guished Service Cross“ ausgezeichnet und bis zum Major befördert. Als auch nach dem Krieg Home Rule weiter verzögert wurde, schloß er sich der republikanischen Bewegung an. Während des Unabhängigkeitskrieges unterhielt Childers Kontakte zur internationalen Presse, ab März 1921 vertrat er den verhafteten Publicityminister FitzGerald. Als Richter am District Court für Pembroke und Rathmines war Childers Teil der republikanischen Untergrundjustiz. Er war Sekretär der irischen Delegation während der Vertragsverhandlungen, von Anfang an aber gegen einen Kompromiß mit England. Nach der Vertragsspaltung wurde er wegen seiner teil-englischen Abstammung und imperialistischen Vergangenheit zu dem Feindbild der vertragsbefürwortenden Seite. Während des Bürgerkrieges organisierte Childers republikanische Propaganda in Munster, bis er verhaftet und am 24. November 1922 in Dublin hingerichtet wurde. ${ }^{36}$

Neben Childers schrieben alle namhaften republikanischen Propagandisten für die Poblacht, darunter Brennan, Gallagher und Mary MacSwiney. Doch trotz dieses qualifizierten Personals konnte die Poblacht mit der Dubliner Tagespresse nicht konkurrieren. Die Poblacht litt an chronischem Geldmangel. Ein Korrespondentennetz zu finanzieren, war völlig unmöglich: Doch ohne Neuigkeiten konnte sich das Blatt nicht zu einer republikanischen Tageszeitung entwickeln. Dazu kamen organisatorische Probleme: Im Februar boykottierten alle größeren Dubliner Druckereien das Blatt. Als Childers nach drei Tagen dann doch noch einen Drucker fand, fehlte ein effizientes Verteilungssystem; die Poblacht blieb in Bündeln beim Drucker liegen. ${ }^{37}$

Auf die finanziellen und organisatorischen Probleme stellte sich Childers und seine Redaktion schnell ein. Schlimmer war für sie, daß es kein funktionierendes Propagandadepartment mehr gab. Die erfahrenen Propagandisten der Poblacht konnten so die republikanische Propaganda weder organisatorisch, noch inhaltlich steuern und so keine einheitliche Propagandastrategie durchsetzen. Andere republikanische Propagandisten machten in eigenen Blättern ihre eigene Publicity, orientierten sich dabei an ihrem Ver-

36 Zusammengefaßt nach: DNB, 1922-1930, S. 180-2; FLK, DeV, 207, Lebenslauf von Erskine Childers durch Mary A. Childers, ca. 18. November 1922; KOTSONOURIS, Retreat, S. 48. Zu Childers gibt es mittlerweile drei weitgehend narrativ angelegte Biographien: BURKE WILKINSON, The Zeal of the Convert. The Life of Erskine Childers. Washington 1978; ANDREW BOYLE, The Riddle of Erskine Childers. A Biography. London 1977; Jim Ring, Erskine Childers. London 1996.

37 TCD, GP, 10050/492, report on meeting, 14. März 1922; TCD, CP, 7815, Childers Diary, 9. Februar 1922-13. Februar 1922: Bemerkungen zur Herausgabe von AN POBLACHT; Optimistischer: TCD, CP, 7808/298, financial statement, 3. März 1922. 
ständnis von „the Republic“, nicht an der Redaktion der Poblacbt. Allein in Dublin erschienen vier weitere Blätter mit republikanischer Tendenz, auf die die Propagandaprofis der Poblacht nur wenig Einfluß hatten.

J. J. O'Kellys Catholic Bulletin war schon vor 1916 das Sprachrohr eines anti-britischen katholischen Kulturnationalismus gewesen und enthielt Artikel in englischer und irischer Sprache. Es argumentierte dabei auf sehr hohem und abstraktem Niveau, setzte sich detailliert mit allen juristischen Teilaspekten des Vertrages auseinander. Das Catholic Bulletin verfolgte auch nach der Vertragsspaltung eine konsequent anti-britische Rhetorik, häufig in seitenlangen historischen Exkursen. O'Kellys Credo: Nur durch irische Uneinigkeit sei es England gelungen, Irland jahrhundertelang zu unterdrücken. O’Kelly mußte es wissen: Vor 1916 war er neben Cathal Brugha und Beaslai innerhalb der Gaelic League ein einflußreicher und besonders obstruktiver Intimfeind von Pearse, dem späteren Führer der Neunzehnsechzehner, gewesen. ${ }^{38}$ Obwohl das Catholic Bulletin betont wohlwollend mit den führenden Vertragsbefürwortern umging und einen Krieg ehemaliger Kameraden ablehnte, unterstütze es den politischen Flügel der Republikaner. Vor allem de Valera würdigte es als "colossus of his time“ ${ }^{39}$ Erst nach 1926 wandte sich das Blatt gegen de Valera, wurde Stimme eines kompromißlosen dogmatischen Republikanismus. ${ }^{40}$

Patrick Little, der Herausgeber der Wochenzeitschrift New Ireland, war in der Vertragsfrage lange unentschieden gewesen. Schließlich unterstütze er de Valera, doch auch er gemäßigter als die Poblacht. New Ireland propagierte wie das Catholic Bulletin "national unity“. ${ }^{41}$ New Ireland und Catholic Bulletin waren in zurückhaltend reflektierendem Stil geschrieben. Sie entsprachen zwar nicht ganz der Linie der Poblacht, machten dafür den Republikanismus einer gemäßigten und intellektuelleren Leserschaft zugänglich. J.J. O'Kelly war selbst Mitglied des „committee of direction“ der Poblacht, und auch Patrick Little kooperierte mit der Poblacht-Redaktion, verstand sich als Presseagent de Valeras. Damit konnten die offiziellen Propagandisten leben. ${ }^{42}$

38 RuTH EDWARDS, Triumph, S. 88; vgl. ebd., S. 85, 87.

39 Catholic Bulletin, März 1922, S. 129.

40 Brian P. Murphy, J. J. O'Kelly (,Sceilg') and the Catholic Bulletin: Cultural Considerations, Gaelic, Religious and National, c. 1898-1926, (Ph.D., UCD). Dublin 1987, S. 420, 423; TERENCE BROWN, Ireland, S. $71 \mathrm{f}$.

41 NEW IRELAND, 22 April .1922, S. 307-13: „Dev’s position made clear“.

42 TCD, GP, 10050/491, „Republic of Ireland“, Committee of direction; TCD, GP, 10050/492, report on meeting, 14. März 1922; University College Dublin, Patrick Little Papers (UCD, LP), P28/2, Patrick Littles Notizbuch. 
Unangenehm waren für Childers dagegen die Sympathieerklärungen und wohlwollenden Ratschläge der republikanisch-kommunistischen Worker's Republic ${ }^{43}$ noch unangenehmer die radikalen Polemiken des Wochenblattes The Plain People. Anders als die zurückhaltend formulierende Poblacht argumentierte The Plain People in einer stark religiös gefärbten Metaphorik und in einem aggressiven und beleidigenden Tonfall - was die Redakteure offenbar für den Ton der „einfachen Leute“ hielten. ${ }^{44}$ Das Blatt verstand sich als sozialistisch, obwohl es fast ausschließlich die antimaterielle Republic predigte. ${ }^{45}$ Es erkannte die Führungsrolle de Valeras nicht an und beleidigte jeden persönlich, den sie verdächtigte, Kompromisse einzugehen. ${ }^{46}$ Auch ihre radikale Position zu den Katholikenverfolgungen in Nordirland mußte gemäßigte Republikaner irritieren. Die Plain People unterstützte völlig konträr zur offiziellen Linie der Poblacht - Rachemorde an südirischen Protestanten. ${ }^{47}$ Doch wie sollten Childers und de Valera Einfluß auf die Plain People nehmen, wenn sie bis Mitte Mai 1922 nicht einmal wußten, wer das Blatt herausgab?48

Auch auf die Propaganda außerhalb Dublins hatten Childers und seine Redaktion keinen Einfluß. Die örtliche vertragsablehnende IRA ernannte hier häufig einen „O/C Publicity“,49 der mit mehr oder meist mit weniger Talent die Presse mit den offiziellen Berichten der IRA versorgte. Die unprofessionellen, übertriebenen und häufig übermäßig polemischen Artikel demontierten die Glaubwürdigkeit der republikanischen Propaganda. Um das zu illustrieren, brauche ich einen Zeugen: den unionistischen Journalisten W.H. Bretherton.

Bretherton verkörperte in einer Person die innere Zerrissenheit des südirischen Unionismus; denn er führte ein politisches Doppelleben: Als Journalist der Irish Times folgte er deren Politik eines gemäßigten und konstruktiven Unionismus, während er sich als Irlandkommentator der unionistischen Morning Post als polemischer Zyniker erwies. Dabei entwickelte er häufig geradezu paranoide antibritische Verschwörungsszenarien, ${ }^{50}$ viel-

43 Worker's Republic, 24. Dezember 1921, S. 5.

44 Explizit in: Plain People, 9. April 1922, S. 2. Vergleiche dagegen den zurückhaltenden und reflektierenden Stil der AN POBLACHT, exemplarisch: 17. Januar 1922, S. 1, Artikel von Gallagher zu den Ausfällen von Arthur Griffith gegen Childers.

45 Plain People, 9. April 1922, S. 2.

46 Plain People, 7. Mai 1922, S. 2.

47 Plain PeOple, 28. Mai 1922, S. 2; An Poblacht, 4. Mai 1922, S. 4.

48 FLK, DeV, 239a, Lynch an de Valera, 9. Mai 1922; de Valera an Lynch, 12. Mai 1922.

49 O/C: Officer Commanding.

50 NAI, D/T, S-4386, Memo Morning Post, 11. Juni 1923; vgl. NAI, D/T, S-1322, Telegramm Brethertons an die MORNING POST, ca. Mai 1922. 
leicht auch, weil es ein beliebter "practical joke“ unter nationalistischen Iren war, britische Journalisten mit abenteuerlichen Geschichten zu desinformieren. ${ }^{51}$ Hatte Bretherton eine Identitätskrise, oder hatte er bei der Irish Times nur eine zweite Verdienstmöglichkeit gefunden? Welcher der „echte“ Bretherton war, läßt sich nicht mit Sicherheit sagen. Doch waren seine Kommentare über die „unzivilisierten“, „denkunfähigen“ „Southern Irish Bosthoon[s] “52 von einer solchen Gehässigkeit, daß man sich leicht vorstellen kann, welche Wut und Freude Bretherton beim Schreiben gehabt haben muß.

Bretherton kommentierte für die Morning Post auch den Propagandakrieg zwischen Vertragsbefürwortern und -gegnern und beobachtete, wie unprofessionell übertriebene, lokal organisierte Publicity die Glaubwürdigkeit der Republikaner demontierte:

Both sides continue to court a maximum of publicity, but while the Free Staters have abandoned the imaginative flights that were their chief ornament of the Dail Eireann Propaganda Bureau for an almost departmental austerity, the Republicans are giving rein to fancy with an unfettered license that even the Hun would have envied. For example referring to the shooting of Commandant Hurley by Republicans at Galway, the Republican O/C Publicity explains that Hurley began shooting and continued - a scuffle ensued and before Hurley was disarmed he fired five more shots, some of which must have entered his own body. This is publicity de luxe. Lenin and Trotsky have never produced anything like it. By comparison the efforts of Childers recede into the halfpenny place..$^{53}$

Selbst Bretherton, der immer die mißgünstigste Deutung bevorzugte, mußte zugeben, daß die freistaatliche Propaganda zurückhaltend formuliert war. Das lag vor allem daran, daß bei den Vertragsbefürwortern ein routinierter Propagandaprofi die Organisation und den Inhalt der zivilen Propaganda zentral kontrollierte: FitzGerald. Er übernahm das funktionierende Publicity Department des revolutionären Dail Eireanns, aus dem er schnell alle vertragsablehnenden Mitarbeiter entließ.54

Durch das Neben- und Durcheinander von Behörden der revolutionären Republik und denen des zukünftigen Freistaats gab es auch bei der Propa-

51 Lankford, Hope, S. 228; Memory, Memory's, S. 135.

52 NAI, D/T, S-4386, Memo Morning PosT, 11. Juni 1923; vgl. NAI, D/T, S-1322, Telegramm Brethertons an MORNING POST, 21. März 1922.

53 NAI, D/T, S-1322, Telegramm Bretherton an MORNING POST, 5. April 1922.

54 NAI, DE Correspondence, DE 2/10, Report on Publicity, ca. Februar 1922; National Archive of Ireland, Dail Eireann Minutes (NAI, DE Minutes), DE 1/4, 11. Januar 1922; National Archive of Ireland, Department of Foreign Affairs, Provisional Government and Irish Free State Political Matters, (NAI, DFA, PG/IFS), box 3, Anonymer Entwurf einer Antwort auf Anfrage in Dail Eireann, 3. Mai 1922; ebd., box 9, Gavan Duffy an Griffith, 20. April 1922; vgl. KeOGH, Ireland and Europe, S. 11 f.; BRENNAN, Allegiance, S. 335. 
ganda zwei Stellen: das Publicity-Ministerium des ehemals revolutionären Dail Eireanns und das Press Room Department der Provisorischen Regierung. Doch was nach außen verwirrend wirkte, bereitete im Inneren keine Probleme: Beide Stellen kontrollierte FitzGerald, beschäftigte in ihnen teilweise dieselben Mitarbeiter. ${ }^{55}$

Propaganda zum anglo-irischen Vertrag war die wichtigste Aufgabe dieser Behörden, die fast unmittelbar nach der Vertragsspaltung eine erste Kampagne in der Tagespresse organisierten. ${ }^{56}$ Die Publicitybehörden wirkten als Schaltstellen zwischen nationaler sowie internationaler Presse und der Regierung: Sie veröffentlichten offizielle Regierungsstatements, vermittelten Interviews mit Regierungsangehörigen oder dementierten Presseberichte. Die Propagandabehörden informierten nicht nur die Presse über die Regierung, sondern auch umgekehrt; sie informierten Regierung und Armeeführung über die Presse, spürten dazu der veröffentlichten Meinung systematisch nach, sammelten und archivierten Presseausschnitte. ${ }^{57}$ Wichtigstes Propagandamedium für die Publicitybehörden waren die Dubliner Tageszeitungen, die eng mit der Regierung kooperierten. ${ }^{58}$ Sie gaben offiziellen Regierungserklärungen viel Raum im redaktionellen Teil und veröffentlichten Grundsatzartikel von Regierungsmitgliedern. Wo Propaganda ein besonders breites Publikum erreichte, war sie Chefsache. Zumindest erschien sie unter dem Namen des Chefs: So druckten der Freeman und der New York American eine zwölfteilige Artikelserie von Collins. ${ }^{59}$

Dazu produzierten die Publicitybehörden zahllose eigene Pamphlete und Broschüren. Am 25. Februar 1922 gründete die vertragsbefürwortende Propaganda den Free State. Dieses halboffizielle Regierungsorgan erschien wö-

55 National Archive of Ireland, Provisional Government Minutes (NAI, PG Minutes), G1/1, 25. Janaur 1922; 27. Januar 1922; 8. Februar 1922; NAI, D/T, S-1882, Memorandum des Sekretärs des Executive Councils, Michael McDunphy, 19. Mai 1936. Formal unterstand das Press Room Department dem Sekretariat der Provisorischen Regierung. Siehe: ebd., Sean Lester an Michael McDunphy, 24. Februar 1923; Sean Lester an FitzGerald, 28. Februar 1923.

56 NAI, DE Minutes, DE 1/4, 13. Januar 1922: „The Minister of Publicity was instructed to make arrangements for a series of articles on the treaty to appear in the press."

57 Etwa: National Archive of Ireland, Department of the Taoiseach, Constiution Committee (NAI, D/T, CoCo), „O“, Ordner mit Zeitungsausschnitten zum Constitution Committee; NAI, D/T, S-1322, Berichte über die IRA in den Four Courts.

58 UCD, FGP, P80/281, Managing Director FREEMAN's JOURNAL an FitzGerald, 7. Februar 1922: Angebot eine mehrteilige Artikelserie Richard Mulcahys über die IRA zu drucken. Vgl. Special Correspondent Freeman's Journal an Griffith, 23. März 1923; NAI, DE Correspondence, DE 2/10, Report on Publicity Department, ca. Februar 1922.

59 Freeman's Journal, 2. Februar 1922, S. 5; 6. Februar 1922, S. 4 f.; BeAslai, Michael Collins, S. 359; vgl. Pamphlet mit mehreren Reden von Collins, in: TCD, Early Printed Books, Samuels Collection, Box 2/3, Collins, Arguments for the Treaty. 
chentlich und enthielt überwiegend Grundsatzartikel, häufig von prominenten vertragsbefürwortenden Politikern und Regierungsmitgliedern, darunter Griffith, Kevin O'Higgins, Eoin MacNeill, Ernest Blythe und immer wieder FitzGerald. ${ }^{60}$ Daneben gab es zwei inoffizielle vertragsbefürwortende Propagandablätter: Patrick O'Hegarty veröffentlichte, finanziert von der IRB, den Separatist. ${ }^{61}$ Der vertragsbefürwortende Abgeordnete Sean Milroy belebte Young Ireland wieder, eine Zeitschrift, die Griffith im Unabhängigkeitskrieg herausgegeben hatte. ${ }^{62}$

Ein Gutteil der Propaganda richtete sich nach wie vor an das Ausland, vor allem die USA.63 Dorthin schickte die Führung der Vertragsbefürworter vom 9. März 1922 bis zum 10. Juni 1922 ihren zweiten ausgewiesenen Propagandaspezialisten: Beaslai. Damit er mit seiner Propaganda dort auch den nötigen Eindruck machte, wurde Beaslai kurzer Hand zum General befördert. Solange er in Irland war, gab Beaslai weiter die Armeezeitung $A n$ tOglach heraus und leitete die Army Publicity der vertragsbefürwortenden Truppe.64

In Irland existierte um 1922 eine vielfältige Presselandschaft: Neben den drei Dubliner Tageszeitungen waren es vor allem britische Presseimporte und die zahllosen Provinzblätter, die landesweit ein breites Massenpublikum erreichten. Die von Sinn Fein während des Unabhängigkeitskrieges herausgegebenen Untergrundblätter besetzten demgegenüber nur ein kleines Marktsegment. Sinn Feins Propaganda erhielt ihre Durchschlagskraft nicht durch ihre Propagandablätter, sondern durch die professionell hergestellte tägliche Pressemitteilung der revolutionären Regierung, das Irish Bulletin. Weil das Irish Bulletin auf bewußte Verfälschungen verzichtete, genoß es bei der in- und ausländischen Presse bald eine hohe Glaubwürdigkeit und beeinflußte so die Redakteure.

Die führenden Propagandisten des Unabhängigkeitskrieges bestimmten ab 1922 auch die Propaganda der konkurrierenden Lager: FitzGerald und Beaslai auf Seiten der Vertragsbefürworter, Childers, Brennan und Gallagher auf Seiten der Republikaner. Doch während es FitzGerald gelang, eine professionelle Propagandabehörde zentral zu steuern, hatten die republika-

\footnotetext{
FREE STATE, 25. Februar 1922, 18. März 1922, 25. März 1922.

GLANDONE, Advanced Nationalist Press, S. 224.

National Library of Ireland, Young IRELAND, Biographical Note.

NAI, DE Correspondence, DE 2/10, Report on Publicity Department, ca. Februar 1922.

NLI, BP, box 30, Memo on Work of Army Publicity, ca. Februar 1922; ebd., „Volunteer Relics“; NAI, S-1760, Brief an MacDunphy, 12. September 1924; FrEEMAN'S JOURNAL, 23. Mai 1922, S. 5; LIMERICK LEADER, 19. April 1922, S. 3.
} 
nischen Propagandaprofis weder die finanziellen Ressourcen noch den nötigen Einfluß, um die Legitimationsstrategie ihrer Seite effizient zu kontrollieren.

\section{II. „THE REPUBLIC“ UND REALPOLITIK}

Organisatorisch waren die Vertragsbefürworter den Vertragsgegnern hoch überlegen. Aber wer konnte die überzeugendere Geschichte erzählen? Im Propagandakrieg standen beiden Seiten verschiedene rhetorische Legitimationsstrategien offen: „1916“, Home Rule, anti-nordirischer und anti-britischer Nationalismus, Kultur- oder Sprachnationalismus, Katholizismus, demokratische Partizipation, liberale Abwehrrechte, Pragmatismus, law and order, Materialismus und/oder soziale Gerechtigkeit. Aus diesen Legitimationsmustern konnten sich die Propagandisten jedoch nicht wahllos bedienen. Sie mußten verschiedene Teile so zusammendenken, daß sie eine sinnvolle Geschichte ergaben. Wie einzelne Teile zusammenpassten, ob sie sich sinnvoll ergänzten oder einander widersprachen, lag an der politischen Kultur der Propagandisten. Politische Kultur und Propagandastrategie bedingten einander, waren aber nicht zwangsläufig identisch; denn je flexibler die politische Kultur war, um so kreativer konnten die Propagandisten an ihrer Geschichte arbeiten, um so besser konnten sie sich notfalls verstellen und taktisch von den Grundlagen ihres politischen Denkens abweichen.

Wenn sich die Propagandaspezialisten für eine bestimmte Geschichte entschieden, war das nicht „nur“ Rhetorik. Während das Sprechen über die Republik bisher die Revolution angeschoben und national unity garantiert hatte, konstituierten sich jetzt konkurrierende Gruppierungen über das politische Sprechen - auch quer zu nur scheinbar präexistenten sozialen Schichten und Interessen. ${ }^{55}$ Dabei eröffneten unterschiedliche Legitimationsstrategien ganz unterschiedliche Handlungsmöglichkeiten; denn nur was denkbar und sagbar war, war auch machbar. Und umgekehrt: Was man machte, mußte man auch sagen, erklären können. Wenn die Revolutionäre auf neue Handlungsmöglichkeiten zurückgriffen, mußten sie ihre Propagandageschichte anpassen, eventuell sogar ihre politische Kultur. Diese Interaktion von revolutionärem Sprechen und Handeln verlieh dem Bürgerkrieg seine Dynamik. ${ }^{66}$

65 Vgl. MANHEIM, Aufklärung, S. 29.

66 SAhlins, Islands, S. 7, 44, 149; STeInmetZ, Das Sagbare, S. 18-20; vgl. Baker, Political 
Konkret: Als die Vertragsbefürworter für den Vertrag stimmten, eröffneten sie sich völlig neue Handlungsmöglichkeiten. Sie beendeten den Unabhängigkeitskrieg, bekamen Macht über Irlands innere Angelegenheiten, machten Karriere und verdienten viel mehr Geld als zuvor als Berufsrevolutionäre. Doch nach dem Schritt zur Realpolitik konnten sie sich kaum mehr über "the Republic" legitimieren. Sie mußten einen Teil ihrer politischen Wertvorstellungen anpassen und sich eine neue Legitimationsstrategie erfinden. Wie wollten sie die Phantasie einer hochpolitisierten und emotionalisierten Bevölkerung begeistern? Konnten und wollten sie die traditionelle nationale Rhetorik durch blanken Materialismus ersetzen?67

Die Republikaner hatten das umgekehrte Problem: Ihre dogmatische republikanische Legitimationsstrategie eröffnete kaum Handlungsspielraum. Sie orientierte sich an der „historischen Wahrheit“ des Republikanismus, kaum an den materiellen Bedürfnissen ihres (potentiellen) Publikums. So war die Rhetorik der Republikaner hochgradig redundant, unflexibel und kaum zu taktischen Zugeständnissen in der Lage. Ihre kompromißlose Deutung der Realität kollidierte an vielen Punkten mit der „actual complexity of contemporary, Irish and Anglo-Irish reality."68

Auch der Schriftsteller Sean O’Faolain, der während des Bürgerkrieges zunächst an Bomben für die IRA, später als Propagandist an "the Republic“ gebastelt hatte, erahnte dieses grundlegende Dilemma von Vertragsbefürwortern und -gegnern. O'Faolain, der sich später weitgehend dem politischen Idealismus seiner Jugend entfremdete, rationalisierte dieses Dilemma rückblickend als Konflikt zwischen Emotion und Verstand:

If men do not balance feelings and intelligence they lose command of both - and worse of their object. I fear that in 1922 our realists said goodbye to their feelings. I cannot say that we idealists said goodbye to our intelligence, because, alas, if we had any worthy of the name I saw but little sign of it in those disheartening days of Civil War. ${ }^{69}$

So schlagend O'Faolains Diagnose scheint, sie verkürzt das Problem: Wie ich in diesem Kapitel zeigen werde, hatten auch die Vertragsbefürworter noch jede Menge nationaler Emotionen, und gerade der politische Arm der Vertragsgegner konnte immer noch denken - nur effizient Politik machen

Culture of the Old Regime, S.XII; SpIEgel, History, S. 83; vgl. HunT, Politics, S. 19-119, 253.

67 Vgl. die Bedenken eines anglo-irischen Beobachters, in: THE Round TABLE, XII, 47, (Juni 1922), S. 509.

68 ENGLISH, Green on Red, S. 162.

69 O’FaOlain, Vive Moi, S. 190. 
konnten die Republikaner mit ihren Überlegungen und die Freistaatler mit ihren Emotionen kaum mehr.

\section{REPUBLIKANISCHE HANDLUNGSKRISE}

Für die moderateren Politiker wie de Valera, Childers, Gallagher oder den Überläufer aus dem vertragsbefürwortenden Lager Robert Barton erwies sich der republikanische Dogmatismus schnell als (kulturelle) „Zwangsjacke“70. Ohne realpolitische Perspektive war die Mehrheit der Bevölkerung nicht für die Republikaner zu mobilisieren. So ließ sich auch keine Politik mit Großbritannien oder der Provisorischen Regierung machen. Doch wie konnten die Revolutionäre „the Republic“ flexibilisieren?

De Valera versuchte schon früh, ein Konzept zu finden, das zwischen Vertrag und „the Republic“ vermittelte; ein Konzept, dem im Idealfall die Revolutionäre Irlands, die irische Bevölkerung und die britische Regierung zustimmen sollten. Irland sollte nicht zwangsweise Teil des britischen Empires werden, sondern sich „freiwillig“ von außen an dieses Empire assoziieren. De Valera nannte das „external association“. Schon bei den Vertragsverhandlungen hatte de Valera versucht, „external association“ als irische Minimalforderung durchzusetzen. ${ }^{71}$ In einer nichtöffentlichen Sitzung während der Vertragsdebatte formulierte er „external association“ zu einem alternativen anglo-irischen Vertrag um. Absatz für Absatz orientierte er sich dabei an den Vorgaben des Vertrages.

Sein sogenanntes Document No. 2 unterschied sich nur auf der symbolischen Ebene vom Vertrag, orientierte sich so nah wie möglich an den britischen Vorgaben. In de Valeras eigenen Worten: „If they [the British] say the crown is only a shadow, why do they want the shadow? Why do they want the shadow, and why should not we have it?"72 Irlands außenpolitische und militärische Souveränität blieb, wie im Vertrag, eingeschränkt. Auch die Passagen zu Nordirland übernahm de Valera zunächst wörtlich aus dem Vertrag, bevor er sie durch eine unverbindliche Absichtserklärung zur Wiedervereinigung ersetzte.

Während sich an der machtpolitischen und territorialen Beschränkung der irischen Souveränität kaum etwas änderte, entwickelte de Valera eine

70 Dieser Terminus wurde wahrscheinlich in der Zeit kurz vor den Vertragsverhandlungen von de Valera selbst geprägt: O'HEGARTY, Victory, S. 87. Weil er so griffig war, wurde er auch von der historischen Forschung übernommen, exemplarisch: BOYCE, Nationalism, S. 325. An Poblacht, 5. Januar 1922, S. 1f.; 3. Januar 1922, S. 2; HopkinSON, Green, S. 27.

72 Debate on Treaty, Private Sessions, de Valera, 15. Dezember 1921, S. 150. 
Nomenklatur, die die völkerrechtliche Gleichheit von Irland und Großbritannien suggerierte. Aus der gemeinsamen Staatsbürgerschaft des Vertrages machte de Valera zwei gegenseitige Staatsbürgerschaften. Was symbolisch Irlands Gleichwertigkeit und Souveränität garantieren sollte, hatte faktisch dasselbe Ergebnis: Iren waren auch in Großbritannien, Walliser, Schotten und Engländer auch in Irland Staatsbürger. Am wichtigsten: Artikel Eins von de Valeras Document No. 2 machte das im Vertrag nur implizit garantierte Prinzip der Volksouveränität deutlich sichtbar:,That the legislative, executive, and judical authority of Ireland shall be derived solely from the people of Ireland." Die Abgeordneten des irischen Parlaments mußten keinen Treueid auf den englischen König schwören, sondern ihn nur als symbolisches Oberhaupt einer partnerschaftlichen Gemeinschaft freier Länder „anerkennen“. Protokollarisch war Irland so weder Teil der britischen Monarchie noch des Empire, mußte sich nicht symbolisch unterordnen. Damit erhielt Document No. 2 nach Logik der Poblacht „the existing Republic"73, obwohl de Valera bewußt auf den Terminus „Republic“ verzichtete, um „external association“ für die britische Seite so akzeptabel wie möglich zu machen. ${ }^{74}$

Weil de Valera wußte, wie mißverständlich Document No. 2 war, bat er das revolutionäre Parlament, seinen Vorschlag vertraulich zu behandeln. ${ }^{75}$ Als Griffith Document No. 2 dennoch an die Presse weitergab, wurde es zu dem propagandistischen Eigentor für die Vertragsgegner. ${ }^{76}$ De Valera scheiterte diesmal mit der für ihn so kennzeichnenden und später so erfolgreichen Taktik der „labyrinthine language“77; denn die Vertragsbefürworter wollten für „a quibble of words“78 keinen neuen Krieg mit Großbritannien riskieren. Schließlich hatte die britische Delegation „external association“ während der Vertragsverhandlungen nicht akzeptiert, warum sollte sie es nun tun? Die vertragsbefürwortende Propaganda verspottete Document No. 2: Die Vertragsgegner seien Schwätzer, Haarspalter eine „armed junta

\footnotetext{
AN POBlaCHT, 5. Januar 1922, S. 2.

74 TCD, Early Printed Books, Samuels Collection, box 1/6, The Alternative to the ,treaty', ,Document No. 2‘; AN POBlaChT, 5. Januar 1922, S. 1 f.

75 Debate on Treaty, Private Session, de Valera, 16. Dezember 1921, S. 216.

76 Debate on Treaty, Griffith, 5. Januar 1922, S. 267; Catholic Bulletin, supplement 1921, S. 3; Hopkinson, Green, S. 39; ANDrews, Dublin Made Me, S. 205.

77 RONAN FANNING, ,The Rule of Order': De Valera and the IRA, in: MURPHY und O'CARROLL (Hrsg.), De Valera, S. 160-72, hier: S. 160-7, Zitat: S. 167; GARvin, 1922, S. 50f.; MURRAY, Voices, S. 43, 44, 47, 49-51.

78 Free State, 19. August 1922, S. 2; vgl. Debate on Treaty, Griffith, 19. Dezember 1921, S. 21.
} 
of documentarians" ${ }^{79}$ Document No. 2 beweise, daß die Republikaner zu denselben Kompromissen mit Großbritannien bereit seien wie die Vertragsbefürworter. Um de Valera zu demontieren, instrumentalisierten und verdrehten die Vertragsgegner dessen Worte. De Valera verwechsele „shadow“ und „substance" 80 , hetze die Jugend auf "to go out and die for a shadow."81

War de Valeras Vorschlag Document No. 2 nur ein „shadow“, „a quibble of words“, ein „cloud-cuckoo-land“?82 Document No. 2 in Nachfolge der vertragsbefürwortenden Propaganda einfach als irrationales Hirngespinst abzutun, wäre zu kurz gegriffen. Aus der Perspektive von Dezember 1921 war Document No. 2 eine große Leistung. Es blieb die einzige programmatische Innovation der Republikaner bis weit nach dem Bürgerkrieg. De Valera verpackte die Essenz des Vertrages so, daß sie selbst für viele intransigente Republikaner, wenn auch unter Zähneknirschen, zu akzeptieren war. ${ }^{83}$ Document No. 2 war ein Kompromiß, der den meisten Republikanern erlaubt hätte, ihre politische Kultur zu bewahren. Als Eiertanz um die richtige Nomenklatur leistete es einen Spagat zwischen zwei feindlichen Weltbildern, definierte einen gemeinsamen Boden zwischen „the Republic“ und „Crown and Empire“. Das Schwammige, Miß- und Unverständliche an Document No. 2 und de Valeras Sprache war dabei Teil von de Valeras Strategie, die Unterschiede zwischen dem vertragsbefürwortenden und vertragsablehnenden Standpunkt und damit auch seinen eigenen Standpunkt zu verwischen.

Dennoch ließen sich die radikaleren Republikaner nicht gänzlich von de Valera überzeugen: Gerade vielen der „gunmen“ war Document No. 2, dieses „essay in ambiguity“ 84 , zu akademisch und kompliziert. So gab der prominente IRA-General Rory O'Connor in einem Interview mit dem Irish Independent offen zu, Document No. 2 nie gelesen zu haben. Er und andere Radikale lehnten es genauso pauschal ab wie den Vertrag, von dem O'Connor im gleichen Interview sagte, er habe ihn nicht verstanden. Document No. 2 und Vertrag waren für Radikale wie ihn nicht „the Republic“

79 Young IRELAND, 8. April 1922, S. 4 (meine Hervorhebung).

80 YOUNG IRELAND, 25. Februar 1922.

81 Debate on Treaty, Sean Milroy, 20. Dezember 1921, S. 71; vgl. Dail Eireann (Hrsg.), Official Report: Parliamentary Debates 1922-23 (= DAIL DeBATES), (Volume I-V). Dublin o.J, hier: Bd. 2, Sean Milroy, 8. Dezember 1922, S. 63 f.; National Library of Ireland, William O’Brien Collection (NLI, WOB), L.O., P117, Flugblätter, no. 24, no. 25, no. 38, ca. März 1922.

82 IRISH Times, 23. Dezember 1921, S. 4.

83 Etwa für den intransigenten Cathal Brugha: DEBATE ON TREATY, Cathal Brugha, 7. Januar 1922, insbes., S. 330-3.

84 MacDonagh, Ambiguity, S. 105. 
und damit genug. ${ }^{85}$ So dachten sicher auch viele vertragsablehnende Guerilleros, was Beaslai als Argument für den Vertrag formulierte: „Men have died to the cry ,up the Republic', but I cannot imagine they would die for the cry of ,up External Association' 86

Zwar bemühte sich die republikanische Propaganda, Document No. 2 zu verteidigen. Doch de Valeras Vorschlag eignete sich nicht für griffige Parolen, eher für differenzierte Überlegungen. ${ }^{87}$ So verfaßte Childers eine mehrteilige Artikelserie in der Poblacht, die den Vertrag und Document No. 2 Artikel für Artikel verglich. Childers erreichte dabei ein abstraktes und differenziertes Argumentationsniveau, das für die sonst so redundante vertragsablehnende Propaganda erstaunlich war. Doch wer wollte so etwas schon lesen?88 Für die Mehrheit der Bevölkerung war de Valeras differenzierte beziehungsweise haarspalterische Argumentation, die nichts an ihrem alläglichen Leben änderte, nur schwer nachzuvollziehen. ${ }^{89}$

Als Mißerfolg wurde Document No. 2 auch für die gemäßigten Republikaner immer unattraktiver. Die republikanischen Politiker, auch de Valera und seine Propagandisten, gaben deshalb Document No. 2 schnell auch offiziell auf und kehrten zur orthodoxen Rhetorik von „the Republic“ zurück. 90

\section{FREISTAATLICHE LEGITIMATIONSKRISE}

Seit der Vertragsspaltung orientierte sich die Führung der Vertragsbefürworter flexibel am realpolitischen Erfolg. Zu diesem pragmatischen Handeln mußte sie im nachhinein eine passende Propagandastrategie erfinden. Während die Republikaner trotz Document No. 2 in einer Handlungskrise steckten, litt die freistaatliche Seite unter einem Legitimationsdefizit; denn als „Kompromißler“ konnten sie nicht mehr ungebrochen auf das republi-

85 Irish IndePendent, 23. März 1922, S. 5; Townshend, Political Violence, S. 364; O’MALLEY, Singing Flame, S. 45.

86 Debate on Treaty, Private Session, Beaslai, 17. Dezember 1921, S. 231.

87 So auch: CATHOLIC Bulletin, supplement 1921, S. 2; AN POBLACHT, 21. Februar 1922, S. 1, 4; UCD, MSW, P48a/377, Mary MacSwiney an verschiedene Redakteure, 23. Dezember 1921.

88 UCD, MSW, P48a/341, Erskine Childers: Clause by Clause. A Comparison between „The Treaty" and Document No. 2“. O.J. [Reprint 1923].

89 Voice of Labour, 7. Januar 1922, S. 3; O’FaOlain, Vive Moi, S. 187; Auch einige Historiker stolperten über de Valeras Ambivalenzen: VAliulis, Mulcahy, S. 114; HopKinson, Green, S. 27; ungenau auch: FOSTER, Modern Ireland, S. 505.

90 An Poblacht, 28. Februar 1922, S. 4; TCD, Early Printed Books, Samuels Collection, Box 2/3, Collins, Arguments for the Treaty, S. 28; NLI, WOB, L.O., P117, Flugblatt, no. 29, ca. Mai 1922. 
kanische Geschichtsgesetz, die nationale Martyrologie und das britische Feindbild zurückgreifen. Sie mußten versuchen, das nach wie vor entscheidende nationale Legitimationsfeld über Umwege zu besetzen.

\section{a) Auf der Suche nach nationaler Legitimation}

Karriere, gute Bezahlung, fester Sold, ein geregeltes bürgerliches Leben, also alles, was den Vertrag für die Revolutionäre attraktiv machte, erwies sich als propagandistische Achillesferse für die Vertragsbefürworter; denn diese Annehmlichkeiten blieben langfristig als britischer Materialismus diskreditiert. Das traditionelle Weltbild vom materialistischen England kontra spirituellem Irland fiel den Vertragsbefürwortern in den Rücken. Gegen das herrschende Idealbild des asketischen Revolutionärs ließen sich gesichertes Einkommen und Karriere nicht als legitime Anliegen eines Berufspolitikers begründen. Im Gegenteil: Die vertragsbefürwortende Rhetorik hielt selbst am anti-britischen Antimaterialismus fest. Sie diskreditierte, wo immer es ging, die Vertragsgegner für materielle Motive. ${ }^{91}$

Insgesamt konnte die republikanische Propaganda Antimaterialismus jedoch wesentlich glaubhafter besetzen: Die IRA hielt an ihrem asketischen Selbstverständnis fest: „We are not paid hirelings to bear arms for any paymaster who comes along". ${ }^{92}$ In Opposition dazu porträtierte etwa eine Karikatur der Plain People die beiden wichtigsten Führungspersönlichkeiten des Freistaats, Griffith und Collins, als anglisierte Säufer, die um die Gunst am luxuriösen Dubliner Hof des britischen Governor Generals buhlten. ${ }^{93}$ Dabei argumentierte die vertragsablehnende Propaganda häufig mit den Gesetzmäßigkeiten des republikanischen Geschichtsbildes. So wußte das Catholic Bulletin: „Assured materialism and bloated prosperity are and always have been antagonistic to the obvious facts and lessons of Irish history." 94

Andererseits lagen die konkreten Vorteile des Vertrages offensichtlich auf der Hand. Sie brachten den Vertragsbefürwortern den entscheidenden uneinholbaren Vorsprung vor den Republikanern. Doch um das materielle Argument für die vertragsbefürwortende Propaganda zu nutzen, mußten die Vertragsbefürworter von den vielen Einzelinteressen abstrahieren. Sie muß-

91 TCD, Early Printed Books, Samuels Collection, Box 2/3, Collins, Arguments for the Treaty, S. 23; Freeman's Journal, 6. Februar 1922, S. 5; IrISH STATESMAN, 15. September 1922, S. 40.

92 An Poblacht-SCOtTish Edition, 23. September 1922, S. 2.

93 Plain People, 21. Mai 1922, S. 3.

94 Catholic Bulletin, Juli 1922, S. 425. 
ten den „britischen Materialismus“ umdeuten, zu einem objektiven Prinzip erheben: So sprachen sie abstrakt vom Aufbau der Nation, von Industrie, Landwirtschaft, Fischerei, nicht von den damit verbundenen materiellen Vorteilen des Einzelnen. ${ }^{95}$ Sie beriefen sich deshalb auf „common sense“, „the facts“",responsiblity“; der Vertrag sei anders als „the empty name of the Irish Republic" nicht „a phrase“, sondern „a reality of freedom“ .96

Doch solch eine rationale Argumentation reichte kaum aus, um eine politisch stark emotionalisierte Bevölkerung anzusprechen, die an Opfermut, „Heldentod“ und Märtyrer gewohnt war. Zum Entsetzen des protestantischen Intellektuellen George Russle und der sozialistischen Voice of Labour thematisierten beiden Seiten soziale und ökonomische Fragen kaum. ${ }^{97} \mathrm{Na}-$ tionalismus blieb die alles entscheidende Legitimationsebene.

Das war nicht nur eine kalkulierte Propagandastrategie nach außen: Bis auf wenige Ausnahmen wie Griffith und Eoin MacNeill hatte die gesamte vertragsbefürwortende Elite selbst am Osteraufstand teilgenommen. ${ }^{98}$ Alle waren aktive Revolutionäre im Unabhängigkeitskrieg gewesen. Auch wenn sie jetzt Realpolitik betrieben, brauchten sie auch für ihr eigenes Selbstverständnis dringend eine nationale Legitimation. Doch wie?

Konstitutioneller Nationalismus war dabei keine Lösung. Die „Free Stater" zu „Home Rulern“ umzukodieren, war ein Lieblingsthema der republikanischen Propaganda, keine sinnvolle Selbstdefinition. ${ }^{99}$ Dazu hatte Sinn Fein die Home Rule-Bewegung nach 1916 zu gründlich diskreditiert. Die Vertragsbefürworter wollten gerade nicht das letzte Glied in einer angeblichen Tradition eines sauberen parlamentarischen Nationalismus sein, zu dem manche Historiker sie gerne stilisieren. ${ }^{100}$

Statt dessen versuchte die vertragsbefürwortende Propaganda, hier FitzGerald, „1916“ und die nationalen Aufstände den Republikanern streitig zu machen und sie selbst zu besetzen: "They not only kept that [national] spirit alive, but prooved that this spirit was unconquerable." Dabei verschob sich die bisher verbindliche Wertung des Osteraufstandes: „1916“ wurde für sie

95 Free State, 22. Mai 1922, S. 4, Artikel von Griffith; Young Ireland, 13. Mai 1922, S. 2.

96 Zitate: Irish Independent, 3. April 1922, S. 6; Free STATE, 25. Februar 1922, S. 4; Debate on TreatY: Sean Milroy, 20. Dezember 1921, S. 70; Free STATe, 20. Mai 1922, S. 5; 27. Mai 1922, S. 4; 25. Februar 1922, S. 4.

97 IRISH HomeSTEAD, 4. März 1922, S. 130; 8. April 1922, S. 222; 10. Juni 1922, S. 361; 5. August 1922, S. 476; VOICE OF LABOUR, 14. Januar 1922, S. 3.

98 Vgl. LEE, Irland 1912-1985, S. 67; Ernest Blythe wurde zusammen mit Liam Mellows kurz vor dem Aufstand inhaftiert: RUTH EDWARDS, Triumph, S. 264, 306, 337.

99 AN Poblacht, 3. Januar 1922, S. 1 f.; 5. Januar 1922, S. 1; 17. Januar 1922, S. 2.

100 Farrell, Paradox, S. 18, 21 f.; LyOnS, Three Essays, S. 255 f., differenzierter: ebd., S. 226; RiCHARD DAVIS, Griffith, S. 13, 36f., 39-41, 43; GRAHAM WALKER, Propaganda, S. 116. 
von einem verbindlichen Modell für zukünftiges Handeln zu einem einmaligen historischen Ereignis. Es zu wiederholen, sei sinnlos und unmoralisch. ${ }^{101}$ Die Vertragsbefürworter ehrten die nationalen Revolutionäre in Gedächtnisartikeln ${ }^{102}$ und durchkämmten ihre Werke und Reden nach Klassikerzitaten, mit der sich ihre Realpolitik rechtfertigen ließ.103

Doch über diese Ansätze hinaus gelang es selbst FitzGerald nicht, die vertragsbefürwortende Politik in direkter Kontinuität mit den „great dead“ darzustellen. Sein Rückgriff auf die revolutionäre Tradition blieb rational vermittelt. Die freistaatliche Propaganda konnte nicht verhindern, daß die Republikaner „the Republic“, insbesondere die nationale Martyrologie, weitgehend monopolisierten. Wie ein scharfsinniger britischer Beobachter kurz vor dem Bürgerkrieg fast mitleidig feststellte: „The opposition is sounding the authentic call of national freedom. Unquestionably its leaders are ,patriots'."104

Die Vertragsbefürworter saßen also zwischen den Stühlen, mußten sich einen neuen Nationalismus erfinden beziehungsweise aus alten Versatzstücken zusammenklittern. Nur ein scheinbarer Ausweg aus diesem Dilemma war die „stepping-stone“-Theorie, die These, der Vertrag sei nur ein erster Schritt zur Republik. ${ }^{105}$ Man könne also die Grenzen des Vertrages austesten: „no treaty except for Doc[ument No.] 2 ever pursued to be a final word."106 Den Republikanern warf die vertragsbefürwortende Propaganda vor, sie würden den Vertrag so ungünstig wie möglich, also „from the Imperialist point of view“ lesen. ${ }^{107}$ Soweit war die „stepping-stone“-These ein schlagendes Argument. Doch über diese abstrakte Ebene hinaus konnten FitzGerald und seine Mitarbeiter damit kaum Propaganda machen.

Nicht nur, daß die Republikaner die „stepping-stone“-Theorie als unehrenhaft ablehnten, weil die Vertragsbefürworter offenbar von vornherein planten, ihren „falschen Eid“ gegenüber dem König wieder zu brechen. 108 Konkrete „stepping-stone“-Politik lieferte keine verwertbare Propaganda. Wo die Revolutionäre nach der Logik von „the Republic“ handelten, pro-

101 FreE STATE, 25. Februar 1922, S. 1 Artikel von FitzGerald.

102 United IrISHMEN, 15. Februar 1923, S. 4f.; 22. März 1923, S. 3; 8. März 1923, S. 1.

103 FreE STATE, 22. Mai 1922, S. 4, Artikel von Griffith; 4. März 1922, S. 4; 22. April 1922, S. 2; Debate On Treaty, Beaslai, 8. Januar 1922, S. 179; United Irishmen, 7. April 1923, S. 1.

104 The Round TABle, XII, 47, (Juni 1922), S. 509.

105 Debate on Treaty, Collins, 19. Dezember 1921, S. 32.

106 Free STATE, 4. März 1922, S. 4, vgl. Frontispiz des FreE STATE mit dem Klassikerzitat von Charles Parnell: „No man has a right to fix the boundary of the march of a Nation..."

107 Free State, 20. Mai 1922, S. 5; vgl. dazu Catholic Bulletin, März 1922, S. 135: Analyse des Vertrages über Zitate englischer Politiker.

108 AN Poblacht, 5. Januar 1922, S. 1 f.; New Ireland, 22. April 1922, S. 308. 
duzierten sie den Stoff für Geschichten von Helden, Märtyrern und britischer Aggression. „Stepping-stone“-Politik spielte dagegen der republikanischen Propaganda in die Hände: Sie thematisierte die Grenzen der irischen Souveränität, erzählte von zähen Verhandlungen, neuen Kompromissen, peinlichen Rückziehern und nur kleinen Erfolgen.

So verzichtete die Freistaatsführung darauf, mit ihren stark republikanisch beeinflußten Verfassungsplänen Propaganda zu machen. Statt dessen verhängte die Provisorische Regierung eine Nachrichtensperre, um Spekulationen in der Presse zu verhindern und ersparte sich so später einen demütigenden öffentlichen Rückzieher. ${ }^{109}$

Mit ihrer anti-britischen und republikanischen „stepping-stone“-Politik konnten die Vertragsbefürworter keine nationale Propaganda machen; paradoxerweise aber mit der Politik, die auf Konsens mit Großbritannien beruhte. Das Umsetzen des Vertrages ließ sich relativ leicht national deuten. Ein in inneren Angelegenheiten souveränes Parlament, Frieden und vor allem der überall sichtbare Abzug der britischen Krontruppen: Als greifbare Erfolge einer „nationalen“ Politik waren sie das durchschlagende und endlos wiederholte Argument. ${ }^{110}$

Während die Vertragsbefürworter mit diesen nationalen Erfolgen ihrer Politik Propaganda machten, versuchten sie, die „antinationale“ Seite des Vertrages, das Ende der „existing Republic“ zu verschleiern. Um sich gegen diesen Dreh- und Angelpunkt der vertragsablehnenden Propaganda zu schützen, versteckte sich die Führung der Vertragsbefürworter hinter einer republikanischen Fassade: Dail Eireann. Obwohl das Machtzentrum der Vertragsbefürworter die Provisorische Regierung, vor allem Collins, war, hielten sie parallel dazu an der revolutionären Regierung und am revolutionären Parlament fest. In ihrem Windschatten ließ sich der Vertrag leichter umsetzen. Gerade Griffith argumentierte als neuer Präsident der Republik immer wieder, daß die Republik ja noch existiere, zumindest bis der Vertrag von der Bevölkerung in einer freien Wahl akzeptiert sei. Auch gegenüber Großbritannien war Dail Eireann nützlich: als letzte Sicherheit, falls die Übergabeverhandlungen scheiterten. ${ }^{111}$

109 NAI, D/T, S-8952, Darrell Figgis an Griffith, 18. Januar 1922; Diarmud O’Hegarty für Collins an Darrell Figgis, 27. Januar 1922; NAI, D/T, CoCo, „O“, Minutes of Constitution Committee, 27. Januar 1922; 28. Januar 1922; 30. Januar 1922; NAI, PG Minutes, G1/1, 28. Januar 1922; vgl. (die fast nicht vorhandene) Berichterstattung, in IRISH INDEPENDENT, 31. Januar 1922, S. 5; CURRAN, Birth, S. 200-17; BOYCE, Nineteenth Century, S. 275 f.

110 TCD, Early Printed Books, Samuels Collection, Box 2/3, Collins, Arguments for the Treaty, S. 25; FREE STATE, 25. Februar 1922, S. 1, Artikel von FitzGerald.

111 Dail Debates, Griffith, 28. Februar 1922, S. 100; 26. April 1922, S. 285 f.; NAI, D/T, 
Auch die Irish Republican Army nutzte die Führung der Vertragsbefürworter als republikanische Fassade. Der neue Verteidigungsminister Richard Mulcahy versicherte noch am Ende der Vertragsdebatten: „The Army will remain the Army of the Irish Republic. "112 Diese Erklärung war mehr als ein Versuch, Bevölkerung und Vertragsgegner zu täuschen. Dahinter stand die Hoffnung, daß eine einige IRA - „army unity“ - einen Bürgerkrieg verhindern würde. Gleichzeitig und konträr zu dieser auf Konsens zielenden Politik diente das Etikett „IRA“ der Führung der Vertragsbefürworter als Tarnung, um dahinter so schnell wie möglich eine loyale Truppe aufzubauen und aufzurüsten. Es sicherte ihr ein Stück republikanischer Legitimität, bremste das Tempo, in der sich die vertragsablehnende IRA selbständig machte. Wenn „army unity“ den Bürgerkrieg nicht verhindern konnte, dann wollte ihn die Provisorische Regierung wenigstens gewinnen. ${ }^{113}$

Schwer zu durchschauen und sehr glaubwürdig war die republikanische Fassade nicht. So störte sich die unionistische Irish Times wenig daran, daß das ehemals revolutionäre Parlament fortbestand. Sie akzeptierte Dail Eireann als irisches Etikett für „Parliament of Southern Ireland““.114 Die republikanischen Propagandisten geißelten zwar Dail Eireann immer wieder als Täuschungsmanöver, ${ }^{115}$ gleichzeitig nutzten die republikanischen Politiker aber das ex-revolutionäre Parlament für ihre Propaganda. Die republikanischen Abgeordneten versuchten, den vertragsbefürwortenden Ministern nachzuweisen, wo ihre Politik gegen „the Republic“ verstieß. Dabei ging es nicht um Realpolitik: Beide Seiten wußten, daß die Minister Dail Eireanns wenig effizient, aber so gut wie möglich, vertragsbefürwortende Politik machten. Worauf es für beide Seiten in einer Art Versteckspiel ankam, war, ob sich die vertragsbefürwortenden Minister dabei erwischen ließen, wenn sie gegen die offizielle republikanische Terminologie verstießen. Gerade die Fragestunde Dail Eireanns entwickelte sich schnell zu einem rhetorischen Ritual aus Fangfragen und ausweichenden Antworten: Wie vertrat Propagandaminister FitzGerald trotz seiner vertragsbefürworten-

S-8736, Michael MacDunphy, Memo Dual Government 1922, 1. September 1922; FreEMAN'S JOURNAL, 10. Mai 1922, S. 4.

112 Debate ON TREATY, Richard Mulcahy, 10. Januar 1922, S. 424.

113 Valiulis, Mulcahy, S. 123-8; FLK, DeV, 251, Statement Director Publicity Army [IRA], 30. März 1922; ANDREws, Dublin Made Me, S. 209.

114 IRISH TIMES, 25. April 1922, S. 4.

115 An Poblacht, 22. März 1922, S. 4; O’Donoghue, No Other Law, S. 202-4, insbes., S. 202: „the master stroke of pro-Treaty policy.“ 
den Haltung die Republik im Ausland?116 Benutzte Landwirtschaftsminister Patrick Hogan das Briefpapier Dail Eireanns oder das Briefpapier der Provisorischen Regierung? Ging er seinen Verwaltungsaufgaben als Minister Dail Eireanns oder als Minister der Provisorischen Regierung nach ${ }^{117}$

\section{b) Nationalismus obne Feindbild? - Nordirland-Propaganda und anti-britische Rhetorik}

Das traditionelle britische Feindbild war der Kern des antithetischen Weltbildes und hatte bisher Nation definiert und „national unity“ hergestellt. Mit der unkompromittierten republikanischen Rhetorik ließ es sich nach wie vor leicht verbinden und dabei direkt auf die Vertragsfrage beziehen:

The Slave Staters [...] ask you to surrender your national birthright, to bend your knee to the English King, to acknowledge that you are the fellow-citizen of your racial foes, to save and support the British Empire that has crushed your country. 118

Die Führung der Vertragsbefürworter konnte dagegen nicht mehr ungebrochen auf das britische Feindbild zurückgreifen. Nach dem Kompromiß mit Großbritannien war das wenig glaubhaft. Außerdem irritierte anti-britische Rhetorik die neuen Verbündeten: Großbritannien, die Unionisten in Südirland und die britischen Mitarbeiter in der freistaatlichen Administration. ${ }^{119}$ Dennoch argumentierte die vertragsbefürwortende Propaganda weiter anti-britisch, wenn auch über Umwege. So verteidigten FitzGerald und Ernest Blythe in ihren Grundsatzartikeln die konkreten Vorteile des Vertrages als Teilsieg in einem siebenhundertfünfzigjährigen Kampf mit einem barbarischen Feind. ${ }^{120}$

Auch wenn die britische Regierung oder die britische Presse der Provisorischen Regierung wohlwollende Ratschläge gaben, reagierte die Führung der Vertragsbefürworter mit anti-britischen Attacken. Indem sie sich so gegen jede Einmischung wehrte, demonstrierte sie irische Souveränität.121 Auch noch nach dem Ausbruch des Bürgerkrieges argumentierte die vertragsbefürwortende Propaganda anti-englisch; diesmal gegen die Republikaner gerichtet: Sie warf den Republikanern vor, das von ihnen verursachte

116 Dail Debates, Constanze Markievicz, de Valera, Cathal Brugha, FitzGerald, jeweils 28. Februar 1922, S. 99-101.

117 Dail Debates, Liam Cosgrave, 28. Februar 1922, S. 98; Patrick Hogan, Sean MacEntee, Austin Stack, jeweils 2. März 1922, S. 184.

118 Plain PeOple, 9. April 1922, S. 2.

119 IRISH Times, 19. März 1923, S. 4; RONAN FANNIG, Department of Finance, S. $79 \mathrm{f}$.

120 FreE STATE, 25. Februar 1922, S. 1, Artikel von FitzGerald.

121 Free State, 1. Juli 1922, S. 4; vgl. NAI, PG Minutes, G1/2, 7. April 1922. 
Chaos liefere den britischen Imperialisten den ersehnten Vorwand „[to] make your Nation once again the prey of the ancient enemy, England."122 Am glaubhaftesten ließ sich die anti-britische Rhetorik aber gegen die Unionisten in Nordirland wenden. Diese dienten der vertragsbefürwortenden Propaganda als willkommener Ersatzfeind.

Die Unionisten in Ulster verteidigten ihre protestantische Identität, ihre britische „Irishness“ mit der gleichen Hingabe und Brutalität wie die revolutionären Nationalisten ihre katholisch-nationalistische „Irishness“. Der protestantische Unionismus war ein ähnlich stimmiges und unter seinen Prämissen logisches Weltbild wie der Nationalismus Sinn Feins. Wie die Nationalisten wußten auch die Unionisten, was Gut und Böse war und nach welchen Gesetzen die Geschichte verlief. Sie fürchteten nach der Gründung eines katholischen Freistaats ein neues „1641“, ein neues „Massaker“ durch die Katholiken. ${ }^{123}$

Bis September 1922 fanden in Nordirland, besonders in Belfast, regelrechte Katholikenpogrome statt. Protestantische Arbeiter und die zu einer paramilitärischen Hilfstruppe umorganisierte Ulster Volunteer Force vertrieben Katholiken von ihren Arbeitsplätzen und aus ganzen Straßenzügen in Belfast. Die nordirische Regionalregierung duldete, ja ermutigte diese Übergriffe. Bis Ende des Jahres starben allein in Belfast 230 Personen bei politischen Unruhen. Die Opfer waren überwiegend Katholiken, darunter ganze Familien. ${ }^{124}$

Die Revolutionäre, die während des Unabhängigkeitskrieges, während der Verhandlungen mit England und während der Vertragsdebatten das Thema Nordirland gegenüber der Frage von „Crown“ und „Republic“ als zweitrangig zurückgestellt hatten, entdeckten es ab Januar 1922 für ihre Propaganda. Auf beiden Seiten zeigte sich die vom vertragsbefürwortenden Blatt Free State scheinheilig beklagte „inevitable tendency to exploit the Northern situation for political ends. "125 Wie Graham Walker nachgewiesen hat, unterschied sich die anti-nordirische Propaganda von Vertragsbefürwortern und -gegnern zunächst kaum. ${ }^{126}$ Beide Bürgerkriegsparteien

122 YOUNG IRELAND, 22. Juli 1922, S. 1, 3.

123 LYONS, Burden, S. 96-8; ders., Culture and Anarchy, S. 24-7, 113-45; zum Zusammenhang zwischen kulturellen und sozialen Konflikten und zum Primat kultureller Faktoren: insbes. ebd., S. 138-41, 144 f.; JeNnIfFER TODD, Unionist Political Thought, 1920-1972, in: BOYCE et. al. (Hrsg.), Political Thought, S. 190-211, hier: S. 191-8.

124 LAfFAn, Partition, S. 91; Townshend, Political Violence, S. 341-4.

125 Free STATE, 10. Juni 1922, S. 1; LAfFAn, Partition, S. 75, 79-83, 86-8; LyONS, Three Essays, S. 253 f.: Von 338 Seiten Vertragsdebatte füllte die Nordirland Frage gerade neun.

126 Graham Walker, Propaganda, S. 103-7, insbes. 105. 
verurteilten „butchery, horror [and] outrage“127 in fast identischem Wortlaut: Verfolgt von den „orange mobs“, lebten die Katholiken in Nordirland „under the black shadow of persecution and death."128 Gerade wo Frauen und Kinder betroffen waren, suchte die Propaganda nach drastischen Bildern. Dem aggressiven Norden stellten beide Seiten ein friedliches, in religiösen Fragen tolerantes nationales Irland gegenüber. Genauso übereinstimmend schätzten Freistaatler und Republikaner die Teilung Irlands als prinzipiell illegitim ein: „Ulster is ours.“129

Einige wenige radikale Nationalisten meinten dabei, die Protestanten seien keine Iren, sondern Nachfahren einer andere „Rasse“, nämlich britische Siedler. Sie sollten nach England und Schottland zurückkehren - nach dreihundert Jahren. Die große Mehrheit der Nationalisten machte die Unionisten dagegen $\mathrm{zu}$ fehlgeleiteten und vom britischen Materialismus korrumpierten Iren: ein Produkt britischer Parteipolitik. ${ }^{130}$ Im gewohnt kreativen Umgang mit der Geschichte behaupteten sie, protestantische Siedler und katholische Bevölkerung seien wegen der vielen gemischten Heiraten ethnisch nicht mehr zu unterscheiden. Die Nationalisten ignorierten dabei, daß Mischehen und Konversionen in den letzten dreihundert Jahren verpönte Ausnahmen gewesen waren. ${ }^{131}$

„Orangeism“132 als ein legitimes Konkurrenzmodell zum Nationalismus anzuerkennen, lag außerhalb der Denkgrenzen fast aller Vertragsbefürworter und -gegner. Eine bald nach dem Waffenstillstand eingesetzte Kommission, die der Sinn Fein-Führung den Unionismus näher bringen sollte, änderte daran wenig. ${ }^{133}$ Wie Anhänger der Home Rule-Bewegung und revolutionäre Sinn Fein vor ihnen, setzten sie sich nicht mit den Prämissen des Unionismus auseinander. Diese traditionelle Ignoranz tarnten die Propagandisten beider Seiten damit, daß sie Nordirlandpropaganda bevorzugt von protestantischen Überläufern aus Ulster schreiben ließen. ${ }^{134}$

Die Nordirlandpolitik von Vertragsbefürwortern und -gegnern war genauso phantasielos wie ihr Verständnis des Unionismus. Ohne Zugang zur Denkweise der Unionisten setzten sie auf die Rezepte, mit denen auch

127 YOUNG IRELAND, 10. Juni 1922, S. 4.

128 An POBLACHT, 18. Juni 1922, S. 4.

129 An Poblacht, 15. Juni 1922, S. 2; Free State, 10. Juni 1922, S. 1.

130 AN POBlaCHT, 29. März 1922, S. 6; vgl. Young IREland, 4. März 1922, S. 5.

131 LafFan, Partition, S. 15f., 25, 72-5, 123 f.; LYONS, Culture and Anarchy, S. 139.

132 Exemplarisch: YOUNG IRELAND, 4. März 1922, S. 5.

133 HOPKINSON, Green, S. 21.

134 An Poblacht, 29. März 1922, S. 6, Artikel von Aodh de Blacam; Free State, 10. Juni 1922, S. 1, Artikel von Ernest Blythe. 
schon Home Rule und Sinn Fein gescheitert waren: wirtschaftlicher Boykott, politischer Druck und Vertrauen auf die Kraft der „historischen Warheit". Eine Minderheit in beiden Bürgerkriegslagern schloß auch militärische Gewalt nicht aus. ${ }^{135}$

Die große Mehrheit von Vertragsbefürwortern und -gegnern meinten, Nordirland sei viel zu klein, um wirtschaftlich zu überleben. Beide Seiten gingen optimistisch und naiv davon aus, daß die im Vertrag vorgesehene Grenzkommission das nordirische Staatsgebiet um gut ein Drittel reduzieren werde. Die meisten Nationalisten hofften, Nordirland werde sich einem wirtschaftlich prosperierenden Süden anschließen. Sobald der Unionismus sich als unrentabel erweise, verlöre er seine Grundlage; die vom britischen Materialismus verblendeten Protestanten würden sich „wieder“ ihrer wahren Zugehörigkeit besinnen. ${ }^{136}$

Während für die Vertragsgegner, die ungebrochen auf die Rhetorik von 1916 und das britische Feindbild zurückgreifen konnten, das „alien Government" 137 in Nordirland nur ein Feind zweiter Klasse war, benötigten die Vertragsbefürworter die „Orange gang" 138 dringend als Feindbild. Erst über den Feind in Nordirland konnte sie ungebrochen auf das Herzstück des irischen Nationalismus zugreifen: die anti-britische Rhetorik und das antithetische Weltbild von materiellem England kontra spirituellem Irland. Die vertragsbefürwortende Propaganda konnte so wieder Märtyrergeschichten erzählen und die Oppositionen edel - verschlagen, stark schwach, leiden - unterdrücken besetzen. ${ }^{139}$ Als eigentlichen Aggressor, hinter den protestantischen Nordiren, ortete sie England: „No amount of Propaganda can obscure the fact that Britain, and Britain alone, is responsible for the present situation."140 Mit solcher Propaganda beeindruckte FitzGerald selbst seine direkten republikanischen Gegenspieler, die vertragsablehnenden Propagandisten Childers und Mary MacSwiney. ${ }^{141}$

Nordirlandrhetorik setzte nationale Emotionen frei, machte die brüchige, kopfgesteuerte, nationale Legitimation der Vertragsbefürworter lebendig. Nordirlandrhetorik war eine Chance, möglichst viele Anhänger,

135 Laffan, Partition, S. 76f.; FosTer, Modern Ireland, S. 530; TOwnshend, Political Violence, S. 343.

136 Young Ireland, 17. Juni 1922, S. 5f.; LafFan, Partition, S. 85-8, S. 99-105.

137 Catholic Bulletin, Juli 1922, S. 425; vgl. Plain People, 4. Juni 1922, S. 1.

138 YOUNG IRELAND, 25. November 1922, S. 2.

139 Free State, 10. Juni 1922, S. 1; Young Ireland, 10. Juni 1922, S. 4; 25. November 1922, S. 2.

140 Free StATE, 3. Juni 1922, S. 5.

141 Dail DebateS, Erskine Childers, 18. Mai 1922, S. 442 f.; Mary MacSwiney, 18. Mai 1922, S. 444 . 
vielleicht sogar die Republikaner, gegen den gemeinsamen Feind zu einen. Deshalb produzierte die vertragsbefürwortende Propaganda und Presse mehr und im Ton oft aggressivere Pamphlete und Artikel als die republikanischen Propagandisten der Poblacht. ${ }^{142}$ Nordirlandpropaganda war den Vertragsbefürwortern so wichtig, daß sie nicht FitzGerald, sondern Collins persönlich koordinierte. Schon im Februar organisierte er eine anti-nordirische Pressekampage. Nordirlandpolitik und damit auch Nordirlandpropaganda waren Chefsache. ${ }^{143}$

Diese Nordirlandpolitik beschränkte sich nicht nur auf Rhetorik. Die Provisorische Regierung erkannte den nordirischen Staat nicht an und unterstützte, wo es ging, eine Politik des passiven Widerstandes in Nordirland - auch finanziell. So zahlte sie bis November 1922 die Gehälter der katholischen Lehrer in Nordirland. ${ }^{144}$ Gerade Collins verfolgte eine aggressive Nordirlandpolitik, die vertragsbefürwortendes und vertragsablehnendes Militär zeitweise tatsächlich gegen den gemeinsamen Feind einte. Vertragsbefürwortende und vertragsablehnende Truppen setzten einen Boykott gegen Waren aus Belfast gemeinsam durch. Als sich die Provisorische Regierung gegenüber Nordirland zeitweise offiziell verpflichtete, den Boykott abzubrechen, tolerierte Collins, daß die vertragsablehnende IRA weitermachte wie bisher: Sie verbrannte Waren aus Nordirland und trieb Geldstrafen von nicht kooperierenden Händlern ein. ${ }^{145}$ Die Regierung duldete in diesem Fall, daß ihre innenpolitischen Feinde das staatliche Gewaltmonopol durchbrachen.

Collins aggressive Nordirlandpolitik ging noch weit darüber hinaus. Auch Bretherton, der zynische Irlandkommentator der Morning Post, hätte sich kaum eine abenteuerlichere Verschwörungstheorie ausdenken können: Ohne daß der Rest der Provisorischen Regierung davon erfuhr, kooperierte Collins mit der vertragsablehnenden IRA, organisierte Geiselnahmen durch die nordirische IRA. Gemeinsam mit führenden Vertragsgegnern bewaffnete er die IRA in Nordirland, lenkte dazu einen Teil der britischen Waffenlieferungen für die vertragsbefürwortenden Truppen nach Nordirland um. Weil die nordirische Polizei bei der IRA keine neuen britischen Waffen finden durfte, lieferte Collins die britischen Waffen an die vertragsablehnen-

\footnotetext{
142 So auch: Graham Walker, Propaganda, S. 103 f.; Für eine besonders aggressive Nordirlandrhetorik exemplarisch die Artikel von Sean MacEachain, in: YOUNG IRELAND, 25. November 1922, S. 2; 23. Dezember 1922, S. 4.

143 NAI, PG Minutes, G1/7, 17. Februar 1922; NAI, D/T, S-1882, Memorandum Michael McDunphy, 19. Mai 1936.

144 Laffan, Partition, S. 96; LitTon, Civil War, S. 51 f., 54.

145 HOPKINSON, Green, S. 68, 82 f.
} 
den Truppen in Munster. Die schickten dafür ihre unregistrierten Gewehre nach Nordirland. Ab März führten vertragsbefürwortende und vertragsablehnende Truppen an der Grenze zu Nordirland gemeinsame Übungen und Überfälle durch. Collins und der vertragsablehnende General Liam Lynch planten eine gemeinsame Offensive gegen Nordirland. ${ }^{146}$

Collins Nordirlandstrategie war zweigleisig angelegt. Er setzte auf Konfrontation und Ausgleich zugleich und probierte aus, welcher Weg erfolgreicher sein würde. Seine offizielle Nordirlandpolitik lief dabei seiner geheimen und aggressiven Nordirlandpolitik scheinbar direkt entgegen. Im Januar und erneut im März 1922 suchte er einen Ausgleich mit Nordirlands Premier James Craig. Collins versprach, den Boykott nordirischer Waren zu beenden. Dafür verpflichtete sich Craig, den vertriebenen Katholiken ihre Arbeitsplätze und Häuser zurückzugeben. Diese vielleicht erfolgversprechendere Ausgleichs- und Versöhnungspolitik war jedoch ein propagandistisches Risiko, vor allem, weil Craig seinen Teil der Vereinbarung genauso brach wie die Provisorische Regierung den ihren. ${ }^{147}$ Das Ende des Boykotts erfreute zwar viele irische Unternehmer, doch untergrub es die brüchige nationale Legitimität der Vertragsbefürworter, die auf den Feind in Nordirland angewiesen waren.

So wertete die republikanische Propaganda die anhaltenden Katholikenverfolgungen als Versagen des Vertrages. Doch weil die Republikaner selbst keine alternative Nordirlandpolitik hatten, war es für sie schwer, den Vertragsbefürwortern die Schuld an der irischen Teilung zuzuschieben. Weil es den vertragsablehnenden Propagandisten also an guten Argumenten fehlte, beschränkten sie sich weitgehend auf Standardformeln. Sie titulierten freistaatliches Parlament und freistaatliche Regierung mit Schlagworten wie „Partition Parliament“ oder „Partition, Government “ "148 und verglichen immer wieder freistaatliche und nordirische $Z_{\text {wangsmaßnahmen miteinan- }}$ der. ${ }^{149}$

Die vertragsbefürwortenden Propagagandisten argumentierten identisch, wenn auch unter umgekehrten Vorzeichen: Sie setzten die Methoden von

146 Hopkinson, Green, S. 80, 83-9, 98; O’Donoghue, No Other Law, S. 250-2; LiTTON, Civil War, S. 49-55; GARVIN, Nationalist Revolutionaries, S. 144; bereits während der Vertragsverhandlungen rüstete Collins die IRA mit illegalen Waffenimporten auf: VALIULIS, Mulcahy, S. 83, 141.

147 Laffan, Partition, 92-4; LitTon, Civil War, S. 49, 52.

148 Daily Bulletin, 27. Oktober 1922; UCD, MP, P7/B/238, Leserbrief von Dorothy MacArdle an IrISH Times, IRISH INDEPENDENT und FrEEMAN'S JOURNAL, 15. November 1922.

149 An Poblacht-SCOTtish Edition, 23. September 1922, S. 2; UCD, RP, P88/286, 10, Flugblatt, ca. Oktober 1923; AN POBLACHT, 28. Februar 1922, S. 6. 
Republikanern und „Orangemen“ gleich und beschuldigten die Vertragsgegner: Allein das von der IRA verursachte Chaos, später der Bürgerkrieg, mache eine „unity between Orange and Green“ unmöglich.150

Die Nordirlandrhetorik half den Vertragsbefürwortern also nur teilweise aus der Legitimationskrise. Wieder standen sie vor ihrem alten legitimatorischen Dilemma: Da sie fast alle realpolitischen Handlungsweisen ausschöpften, gefährdeten sie ihre nationale Legitimation. Ihre offizielle friedliche Nordirlandpolitik ließ sich als „antinational“ diskreditieren. Die aggressive „stepping-stone“-Politik mußte Collins nicht nur vor der Öffentlichkeit, sondern auch vor den meisten seiner Kabinettskollegen geheimhalten. Zumindest einige radikale IRA-Aktivisten waren von seiner Politik beeindruckt: Noch kurz vor dem Bürgerkrieg gingen sie davon aus, eine Offensive gegen Nordirland stehe unmittelbar bevor. ${ }^{151}$

Erst nach Collins Tod im August 1922 begannen die führenden Regierungsmitglieder auch in der Nordirlandfrage mit Realpolitik. Nicht weil sie den Unionismus jetzt als legitime konkurrierende Kultur akzeptierten, sondern weil ihnen die aggressive Politik von Collins ineffizient schien, beendeten sie nach und nach ihre Obstruktionspolitik. Sie setzten nun allein auf die Attraktivität eines wirtschaftlich prosperierenden Südens. Im November 1922 stellten sie die Zahlungen an die katholischen nordirischen Volksschullehrer ein und hörten so damit auf, sich in die Souveränität Nordirlands einzumischen. Parallel zu dieser Politik mäßigten die Propagandabehörden auch ihre offizielle Nordirlandrhetorik, ohne dieses nützliche Thema ganz fallen zu lassen. ${ }^{152}$

Während die Republikaner auch mit Document No. 2 nicht aus ihrer Handlungskrise herausfanden, blieb die nationale Legitimation der Vertragsbefürworter brüchig: Die Provisorische Regierung konnte „1916“ und „the Republic“ nur schwer besetzen. Die „republikanische“ „steppingstone"-Politik war auf Heimlichkeit angewiesen und eignete sich weder als konstitutionelle Verfassungspolitik noch als aggressive Nordirlandpolitik für Propaganda. Dazu war die republikanische Fassade von vertragsbefürwortender IRA und Dail Eireann leicht zu durchschauen, während den „nationalen“ Eigenschaften des Vertrages das Stigma des Materialismus und

150 IRISH INDEPENDENT, 18. Januar 1922, S. 3; 2. Mai 1922, S. 4; YOUNG IRELAND, 25. November 1922, S. 2; DAIL DEBATES, Sean Milroy, 8. Dezember 1922, S. 65; YOUNG IRELAND, 18. November 1922, S. 2.

151 HOPKINSON, Green, S. 98, 102.

152 Young IRELAND, 4. November 1922, S. 1; 11. November 1922, S. 1; Free STATE, 21. Oktober 1922, S. 1; vgl. GRAHAM WALKER, Propaganda, S. $106 \mathrm{f}$. 
des Verrats an der Republik anhaftete. Die Republikaner belegten anti-englische und anti-nordirische Rhetorik in fast identischem Wortlaut, aber mit wirkungsvollerem Kontext.

\section{III. „MAJORITY RULE“, „LIBERAL RIGHTS“ UND „THE REPUBLIC“}

Im folgenden Teilkapitel zeige ich, wie den Vertragsbefürwortern eine überzeugendere Form der nationalen Legitimation gelang: Sie monopolisierten die Werte „majority rule“ und „liberal rights“ und wendeten sie ins Nationale. Ich untersuche, wie IRA und republikanische Politiker auf diesen Anspruch der Freistaatler reagierten und wie ambivalent ihr Verhältnis zu diesen, gegenüber „the Republic“ sekundären Werten war.

\section{FREISTAAT: „MAJORITY RULE“ ALS NATIONALER WERT}

„The sovereign people must rule“: Mit diesem Argument löste die Führung der Vertragsbefürworter ihr legitimatorisches Dilemma. ${ }^{153}$ „The will of the people“ war schnell das Lieblingsargument ihrer Propaganda, es durfte in keinem Artikel fehlen und wiederholte sich in endlosen Variationen, bis es der Redundanz der republikanischen Rhetorik Konkurrenz machte. ${ }^{154}$

"Will of the people“ erhob das materielle Interesse und die Kriegsmüdigkeit der überwiegenden Mehrheit der Bevölkerung zu einem abstrakten Prinzip: demokratische Partizipation, „majority rule“. Das war in Irland und in den wichtigsten Ländern der irischen Diaspora, den USA, Großbritannien und Australien, ein allgemein anerkanntes und kaum hinterfragtes Prinzip.

Obwohl die irische Vorstellung von „majority rule“ über den amerikanischen und vor allem britischen Parlamentarismus vermittelt war, ${ }^{155}$ galt „majority rule“ den Freistaatlern nicht als amerikanischer oder gar „britischer“ Wert. Im Gegenteil: Wo sich die „Britishness“ demokratischer Spielregeln aufdrängte, fühlte sich die freistaatliche Propaganda unter Rechtfertigungszwang: „It may sound like a British stupidity to say that no Parlia-

153 YoUNG IRELAND, 15. Januar 1922, S. 4.

154 Nur einige wenige von sicher hundert möglichen Beispielen: FREE STATE, 18. März 1922, S. 1; 25. März 1922, S. 4, Artikel von Ernest Blythe; 20. Mai 1922, S. 4; 10. Juni 1922, S. 4; 24. Juni 1922, S. 4.

155 BOYCE, Nineteenth Century, S. 9; 283-5, 289; ders., Nationalism, S. 388; GARVIN, Nationalist Revolutionaries, S. 165; MACDONAGH, Ambiguity, S. 107. 
ment can get on without an organised opposition, but it is essentially true..." 156

Wie der Guerillero Charles Stewart Andrews treffend beobachtete, galt Demokratie 1922 in Irland keineswegs als „unumstrittene Göttin“. Termini wie "the democratic processes“ waren, nach Andrews, für die meisten Iren reichlich abstrakte Fremdwörter. ${ }^{157}$ Weil mit dem partizipatorischen Wert Demokratie wenig Emotionen zu wecken waren, nationalisierten die Propagandisten „majority rule“ und stellten ihn als spezifisch irischen, „antibritischen" Wert dar. Die Propagandisten deuteten den irischen Nationalismus im Sinne von „majority rule“ um und machten Volkssouveränität zum Kernstück einer neuen nationalen Legitimation. Dabei demokratisierten sie - fast nebenbei - die Definition von „Nation“, verstärkten damit einen Prozeß, durch den Demokratie in den folgenden Jahren und Jahrzehnten auch in Irland eine „unumstrittene Göttin“ wurde.

Seit den 1870ern, letztlich seit den 1820ern, war „will of the people“ ein Synonym für Nationalismus. Seit der Katholikenemanzipation hatten die konstitutionellen irischen Nationalisten die parlamentarische Tradition Englands nicht nur instrumentalisiert, sondern zu ihrer eigenen gemacht. ${ }^{158}$ Abgesehen vom elitären Nationalismus des revolutionären Republikanismus bestand zwischen „majority rule“ auf der einen, „repeal“, Home Rule oder „a republic“ auf der anderen Seite kein Widerspruch. „Government by the consent of the governed" war einer der beliebtesten Slogans der Sinn Fein-Propaganda vor 1922.159 So verschwammen während des Unabhängigkeitskrieges die Grenzen zwischen autoritär-kollektivistischem und individualistisch-emanzipatorischem Nationalismus. ${ }^{160}$ Solange die Bevölkerung mehrheitlich hinter Sinn Fein stand, ergänzten sich "the Republic“ und "will of the people“.

Erst nach der Vertragsspaltung ließen sich die beiden Konzepte nicht mehr in Einklang bringen. Die Vertragsbefürworter nutzten jetzt die traditionell nationale Lesart von „will of the people“ und spielten ihn gegen die elitäre Republik aus. Das heißt nicht, daß sie das republikanische Weltbild offen in Frage stellten. Aber sie verschoben den Akzent ihrer Argumentation zwischen den beiden Polen „the Republic“ und „will of the people“:

156 FREE STATE, 30. September 1922, S. 2.

157 ANDREWS, Dublin Made Me, S. 218.

158 GARVIN, 1922, S. 22-5, 32-4, 200.

159 Offener Brief von de Valera an Lloyd George, 24. August 1921, in: The Round TABLE, XI, 45, (Dezember 1921), S. 43; GARVIN, Nationalist Revolutionaries, S. 140.

160 Zur Typologie von autoritärem und emanzipatorischem Nationalismus: GREENFIELD, Five Roads, S. 8-12; vgl. HOBSBAWM, Reflections, S. 389. 
Sie relativierten die Vorstellung, die Nation sei präexistent, spirituell und nichts als die Summe ihrer Märtyrer, zu Gunsten einer Definition von Nation als Summe ihrer Staatsbürger. ${ }^{161}$

Die vertragsbefürwortenden Propagagandisten werteten die Gegenwart gegenüber Vergangenheit und Zukunft auf. Was Griffith die „living nation"162 nannte, verband nationale und demokratische Legitimation und setzte sie in eins. Gerade weil die Propagandisten das Martyrium relativierten, sicherten sie ihre Argumentation mit der Dignität selektiver Märtyrerzitate von Wolf Tone bis zu Pearse ab. So zitierten Free State und United Irishman „the Teaching of Pearse“ mit: „That the People are the Nation“.163

Dieses Argument verbanden die Propagandisten mit einer historischen Perspektive: Statt auf die diskreditierte Rhetorik der Home Rule-Bewegung zurückzugreifen, erfanden sie eine eigene republikanisch-demokratische Tradition. Dazu definierten sie den irischen Freiheitskampf um: zu einem „siebenhundertjährigen Ringen“ um Irlands Recht auf demokratische Selbstbestimmung. ${ }^{164}$

Diese demokratisch-republikanische Traditionsbildung war genauso artifiziell wie das republikanische Geschichtsgesetz; denn sie verwischte die Unterschiede zwischen der demokratischen und der republikanischen Tradition des irischen Nationalismus. Es ist schwer $\mathrm{zu}$ beurteilen, wie viele Vertragsbefürworter vor, während oder nach dem Bürgerkrieg zu überzeugten Demokraten wurden. ${ }^{165}$ Die These, der echte Republikanismus sei schon immer demokratisch gewesen, war ein sehr elastischer Umgang mit der Vergangenheit, wenn nicht eine bewußte Lüge. Ob im neunzehnten Jahrhundert oder ob 1916: Republikaner verstanden sich als tugendhafte nationale Elite, hielten Gewalt für legitim und sahen ihre Politik meist als Alternative zu dem „korrupten“, auf dem „will of the people“ basierenden konstitutionellen Massennationalismus. Pluralistisch war dabei weder der elitäre Republikanismus, noch der konstitutionelle Massennationalismus; denn beide definierten „Nation“ über den äußeren Feind, verschoben und vertuschten innerirische Differenzen. ${ }^{166}$

161 Stark typisierend: GARVIN, 1922, S. 143-6.

162 Debate ON TREATY, Griffith, 7. Januar 1922, S. 338.

163 Free State, 20. Mai 1922, S. 3; United Irishman, 7. April 1923, S. 4.

164 TCD, Early Printed Books, Samuels Collection, Box 2/3, Collins, Arguments for the Treaty, S. 20; Free STATE, 25. März 1922, S. 4, Artikel von Ernest Blythe; UCD, FGP, P80/298, official statement, ca. 11. Juli 1923.

165 REgAN, Reaction, S. 551 f.; GARVIN, 1922, S. 205.

166 Zur begrifflichen und historischen Trennung von Demokratie und Republikanismus im irischen Kontext: GARVIN, 1922, S. 8-18. 
Wenn einige Historiker den Bürgerkrieg als Kampf um die irische Demokratie stilisieren, ist dies zwar nicht falsch, greift aber zu kurz, übernimmt den Standpunkt der vertragsbefürwortenden Propaganda. ${ }^{167}$ Die Vertragsbefürworter selbst hatten als Veteranen des Osteraufstandes und des Unabhängigkeitskrieges ein deutlich elitäres Selbstverständnis. Eines von vielen Beispielen dafür war Beaslai, als Freistaatszensor und Propagandist hauptberuflicher Verteidiger der „majority rule“-Rhetorik. Schon als er 1921 die „national unity“ auf dem Ard Fheis beschrieb, schloß sein Verständnis von „democracy in its fullest sense“ konkurrierende soziale oder nationale Interessen aus. Noch elitärer definierte er 1918 in seiner Untergrundarmeezeitung An tOglach die Aufgaben der IRA: „Volunteers are not politicians, they were not created for the purposes of parades, demonstrations or political activities; they follow no political leader as such, their allegiance is to the Irish Nation." 168

\section{REPUblikANER: POLITIKER, MilitÄRS UND „MAJORITY RULE“}

Während Beaslai „Irish Nation“ zumindest ab 1922 im Sinne von „the Irish People“ verstand, bedeutete es für die meisten IRA-Aktivisten, für die er schrieb, „the Irish Republic“. Diese unveräußerbare Republik stand aus vertragsablehnender Sicht außerhalb der Zuständigkeit von „majority rule“: „The sovereignty of the people exists and can only exist in the independence of the people and those only can speak in the name of the Souvereign People who defend that independence "169 Die vertragsablehnende Propaganda umging den a posteriori definierten „majority rule“-Vorwurf der Vertragsbefürworter durch ein a priori definiertes „proper understanding of the Irish people [of] their spirits and aspirations. "170 Gerade de Valera verstand sich persönlich als eine mystische Mitte Irlands mit einem unmittelbaren Zugriff auf die „volonté générale“ der Bevölkerung: „... whenever I wanted to know what the Irish people wanted I had only to examine my own heart and it told me straight off what the Irish people wanted." 171

167 So tendenziell auch: RiCHARD DAVIS, Griffith, S. 39-44; GARVIN, 1922, etwa: S. 2, 18, 30 f., $53,62,127$.

168 AN TOGLACH, 15. August 1918, S. 1; NAI, Sinn Fein, 1094/1/18, Impressions of Ard-Fheis; TOWnsHend, British Campaign, S. 329; GARVIN, Nationalist Revolutionaries, S. 152-4.

169 An Poblacht, 29. März 1922, S. 4; FLK, DeV, 1315/1, Bertold O’Maoileiagh an de Valera, 25. März 1922.

170 NeW IRELAND, 22. April 1922, S. 309, Interview mit de Valera.

171 Debate on Treaty, de Valera, 6. Januar 1922; S. 274. 
Weniger gestützt auf de Valeras „oracular heart" 172 als auf das historische Wissen des republikanischen Geschichtsgesetzes, war die überwiegende Mehrheit der Vertragsgegner und vor allem die IRA überzeugt: die Bevölkerung habe „no right to go wrong“, 173 kein Recht auf ihr „national birthright" $\mathrm{zu}$ verzichten und England freiwillig einen Rechtsanspruch auf Irland zuzubilligen. ${ }^{174} \mathrm{Daß}$ die bestochene und willensschwache Bevölkerung nur selten auf der Seite des wahren Nationalismus gestanden hatte, war für sie eine historische Gesetzmäßigkeit, „from the days when a minority supported Owen Roe O’Neill175“.176

Zumindest aus Sicht der IRA verlor dieses elitäre Verständnis etwas von dem, durch Tom Garvin gerne attestierten, diktatorischen Zynismus, ${ }^{177}$ weil sie mit der Erweckungstheorie des republikanischen Geschichtsgesetzes konform lief. Der prominente Guerillero Ernie O'Malley brachte das in seinem bekannten Ausspruch auf den Punkt: „We have never consulted the feelings of the people. If so, we would never have fired a shot. If we gave them a good strong lead, they would follow." 178 Wenn die IRA erst einmal den richtigen Weg eingeschlagen habe, dann werde sich "das Volk“ schon besinnen. So zitierte das Catholic Bulletin den Hungerstreikmärtyrer Terence MacSwiney: „Those who fight for her [Ireland] are always denounced in the beginnings and justified in the end." 179 Nach dieser Logik werde sich das Problem „will of the people“ durch das republikanische Geschichtsgesetz von selbst lösen - wie nach 1916 und 1919.180 Dieser vom Geschichtsgesetz versprochene Automatismus entsprach dabei dem Aktionismus der IRA: Er machte es überflüssig, die „feelings of the public“ näher zu erwägen und sei es nur aus taktischen Gründen, sondern ermutigte zum (militärischen) Handeln. O’Malley rückblickend am Rande der Selbsterkentnis: „Thought was so difficult when there was no way out [...] If only we could act. That would clarify thinking." 181

172 Free STATE, 29. April 1922, S. 1.

173 An POBlaCHT, 18. Mai 1922, S. 4.

174 An Poblacht-Scottish Edition, 23. September 1922, S. 2; Plain People, 9. April 1922, S. 2; FLK, DeV, 1452, de Valera an Erzbischof Mannix, 6. November 1922.

175 Owen Roe O’Neill, (1590-1649): irischer Adliger, Feldherr, Gegner Oliver Cromwells.

176 UCD, RP, P88/108, circular press statement, ca. Oktober 1923; FLK, DeV, 1315/1, Bertold O’Maoileiagh an de Valera, 25. März 1922.

177 GARVIN, 1922, S. 43.

178 O’Malley, Singing Flame, S. 25.

179 Catholic Bulletin, Juni 1922, S. 409.

180 FLK, DeV, 1315/1, Bertold O’Maoileiagh an de Valera, 25. März 1922; grundlegend, wenn auch relativ normativ: GARVIN, Nationalist Revolutionaries, S. 120 f., 142-4, 149-56.

181 O’Malley, Singing Flame, S. 46; vgl. Andrews, Dublin Made Me, S. 221; O’DOnOGHUE, 
Professor Eoin MacNeill, Mitbegründer der Gaelic League, der Irish Volunteers und Kultusminister des Freistaats, kommentierte diesen Unwillen zur Reflexion wesentlich bitterer: „The charm of allegiance to a formula is its simplicity. It saves thinking. "182 Und wenn er so mit der Engstirnigkeit der Radikalen haderte, dann erinnerte er sich sicher an deren geistigen Stammvater Pearse, den Mac Neill 1916 vergeblich versucht hatte, am Aufstand zu hindern. Doch Kritik an Pearse war auch für die vertragsbefürwortende Propaganda unsagbar, für die meisten Vertragsbefürworter auch undenkbar. Das galt für Mac Neill noch mehr als für alle anderen: Er verdankte sein politisches Überleben allein der Tatsache, daß Pearse in einem seiner letzten Briefe MacNeill ehrenwerte Motive beschieden und ihm sein Eingreifen gegen den Aufstand verziehen hatte. ${ }^{183}$

Einige radikale IRA-Aktivisten ignorierten Publicity nicht einfach, sondern veröffentlichten ihre eigenen unpopulären Ansichten. Berühmt-berüchtigt wurde in dieser Hinsicht ein Interview von General Rory O'Connor, später Kommandeur der IRA in den Four Courts. Ende März beantwortete er die Frage eines Reporters des Irish Independent, ob die IRA eine Militärdiktatur plane mit: „You can take it that way if you like." Sein Rezept gegen das „majority rule“-Argument der Vertragsbefürworter war, zu verhindern, daß die Bevölkerung ihren freien, seiner Ansicht nach falschen, Willen in einer Wahl äußern würde. ${ }^{184}$

Rory O'Connor und die Radikalen in der IRA ließen sich längst nicht mehr von der politischen Führung der Republikaner um de Valera kontrollieren. Schon bald nach der Vertragsspaltung bestimmte die IRA das Tempo und die Richtung der vertragsablehnenden Politik. ${ }^{185}$ Der Vertrag hatte ihre bisher oft nur latente Verachtung für das „word-spinning“ und „spell binding“186 der „political twisters“187 bestätigt. Das Schimpfwort „politician“ wurde nun nicht mehr exklusiv für englische Politiker verwendet, sondern traf zunächst die Vertragsbefürworter, indirekt aber auch die eigene politische Elite. ${ }^{188}$

No Other Law, S. 184, auch S. 204; DEASY, Brother against Brother, S. 43; ENGLISH, Inborn Hate, S. 192, 199.

182 Free STATE, 4. März 1922, S. 4, Artikel von Eoin MacNeill.

183 RUTH EDWARDS, Triumph, S. 240f., 243, 246-250, 264 f., 298, 337.

184 IRISH INDEPENDENT, 23. März 1922, S. 5. Das Interview wurde auch in der Provinzpresse veröffentlicht, exemplarisch: CORK EXAMINER, 23. März 1922, S. 5.

185 VAliUlis, Mulcahy, S. 122.

186 AN POBLACHT, 27. April 1922, S. 4; 18. Mai 1922, S. 3.

187 Plain PeOple, 25. Juni 1922, S. 4.

188 Plain PeOPLE, 14. Mai 1922, S. 2; auch gegen republikanische Politiker gerichtet: WoR- 
Die IRA-Radikalen erfanden ihre eigene "Dolchstoßlegende“. ${ }^{189}$ Sie meinten oder gaben vor, von den korrupten Politikern um den Sieg gebracht worden zu sein, und sie täuschten sich dabei systematisch darüber hinweg, daß die IRA nur deshalb „im Felde ungeschlagen“ geblieben war, weil sie jeder größeren Konfrontation aus dem Weg gegangen war. ${ }^{190}$ Damit argumentierten sie, ohne es zu wissen, fast identisch wie ihre britischen Gegner: auch führende britische Militärs fühlten sich durch das "palaver" und die Verschlagenheit ihrer Politiker um den nahen Sieg über die irischen „Terroristen" gebracht. 191

Doch anders als die professionelle britische Armee, folgte die IRA ihren Überzeugungen, nicht ihren Vorgesetzten oder gar ihrer politischen Führung. Ende März sagte sich die vertragsablehnende IRA auf der sogenannten „army convention“ endgültig vom Parlament und vom vertragsbefürwortenden Hauptquartier los. Sie folgte dabei auch organisatorisch dem Muster von 1916, wählte eine IRA-Exekutive, die wie das Military Council von 1916 aus sechzehn Mitgliedern bestand.192 Wie hatte Beaslai nicht schon 1918 das Selbstverständnis der IRA beschrieben? „Volunteers are not politicians, they follow no political leader as such...."193

De Valera und die Propagandisten der Poblacht hatten ein differenzierteres und ambivalenteres Verhältnis zu „majority rule“. Als Politiker versuchten sie sich in der Kunst des „word twisting“ und „spell binding“, bemühten sich, der Erweckung der Bevölkerung mit propagandistischen Methoden nachzuhelfen. Zwar rangierte auch für sie "majority rule“ eindeutig hinter „the Republic“. Dennoch hofften sie den Vertrag mit politischen Methoden, am besten gestützt von der Mehrheit der Bevölkerung, zu verhindern. Die republikanische Propaganda konnte das Thema „majority rule" deshalb nicht einfach als irrelevant ablehnen. ${ }^{94}$ Sie mußte sich auf die vertragsbefürwortende Version von „majority rule“ einlassen und diese untergraben. Dabei hatte sie einen schweren Stand.

Ker'S Republic, 1. April 1922, S. 1; Andrews, Dublin Made Me, S. 208, auch S. 201; GARVIN, Nationalist Revoutionaries, S. 151; LONGFORD und O’NEILL, De Valera, S. 187, 207; ENGLISH, inborn hate, S. 192-4; ders., Green on Red, S. 161, 174.

189 Diesen deutschen Terminus verwendet auch GARVIN, Nationalist Revolutionaries, S. 143, 149.

190 Catholic Bulletin, supplement 1921, S. 5; ebd., Dezember 1922, S. 758; AN POBlaCHTWAR News, 21. Februar 1923; VAliUlis, Mulcahy, S. 81 f.; FitZPATRICK, Politics, S. 230 f.

191 Macready, Annals, Bd. 2, S. 646, 596f.; vgl. ebd., S. 492f., 585, 602 f., 605, 622, 624, 660.

192 Worker's Republic, 1. April 1922, S. 1; O’Donoghue, No Other Law, S. 224.

193 An TOGLACH, 15. August 1918, S. 2.

194 FLK, DeV, 1315/1, Bertold O’Maoileiagh an de Valera, 25. März 1922. 
Noch auf dem Ard Fheis im Oktober 1921 hatte de Valera öffentlich erklärt: Solange die grundsätzliche nationale Unabhängigkeit Irlands garantiert sei, sei es absolut legitim, politische Meinungsunterschiede konstitutionell zu lösen. Bis Mitte Januar 1922 hielt de Valera an dieser Rhetorik fest. 195

Mit dem Abschied von Document No. 2 und unter dem Druck der radikalen IRA rückte de Valera immer weiter von dieser Position ab. Um die inner-republikanische Einheit nicht zu gefährden, verschob er den Akzent seiner Argumentation von „konstitutionellen Methoden“ immer mehr zum Aspekt „nationale Unabhängigkeit“ - auch wenn das, wie er später zugab oder behauptete, seine eigenen Überzeugungen strapazierte. ${ }^{196}$ Wie schon bei Document No. 2 erreichte de Valera dabei mit seiner kalkuliert ambivalenten Rhetorik nicht Konsens, sondern lieferte durch seine als inkonsequent darstellbare Haltung seinen politischen Gegnern Argumente. ${ }^{197}$

Weil die Republikaner sich in der Gegenwart nicht über „majority rule“ legitimieren konnten, suchten sie sich eine demokratische Legitimation in der Vergangenheit. Im gewohnt elastischen Umgang mit der Geschichte behauptete die vertragsablehnende Führung, die Bevölkerung habe bei der Wahl 1918 die Republik endgültig und unumkehrbar ratifiziert. ${ }^{198} \mathrm{Daß}$ das Wahlprogramm Sinn Feins eigentlich vorgesehen hatte, die revolutionäre Republik auf der Friedenskonferenz in Versailles durchzusetzen und dann die Bevölkerung in einem Referendum endgültig über die Staatsform entscheiden zu lassen, vertuschten die republikanischen Propagandisten. ${ }^{199}$

Die vertragsablehnende Propaganda argumentierte: der gegenwärtige „will of the people“ verstoße nicht nur gegen den legitimen Volkswillen von 1918 und gegen das republikanische Geschichtsgesetz, sondern gegen die Spielregeln von "majority rule“ selbst. Die Republikaner bastelten also nicht nur an der Vergangenheit, sondern auch an der Wahrnehmung der Gegenwart. Sie argumentierten dabei einmal mehr in „Soll“-Zuständen, statt in „Ist“-Zuständen: Die Bevölkerung müsse über den Vertrag „at the point of an English revolver" abstimmen, ohne die britische Kriegsdrohung aber

195 IRISH IndePENDENT, 9. Dezember 1922, S. 5; MAURICE MOYNIHAN, Speeches and Statements of de Valera, 1917-1973. Dublin 1980, hier: S. 74-8, insbes., S. 74, 78; CATHOLIC BULLETIN, Januar 1922, S. 17.

196 FLK, DeV, 273, de Valera an Mary MacSwiney, 9. März 1923.

197 TCD, Early Printed Books, Samuels Collection, Box 2/3, Collins, Arguments for the Treaty, S. 29; NLI, WOB, L.O., P117, Flugblatt, no. 32, ca. Mai 1922.

198 Plain PeOple, 23. April 1922, S. 4; CATholic Bulletin, Januar 1923, S. 22; UCD, RP, P88/286, Flugblatt, ca. Oktober 1923.

199 RiCHARD DAVIS, Griffith, S. 23, 27. 
gebe es keine Mehrheit für den Vertrag. ${ }^{200}$ Dieses Argument war kaum zu widerlegen, doch hatte es einen Schönheitsfehler: Auf die britische Kriegsdrohung hatten Republikaner und Vertragsbefürworter keinen Einfluß, was die vertragsbefürwortende Propaganda als "refusal to face facts" verspottete.201 Auf dem Feld Realpolitik und beim Thema „majority rule“ konnten die Vertragsgegner so nicht mit der Provisorischen Regierung konkurrieren.

\section{ANSCHLÄGE DER IRA AUf DIE PRESSE}

Wenn die Bevölkerung unter britischem Druck gegen ihre als objektiv definierten nationalen Interessen verstieß, konnte das aus republikanischer Perspektive nur einen Grund haben: Die Bevölkerung war durch das erdrükkende Pressemonopol von „drei oder vier Pressemagnaten“202 manipuliert, später durch die Zensur fehlinformiert. ${ }^{203}$ Gegen dieses Pressemonopol versuchte die vertragsablehnende Propaganda erst gar nicht, eine klassische Pressefreiheitsrhetorik zu besetzen. Wieder argumentierte sie national, erkannte historische Gesetze: Die irische „press of supression“ sei „schon immer" anti-national gewesen, stelle sich wie 1916 und davor gegen die nationale Bewegung. ${ }^{204}$ Mit „Irish truth“ kontra „British lies“ griffen die Republikaner ein an der Logik des antithetischen Weltbildes orientiertes Lieblingsargument der revolutionären Propaganda aus dem Unabhängigkeitskrieg wieder auf. Im Kampf gegen den Goliath „britische Lügen“ sei der David „historische irische Wahrheit“ wieder auf seine Untergrundpresse angewiesen, werde totgeschwiegen oder verfolgt. ${ }^{205}$

Als „men of action“ beteiligten sich die meisten IRA-Aktivisten nicht am „word twisting" der Politiker. Sie hatten ihre eigenen Argumente gegen „majority rule“ und das Pressemonopol der Vertragsbefürworter. Wie Beaslai 1918 in An tOglach geschrieben hatte: „The volunteer does not talk, but acts. "206 Wie die IRA im Unabhängigkeitskrieg machten die radikalen IRA-

200 An PoblachT, 4. Mai 1922, S. 4; FLK, DeV, 1907/235-238, Pamphlet „How the treaty was signed“, ca. April 1922.

201 YOUNG IRELAND, 25. Februar 1922, S. 4.

202 NAI, DFA, PG/IFS, Zeitungsausschnitt mit de Valeras Statement, in FrEEMAN's JOURNAL, 17. Februar 1923.

203 IRELAND OVER ALL, 7. April 1922, S. 3.

204 Catholic Bulletin, Januar 1923, S. 22; O’Malley, Singing Flame, S. 40, 140.

205 Young Ireland, 10. August 1919, S. 1; 6. September 1919, S. 1; Irish Bulletin, 16. Dezember 1919, S. 2; FreEMAN's JOURNAL, 17. Dezember 1919, S. 4.

206 AN TOGLaCH, 15. August 1918, S. 1. 
Aktivisten die „anti-nationale“ Presse zur militärischen Zielscheibe, insbesondere wenn sie sich weigerte, offizielle IRA-Proklamationen zu veröffentlichen: So zerstörte die IRA im April 1922 die Druckplatten des Sligo Champion und verbrannte immer wieder britische und nordirische Zeitungen. 207

Doch auch in den von der IRA kontrollierten Gebieten, blieben spektakuläre Aktionen die Ausnahme: Etwa die Anschläge von Dinney Laceys radikaler IRA Einheit auf die Produktionsanlagen des Nationalist im Januar und April 1922. Nur wo, wie hier in Clonmel, ein besonders entschlossener IRA Offizier auf eine Redaktion und ein Management traf, das bereit war für seine politischen Überzeugungen notfalls bankrott zu gehen, eskalierten Konflikte. 208

In der Regel trafen pragmatischere Journalisten auf moderatere IRA-Aktivisten. Sie einigten sich meist friedlich. ${ }^{209}$ Viele Blätter schienen auch gar kein Problem damit zu haben, vertragsablehnende Erklärungen abzudrukken. So erhob ein an „national unity“ orientiertes vertragsbefürwortendes Blatt wie der Clare Champion eine faire Darstellung des republikanischen Standpunktes zur Redaktionspolitik: „The CHAMPION is a newspaper; its duty is to publish the opinions of every section of the community, just as it claims for itself the right to advocate the policy which itself believes best for the country." $210 \mathrm{Ob}$ das nun prinzipiell oder pragmatisch motiviert war, der Clare Champion ersparte sich so viel Geld und eine Menge Ärger mit der IRA.

Irlandweites Aufsehen erregte die Kampagne der IRA gegen das Freeman's Journal. Schon während des Unabhängigkeitskrieges war der Free-

207 Sligo Champion, 29. April 1922, S. 4; Roscommon Messenger, 27. Mai 1922, S. 5; DaILY MaIL, 7. April 1922, S. 9; Eason's Private Archive, Newsagent an Charles Eason, 4. Januar 1922; ebd., Newsagent (Wexford) an Charles Eason, 16. Mai 1922; Zu Anschlägen während des Unabhängigkeitskrieges: CUlleN, Eason, S. 207 f., 210; SKIBEREEN EAGLE, 25. Februar 1922, S. 4; HUGH ORAM, The Newspaper Book. A History of Newspapers in Ireland, 1649-1983. Dublin 1983, hier: S. 143; VALIUlis, Mulcahy, S. 120f.; WARD, Unmanagable Revolutionaries, S. $185 \mathrm{f}$.

208 National Archive of Ireland, Department of Justice (NAI, D/J), H5/200, Schriftwechsel Brendon Long und John Dillon mit diversen Departments der Provisorischen Regierung, Mai, Juni 1922; UCD, MP, P7b/179, Erinnerungen von Tom Ryan, März-August 1963; NATIONALIST, 16. Januar 1922, S. 3; 18. Januar 1922, S. 3; 21. Januar-4. Februar 1922; 17. Mai 1922; vgl. IRISH INDEPENDENT, 20. Januar 1922, S. 4.; FrEEMAN'S JOURNAL, 2. Februar 1922, S. 5; HOPKINSON, Green, S. 40 f., 52, 58, 60, 65-67, 74, 89-92.

209 Exemplarisch: CORK EXAMINER, 9. Januar 1922, S. 7; 10. Januar 1922, S. 4 : „We would ask our readers to note that at the present juncture matter may appear from time to time in our columns, which we can neither approve of nor justify. Ed[itor]. C[ork] E[xaminer]."

210 Clare Champion, 4. Februar 1922, S. 2. 
man radikaleren Republikanern verhaßt, war wiederholt Opfer von Anschlägen geworden.211 Als „organ which defamed the men of '98, of '48, of '67 and of 1916“ war der Freeman für die Republikaner das verkommenste aller anti-nationalen Blätter. ${ }^{212}$ Am 5. Januar 1922, noch während der Vertragsdebatte, sprach der Freeman de Valera jegliche nationale Kompetenz ab und spielte in einem Leitartikel zynisch auf de Valeras spanischen Vater an: „he [de Valera] has not the instincts of an Irishman in his blood." 213 Die intransigenten Politiker Sean Etchingham und Mary MacSwiney forderten noch am selben Tag, den Freeman Reporter von den Debatten Dail Eireanns auszuschließen. 214

Die IRA begann eine militärische Kampagne gegen den Freeman. Radikale IRA-Aktivisten entführten Anfang Februar und erneut im März einen Freeman-Journalisten, um ihn $\mathrm{zu}$ verhören und einzuschüchtern. ${ }^{215} \mathrm{Im}$ Dubliner Innenministerium häuften sich die Briefe schockierter Kioskbesitzer, die sich „all sorts of threats [...] over the FREEMAN“ anhören mußten.216 In Dublin überfiel die IRA Lkws, die das Freeman's Journal auslieferten. ${ }^{217}$ Ab März stoppte die IRA fast täglich alle Züge am Verkehrsknotenpunkt Limerick Junction. Dabei beschlagnahmten und verbrannten sie im Zuge des Belfast-Boykotts nicht nur Waren und Zeitungen aus Nordirland, sondern auch das Freeman's Journal. Der Freeman konnte so in Munster nur noch in Ausnahmefällen erscheinen. ${ }^{218}$ Doch auch wenn sich das Management des Freeman, durch das Nebeneinander von republikanischem Dail Eireann und Provisorischer Regierung verwirrt, vorsorglich an mehrere verschiedene Militär- und Regierungsstellen wandte: Die Führung der Vertragsbefürworter war in dem von der IRA kontrollierten Munster machtlos. 219

211 Cullen, Eason, S. 207 f., 210.

212 UCD, FGP, P80/311, Ernie O’Malley an Patrick Hooper, editor FrEEMAN'S JOURNAL, 24. August 1922. Dieser Brief wurde veröffentlicht in: AN POBLACHT-SCOTTISH EdITION, 23. September 1922, S. 2.

213 FREEMAN'S JOURNAL, 5. Januar 1922, S. 4.

214 Debate ON TREaTY: Sean Etchingham, Mary MacSwiney, 5. Januar 1922, S. $262-4$.

215 Freeman's Journal, 2. Februar 1922, S. 5; 10. Februar 1922, S. 6; 19. März 1922, S. 5; 29. März 1922, S. 5; 19. Dezember.1924, S. 5.

216 NAI, D/J, H5/55, hier: Kopie eines Briefes aus Mulranny, County Mayo, an „The Freeman’s Journal Ltd.“, 1. Mai 1922; Cullen, Eason’s, S. 210.

217 NAI, D/J, H5/55, Berichte der Dublin Metropolitan Police, ca. 4. Mai 1922; 5. Mai 1922.

218 NAI, D/J, H5/55, Mr. MacDonnell an Collins, 15. Mai 1922; TCD, CP, 7816, Childers Diary, 15. Juni 1922.

219 NAI, D/J, H5/55; MacDonnell an Eamon Duggan, 23. April 1922. 
Ende März erreichte die republikanische Kampagne gegen das Freeman's Journal ihren Höhepunkt. Am 30. März 1922 drangen zwischen dreißig und fünfzig bewaffnete Männer in das Verlagsgebäude des Freeman ein. Nachdem sie den Mitarbeitern ermöglicht hatten, ihren persönlichen Besitz in Sicherheit zu bringen und sogar mitgeholfen hatten, Möbel auf die Straße zu tragen, zerstörten die „höflichen“ Aktivisten die Druckanlagen mit Vorschlaghämmern und setzten das Gebäude in Brand. Der Freeman erschien darauf für drei Wochen nur als Notausgabe. ${ }^{220}$

Kurz nachdem die IRA gegenüber dem Freeman ihre Macht bewiesen hatte, versuchte sie im April, in Dublin, Limerick und in Clonmel Vorzensur durchzusetzen. Diese Aktionen waren jedoch nicht zentral koordiniert. Während etwa Lacey in Clonmel den Nationalist faktisch übernehmen wollte, hatte die Dubliner IRA bescheidenere Ziele. Sie wollte nur Artikel über die IRA zensieren. Doch als die Presse diese Anweisung ignorierte, unternahm die IRA außer in Clonmel nichts. ${ }^{221}$

Um die Presse nachhaltig einzuschüchtern, war das Vorgehen der IRA nicht konsequent genug. Gewaltsame Übergriffe beruhten auf dem Gutdünken des örtlichen Offiziers, nicht auf einer koordinierten Strategie. Gewalt, das wirkungsvollste Mittel der IRA, blieb damit die Ausnahme. Der IRA gelang es nicht einmal, die Blätter, die sie überfiel, finanziell zu ruinieren. Im Falle des Freeman's Journal unterstützte die Provisorische Regierung nicht nur die arbeitslosen Angestellten, sondern zahlte an seinen Verbündeten auch ein stattliche Entschädigung. ${ }^{222}$

Die IRA verübte nicht nur Anschläge auf die Presse. Sie störte vertragsbefürwortende Veranstaltungen, beschlagnahmte privates Eigentum, finanzierte sich über Banküberfälle und Zwangsspenden. Allein zwischen 23. März und 19. April 1922 überfiel die IRA 331 Postämter und vom 1. März bis 22. April 1922319 mal die Züge der Great Southern and Western Railways. In großen Teilen Irlands verhinderte die IRA ein Funktionieren der vertragsbefürwortenden Regierung. Weil sie selbst nicht konsequent die Macht übernahm, herrschte in diesen Gebieten Anarchie. ${ }^{223}$

220 IRISH INDEPENDENT, 30. März 1922, S. 5; 31. März 1922, S. 4.

221 Freeman's Journal, 8. April 1922, S. 3; Für Limerick: IRISH INDEPENDENT, 29. April 1922, S. 7; VOICE OF LABOUR, 15. April 1922, S. 4.

222 TCD, CP, 7816, Childers Diary, 15. Juni 1922; NAI, DE Minutes, DE 1/4, 31. März 1922, 10. April 1922; NAI, D/J, H5/55: Sekretär des Innenministers an Arbeitsminister, 10. Mai 1922; Arbeitsminister an Eamon Duggan, 12. Mai 1922.

223 HOPKINSON, Green, S. 40 f., 58, 60, 65 f., 69, 74, 88-90; WARD, Unmanagable Revolutionaries, S. 171; NEESON, Civil War, S. 97-100. 
Doch ausgerechnet dieses realpolitische Desaster half der Provisorischen Regierung, ihr legitimatorisches Dilemma zu lösen. Gerade die Übergriffe auf die Presse schlugen massiv auf die Ebene des Legitimationskampfes durch: sie delegitimierten die Republikaner auf dem demokratischen und liberalen Feld, stützten die "will of the people“-Rhetorik der Vertragsbefürworter und verhalfen der Provisorischen Regierung zu einem Stück nationaler Legitimität.

Wie schon angedeutet, verstand die Presse die Sprache der Gewalt nicht so, wie es sich die radikalen IRA-Aktivisten erhofften. Das galt ganz besonders für die Blätter, die Opfer von IRA-Gewalt geworden waren: Der $\mathrm{Na}$ tionalist, der Sligo Champion und das Freeman's Journal blieben dezidierte vertragsbefürwortende Zeitungen. Statt $\mathrm{zu}$ schweigen und zu gehorchen, erzählte die Presse ihre eigene Geschichte über die Anschläge der IRA, eine Geschichte vom Kampf um liberale und nationale Freiheitsrechte.

Jede Provinzzeitung registrierte den Anschlag auf das Freeman's Journal und fast jede Zeitung widmete dem Thema einen Leitartikel, der die IRA verurteilte. 224 Die Dubliner Tagespresse machte im April 1922 Presse- und Redefreiheit zum Dauerthema ihrer Leitartikel und Berichte. ${ }^{225}$ Die Presse griff dabei auf eine nicht weiter reflektierte „liberal rights“-Rhetorik zurück, stellte Presse- und Redefreiheit als universales Menschen- und Bürgerrecht dar. Pressefreiheit sei „a sacred thing “226, „a fundamental principle of the constitutional methods“227, bewahre das Land vor einer "slavery of the worst character." 228

Nachdem die IRA die Maschinen des Freeman zerstört hatte, verschob sich die Argumentation der Presse zunehmend von „liberal rights“ Richtung „law and order": Ab Mitte April galten Übergriffe auf die Presse nurmehr als eines von vielen Beispielen für das zunehmende Chaos in Irland: „They [the people of Ireland] want ordered and settled Government. They desire freedom for the people. They claim the right of public meeting, of free speech, of a free press and protection of life and property."229 Die

224 U.a.: Nationalist, 1 April 1922, S. 5; CORK Examiner, 3. April 1922, S. 4; Drogheda INDEPENDENT, 1. April 1922, S. 2; MUNSTER NEWS, 1. April 1922, S. 4.

225 U.a.: IRISH INDEPENDENT, 21. Januar 1922, S. 6; 30. März 1922, S. 6; 31. März 1922, S. 4; 3. April 1922, S. 4; 4. April 1922, S. 4; 7. April 1922, S. 4; 20. April 1922, S. 4; 29. April 1922, S. 7.

226 Freeman's Journal, 22. April 1922, secound section, S. 19.

227 CORK EXAMINER, 3. April 1922, S. 4.

228 IRISH INDEPENDENT, 4. April 1922, S. 4.

229 MAYO NEWS, 22. April 1922, S. 2. 
Presse betonte jetzt zunehmend soziale und wirtschaftliche Folgen der republikanischen Aktionen - etwa die ansteigende Arbeitslosigkeit. ${ }^{230}$

Neben der Reaktion der Presse zeigten auch Protestresolutionen von zahlreichen lokalen Selbstverwaltungskörperschaften, nationalen Wirtschaftsverbänden und der irischen Arbeiterbewegung, wie unpopulär die Anschläge waren. ${ }^{231}$ Kurz nach dem Anschlag auf den Freeman, am symbolträchtigen siebten Jahrestag des Osteraufstandes, organisierten Labour Party und ITGWU einen Generalstreik „against militarism“. Ein letztes Mal probte die Arbeiterbewegung dabei das Mittel des syndikalistischen Umsturzes, und wieder geschah es im nationalen Kontext. ${ }^{232}$

So unterstützt von der artikulierten Öffentlichkeit und Tagespresse, konnte die Provisorische Regierung das Feld „liberal rights“ konkurrenzlos alleine besetzen. Sie präsentierte sich als Verteidigerin der Pressefreiheit und der arbeitslosen Angestellten des Freeman. ${ }^{233}$ Damit der Freeman-Fall noch mehr Publicity bekam, gab die Provisorische Regierung die Bitte des Freeman um Entschädigung formal an ihre republikanische Fassade, das theoretisch noch revolutionäre Parlament Dail Eireann, ab. So konnten sie die Republikaner direkt mit einem Thema konfrontieren, bei dem die Vertragsgegner propagandistisch nichts zu gewinnen hatten. ${ }^{234}$

Die republikanische Untergrundpropaganda konnte jetzt gegen freistaatliche Verfolgung und Zensur nicht mehr mit „Liberty of the Press“235 oder Chancengleichheit argumentieren. Und wenn sie es doch versuchte, ließ sie sich bis weit nach dem Bürgerkrieg leicht lächerlich machen: „The Irregulars have broken up and ruined scores of newspaper offices, and now we have one of the propagandists claiming a right to propound the ,republican point of view“."236

Wichtiger als die kaum weiter reflektierte liberale Argumentation war: Wie schon bei „majority rule“ luden vertragsbefürwortende Propaganda und Tagespresse die britisch vermittelte Pressefreiheit mit nationaler Bedeu-

230 Freeman's Journal, 7. April 1922, S. 4; SLIGo CHAMPION, 6. Mai 1922, S. 8; IRISH INDEPENDENT, 31. März 1922, S. 4; 29. April 1922, S. 7; VoiCE OF LABOUR, 15. April 1922, S. 1.

231 Irish Times, 26. April 1922, S. 4; IrISH IndePEndent, 20. April 1922, S. 4; CORK EXAMINer, 7. April 1922, S. 7; Sligo Champion, 29. April 1922, S. 5; RosCOMmON MessenGER, 29. April 1922, S. 5; Irish HOMESTEAD, 29. April 1922, S. 267; Voice of LAbOur, 15. April 1922, S. 4; 22. April 1922, S. 4; 29. April 1922, S. 4; 13. Mai 1922, S. 4.

232 Emmet O’CONNOR, Syndicalism, 148; MitChell, Labour, S. 156 f.; RumpF und HePBURN, Nationalism and Socialism, S. 63.

233 Z.B. die Anzeige in: Evening Herald, 1. April 1922, S. 5.

234 NAI, PG Minutes, G1/2, 3. April 1922; Dail Debates, 27. April 1922, S. 320-23.

235 IRISH IndEPENDENT, 17. August 1922, S. 11, Leserbrief von Patrick Little.

236 TRUTH-WAR ISSUE, 22. August 1922, S. 2. 
tung auf. Erst bezogen auf den Wert erster Ordnung, die nationale Frage, erhielt ein Freiheitsrecht wie Pressefreiheit seine legitimatorische Durchschlagskraft und half so der freistaatlichen Propaganda aus der Legitimationskrise.

Gegen die Presseanschläge der IRA nutzten die Vertragsbefürworter dieselben historischen und anti-britischen Erklärungsmuster, mit denen die republikanischen Politiker gegen das Pressemonopol der Vertragsbefürworter argumentierten.

So erhielt die vertragsbefürwortende Propaganda indirekt wieder Zugriff auf die traditionell wirkungsvollste Rhetorik des irischen Nationalismus: das britische Feindbild. Was lag näher, als den Terror der IRA mit dem britischen Terror der letzten Jahre beziehungsweise Jahrhunderte zu vergleichen? Auch für die freistaatlichen Ex-Revolutionäre zeichnete sich Geschichte immer noch durch Kontinuität, nicht durch Wandel aus: Die IRA sei „like Cromwell“237, die "Castle gang“238, vervollständige „the work which the British had left unfinished."239 Auf diese „Black and Tans of Suffolk Street" 240 übertrug die vertragsbefürwortende Propaganda die bekannten Muster des antithetischen Weltbildes und erzählte erneut die traditionelle Geschichte vom Leiden des spirituellen Irlands unter dem gewalttätigen Unterdrücker. Vor dem Hintergrund dieser konkreten Bedrohung griff auch die "will of the people“-Rhetorik weit besser als zuvor. Sie war jetzt mehr als nur geadelte kollektive Kriegsmüdigkeit, sie gewann, bedroht durch einen konkreten „britischen“ Feind mit einem „cynical disregard for the popular will“241, emotionale Qualität.

„Pressefreiheit“ war ein Argument, das der vertragsbefürwortenden Propaganda und der Dubliner Tagespresse gerade recht kam. Es ließ sich nicht nur national deuten, es entsprach auch dem unmittelbaren Interesse der Blätter, nämlich ungestört ihrer Arbeit nachzugehen. Über Pressefreiheitsrhetorik stilisierten sich der Nationalist und vor allem der Freeman in dutzenden Artikeln als Märtyrer:,The paper that fought for Irish Liberty so long, will not be silenced“.242 So konnte der Freeman verlorenes Prestige

237 Dundalk DemocRaT, 25. März 1922, S. 4.

238 Sligo Champion, 29. April 1922, S. 4.

239 IRISH INDEPENDENT, 22. April 1922, S. 6.

240 Freeman's Journal, 30. März 1922, S. 1. In der Suffolk Street 23 lag die republikanische Propagandazentrale.

241 FREEMAN'S JOURNAL, 22. April 1922, „second section“, S. 19.

242 Freeman's Journal, 30. März 1922, S. 1; vgl. ebd., 1. April 1922, S. 2; 3. April 1922, S. 7; S. auch: ebd., 22. April 1922, „second section“, S. 19; NATIONALIST, 17. Mai 1922, S. 2. 
und damit verlorene Auflage zurückgewinnen. Die Voice of Labour, das einzige Blatt, das vom allgemeinen Pressefreiheitskanon abwich, kommentierte das sarkastisch:

But in the IRA was there no man of sense to speak out against the supreme foly of the smashing of the „Freeman's Journal“? The poor old „Freeman's Journal“ exercised no political influence on Ireland, was suffering from an attenuated circulation, and financially seemed to be in the deepest of deep water. ${ }^{243}$

Doch wo sich das Argument „Pressefreiheit“ nicht zu Gunsten der irischen Presse instrumentalisieren ließ, da war sie kein so „heiliges Ding“ mehr. Pressefreiheit war ein relativer Wert, der auch bei Freistaatsführung und Dubliner Presse hinter der Priorität der nationalen Frage zurückstand. Keine Sympathien hatte die Tagespresse und Provinzpresse für die republikanischen Propagandablätter, die hoffnungslos unterlegen gegen das Pressemonopol der Vertragsbefürworter ankämpften. ${ }^{244}$ Genausowenig verteidigten sie die nordirische Presse, wenn sie im Rahmen des Belfast Boykotts verfolgt wurde. 245

Bezeichnend für die Indifferenz gegenüber dem liberalen, im Gegensatz zum nationalen, Wert „Pressefreiheit“ war die Reaktion der irischen Presse, als die IRA Anfang Januar 1922 den britischen Journalisten A.B. Kay entführte und ihn mit einem Prozeß vor einem selbsternannten Kriegsgericht bedrohte. ${ }^{246}$ Als die britische Pressedelegation in Dail Eireann ihre irischen Kollegen daraufhin aufforderte, einen Protestbrief zu unterschreiben, reagierten diese indifferent bis feindlich. Der Irish Independent argumentierte in seiner folgenden Ausgabe mit der für ihn so bezeichnenden nationalen Stammtischlogik:

Can we be blamed if we who had seen our own colleagues carried off by English forces and our offices invaded by men wearing England's uniform at the dead of the night to bully and threaten Irish journalists, pointed out that our English colleagues had made no protest against these things. Even in the wildest flights of fancy we could not imagine the reporters in the Gallery walking out of the British House of Commons because an Irish journalist had been taken to Dublin Castle. And so we, the mere Irish, did not sign. ${ }^{247}$

243 Voice of Labour, 15. April 1922, S. 4; vgl. Dail Debates, Sean Etchingham, 27. April 1922, S. 321

244 Eine Ausnahme: WATERFORD News, 5. Mai 1922, S. 5.

245 DONEgal Vindicator, 17. Februar 1922, S. 3; 2. Juni 1922, S. 3; vgl. WARD, Unmanagable Revolutionaries, S. 185 f.; Cullen, Easons, S. 210.

246 LANKFORD, Hope, S. 228 f.; CORK EXAMINER, 6. Januar 1922, S. 5-7.

247 IRISH INDEPENDENT, 6. Januar 1922, S. 4; vgl. auch MAYO NEWS, 1. Juli 1922, S. 2. 
Hinter dem nationalen „wie Du mir, so ich Dir“, mußte der liberale Wert Pressefreiheit zurückstehen.

Folgt man Siobhan Lankford und ihrem Sinn für kleine Anekdoten, so nahm die Geschichte für Kay übrigens dann doch ein gutes Ende: Auf Befehl von Collins brachten ihn einige vertragsbefürwortende Aktivisten zurück nach Dublin - nicht ohne sich mit ihrem Schützling auf der Rückbank des Autos ordentlich zu betrinken. Kay war bald sichtlich erleichtert und freute sich nun über die „bloody fine story“, die er zu verkaufen hatte. ${ }^{248}$

Auch die vertragsbefürwortende Führung instrumentalisierte „Pressefreiheit" zu ihren Gunsten, ohne weiter über diesen offenbar selbstverständlichen, universellen Wert nachzudenken. Als die Verfassungskommission konkurrierende Entwürfe beriet, dominierte einmal mehr die nationale Frage. Die Kommission diskutierte wochenlang über den konstitutionellen Status Irlands und über die Rolle des britischen Königs und seiner Repräsentanten. „Liberal rights“ wie Presse-, Meinungs- und Versammlungsfreiheit akzeptierte die Kommission dagegen ohne nennenswerte Diskussionen. ${ }^{249}$ Das in die Verfassung aufzunehmen, galt als Selbstverständlichkeit, über die man nicht weiter zu reden brauchte. Wie ich noch zeigen werde, konnte die Provisorische Regierung zugunsten der primären, also der Vertragsfrage, massiv gegen liberale Rechte wie Presse-, Versammlungs- und Vereinsfreiheit verstoßen.

Für die republikanischen Politiker war der Terror der IRA ein propagandistisches Desaster. Intern kritisierten sie die Übergriffe der IRA - nicht wegen abstrakter Prinzipien wie „Presse-“ oder „Meinungsfreiheit“ - sondern, weil sie unpopulär und damit taktisch unklug waren.250

Doch nach außen distanzierten sich die meisten Politiker und die offizielle Propaganda der Poblacht nicht von den Übergriffen der IRA. Die Poblacht räumte der IRA in den Wochen nach dem Anschlag sogar eine eigene Seite für „Army News“ ein. Dort rechtfertigte die IRA den Anschlag wortkarg als gerechte Strafe für die „statements made therein calculated to cause disaffection and indiscipline in the ranks of the IRA." 251 Wie weit der Anschlag auch die Politik des politischen Republikanismus war, blieb dabei der Phantasie der Leser überlassen. Catholic Bulletin und Poblacht agitierten zwar weiter gegen die „anti-nationale“ Presse, zum Thema IRA-Terror und

248 LANKFORD, Hope, S. $229 \mathrm{f}$.

249 NAI, D/T, CoCo, „O“; siehe auch, NAI, PG Minutes, G1/2, 10. April 1922.

250 Brennan, Allegiance, S. 338; VOICE of LABOUR, 15. April 1922, S. 1; 13. Mai 1922, S. 4; FREEMAN'S JOURNAL, 1. April 1922, S. 2.

251 An Poblacht, 5. April 1922, S. 5, „Army News“. 
insbesondere Freeman's Journal aber schwiegen sie, und das war alles andere als überzeugend.252 De Valera selbst hatte noch im Januar 1922 öffentlich abgelehnt, den Freeman für seine zynischen Ausfälle zu bestrafen. ${ }^{253}$ Jetzt drückte er sich, so gut er konnte, vor einer klaren Aussage zu den zahlreichen Übergriffen der IRA. So verteidigte er die noblen Motive der IRA, stritt aber eine persönliche Verantwortung ab, weil die IRA eine unabhängige Organisation sei. ${ }^{254}$ De Valera und die meisten Politiker versuchten so, die innere Einheit des vertragsablehnenden Spektrums nach außen zu erhalten. Nachdem die „national unity“ kollabiert war, versuchte er, wenigstens „republican unity“ zu erhalten. Dafür nahm er, wie die meisten anderen republikanischen Politiker, widerwillig hin, daß einige radikale IRA-Aktivisten die demokratische und liberale Legitimation des gesamten vertragsablehnenden Lagers endgültig demontierten. ${ }^{255}$

Gleichzeitig bemühte sich die politische Führung, den Schaden zu begrenzen. Führende vertragsbefürwortende und vertragsablehnende Politiker der zerfallenden Sinn Fein verständigten sich kurz nach dem Anschlag auf ein Abkommen, das Irland ein Minimum an Normalität und beiden Seiten einen ungestörten Wahlkampf erlauben sollte. ${ }^{256}$

Am Ende blieb de Valera und den republikanischen Politikern jedoch das Schlechteste aus beiden Welten: Sie trugen die politische Verantwortung für eine Politik, die sie weder wollten, noch steuern konnten. Die zerbrökkelnde Einheit der Vertragsgegner und die mangelnde Kontrolle der Politiker über die IRA wurden jedoch trotzdem öffentlich. Das lag nicht nur daran, daß IRA und auch Cumman na mBan das Abkommen ignorierten und der Presse durch endlose neue Übergriffe neue Geschichten lieferten. ${ }^{257}$ Auch innerhalb des politischen Republikanismus gab es Risse, zwischen orthodoxen Dogmatikern wie Mary MacSwiney, Sozialrevolutionären wie Constanze de Markievicz oder Liam Mellows, dem de ValeraFlügel und den wenigen gemäßigten Politikern, die Gewalt prinzipiell ablehnten.

Das zeigte sich auch beim Thema Freeman: So erinnerte das radikale republikanische Blatt Ireland Over All an den "heilsamen Effekt“, den ein

252 Siehe: An Poblacht, 5. April 1922; 12. April 1922; Catholic Bulletin, Mai 1922.

253 Debate on TReaty, de Valera, 5. Januar 1922, S. 266.

254 NeW IRELAND, 22. April 1922, S. 307.

255 FLK, DeV, 273, de Valera an Mary MacSwiney, 9. März 1923; vgl. Hopkinson, Green, S. 38 f., 70 f., 187; MACARDLE, Republic, S. 677.

256 Irish IndePendent, 3. April 1922, S. 4; vgl. New Ireland, 22. April 1922, S. 308: de Valera dort, „the right of public meeting and free speech will not be interfered with“.

257 Nationalist, 19. April 1922, S. 2. 
ähnlicher Anschlag während des Unabhängigkeitskrieges auf den Irish Independent gehabt habe. ${ }^{258}$ Die Worker's Republic titelte nach dem Anschlag mit: „Bravo Dublin Brigade! The mailed fist [is the only] medicine [... by which] these unscrupulous purveyors of doped news can be made to tell the truth. "259 Andere Politiker wie Frank Fahy, Sean T. O’Kelly, Sean Etchingham oder Seamus Doyle distanzierten sich offen vom Anschlag auf den Freeman. 260

Schon wenig später wurde deutlich, daß auch das republikanische Militär in verschiedene Flügel gespalten war. Die radikaleren Aktivisten um Rory O'Connor, Ernie O'Malley und Liam Mellows besetzten bald die Four Courts und andere Verwaltungsgebäude Dublins, während Liam Lynch und andere prominente Aktivisten der 1st Southern Division mit den führenden vertragsbefürwortenden Militärs Collins und Richard Mulcahy weiter einen Weg zurück zur „army unity“ und damit „national unity“ suchten. ${ }^{261}$

Der vertragsbefürwortenden Propaganda gelang es über den Wert „liberal rights“, vor allem aber über „majority rule“ ihr nationales Legitimationsproblem zu lösen. Dazu deuteten die Propagandisten den siebenhundertfünfzigjährigen Freiheitskampf des republikanischen Geschichtsgesetzes zu einem Kampf um Demokratie und liberale Rechte um. „Majority rule“ und „liberal rights“ wurden als Kern von Volkssouveränität zu nationalen, dem britischen Feind abgerungenen Werten. Außerhalb dieses nationalen Kontexts waren sie auch für die meisten Vertragsbefürworter nur relative Werte.

Die radikaleren Mitglieder der IRA standen liberalen und partizipatori-

258 IRELAND OVER ALL, 7. April 1922, S. 3.

259 Worker's Republic, 8. April 1922, S. 2; vgl. Dail Debates, Sean MacEntee, 27. April 1922, S. 320.

260 IRISH InDEPENDENT, 7. April 1922, S. 4; 13. April 1922, S. 4; FreEMAN'S JOURnAL, 1. April 1922, S. 4; Dail Debates, Sean T. O’Kelly, 27. April 1922, S. 323 f.; Sean Etchingham, 27. April 1922, S. 321.

261 Innerhalb der vertragsablehnenden IRA gab es ein ganzes Spektrum von unterschiedlich radikalen Aktivisten, die sich unterschiedlich stark an „the Republic“ oder „national unity“ orientierten. So konnte Ernie O’Malley, als O/C der 2nd Southern Division seinen radikalen Brigade-Offizier Dinney Lacey nicht kontrollieren. Dagegen kritisierte er selbst während der Limerick Crisis Rory O’Connor für dessen fehlenden Mut zur Offensive. O’Malley, O'Connor und Lacey waren alle drei wesentlich radikaler als Lynch und die Aktivisiten der 1st Southern Division in Munster. Einige prominente Aktivsten der 1st Southern Divison wie Tom Hales, Sean Hegarty und Florrie O'Donoghue schieden sogar wieder aus der Exekutive der IRA aus, um einen Bürgerkrieg zu vermeiden. O’Donoghue und Hegarty nahmen dann trotz vertragsablehnender Überzeugung nicht am Bürgerkrieg teil. Zusammengefaßt nach: HOPKINSON, Green, S. 43, 58f., 63-5, 68, 72, 93-5, 101-3. 
schen Werten indifferent gegenüber. Sie verstanden sich als revolutionäre Elite und orientierten sich an „the Republic“. Die meisten republikanischen Politiker hatten dagegen ein komplexeres Verhältnis zu „majority rule“. Auch für sie war „the Republic“ prinzipiell unveräußerbar. Gleichzeitig bemühten sie sich aber, den freistaatlichen Anspruch auf „majority rule“ und „liberal rights“ zu untergraben und die Mehrheit der Bevölkerung wieder von „the Republic“ zu überzeugen.

Das war von vornherein wenig überzeugend. Völlig chancenlos wurde es durch die Übergriffe der IRA, vor allem durch die spektakulären Anschläge auf die Presse. Die vertragsbefürwortende Propaganda konnte nun das gesamte republikanische Lager diskreditieren und mit den als „britisch“ definierten Eigenschaften aus dem antithetischen Weltbild belegen. Dabei erleichterten die republikanischen Politiker der vertragsbefürwortenden Propaganda noch die Arbeit; denn de Valera und die meisten anderen prominenten Aktivisten distanzierten sich nicht offen von den Anschlägen, sondern versuchten die innere Zerrissenheit des republikanischen Spektrums wenigstens nach außen zu kaschieren. Auch das mit wenig Erfolg.

\section{IV. „NATIONAL UNITY“ ODER KONFRONTATION?}

In diesem letzten Teilkapitel werde ich die unterschiedlichen Konzepte vorstellen, mit denen Militärs und Politiker beider Seiten versuchten, einen Bürgerkrieg zu verhindern. Vor allem den Wahlpakt zwischen de Valera und Collins untersuche ich dabei näher. Schließlich werde ich zeigen, wie die vertragsbefürwortende Führung mit ihrer „stepping-stone“-Politik gegenüber Großbritannien scheiterte und in den Bürgerkrieg stolperte.

\section{RHETORIK DER KONFRONTATION}

Neben den Übergriffen der IRA auf privates Eigentum, Banken oder Zeitungen gerieten auch immer wieder vertragsbefürwortende und vertragsablehnende Truppen aneinander. Im Streit darum, wer die von der britischen Armee geräumten Kasernen besetzen dürfe, gab es Auseinandersetzungen, die bis zu Schießereien führten. Der bekannteste dieser Konflikte, die sogenannte Limerick Crisis, führte schon im März und April 1922 bis an den Rand eines Bürgerkrieges. ${ }^{262}$

262 VALiULIS, Mulcahy, S. 129-33. 
Immer wieder warnte die republikanische Propaganda vor einem Bürgerkrieg. Daran geknüpft war meist die obligatorische Rhetorik des „death before dishonour“: „Who amongst us has not strength to die, that Ireland, the nation which has asserted her independence through three years of torture, through three hundred years of torture, may live." 263 Wenn die republikanische Rhetorik mit einem Bürgerkrieg drohte, dann fast immer defensiv: Sie sprach von einem neuem „self-sacrifice“, davon „[to] save“, „maintain“, „defend the Republic“.264 Dazu waren die Radikalen in der IRA fest entschlossen, hatten verinnerlicht, was Beaslai noch vor dem Unabhängigkeitskrieg vollmundig erklärt hatte: „Volunteers with weapons in their hands must never surrender without a fight. "265 Mit einem Angriff drohten die republikanische Propaganda und die IRA nur verklausuliert, meist in Anspielungen auf ein neues „1916“.266 Allein die kommunistisch-republikanische Worker's Republic propagierte offen: „You cannot have a Republic without going through the furnace of Civil War. ${ }^{267}$

Während de Valera und die republikanischen Politiker sich vor einer klaren Aussage zur konkreten gegenwärtigen Gewalt der IRA drückten, rechtfertigten sie eine zukünftige und damit abstrakte Gewalt der IRA.

Typisch für dieses ambivalente und verklausulierte Verhältnis zur Gewalt war de Valeras berüchtigte Rede, die er am St. Patrick's Day 1922 in Thurles in der Gegenwart bewaffneter IRA-Einheiten hielt:

If they [the Provisional Government] accepted the treaty, and if the Volunteers of the future tried to complete the work of the last four years [...], they would have to complete it, not over the bodies of foreign soldiers, but over the dead bodies of their own countrymen. [...] They would have to wade through Irish blood, through the blood of the soldiers of the Irish government, and through, perhaps, the blood of some of the members of the government in order to get Irish freedom. ${ }^{268}$

In seiner langen politischen Karriere ist de Valera nie wieder ein so kontraproduktiver Propagandazug unterlaufen. Wie schon bei Document No. 2, wie beim Lavieren zwischen „constitutional methods“ und „national sovereignty“ stolperte de Valera darüber, daß die Komplexität und Vielschichtigkeit seines Denkens nach außen schwer vermittelbar war. Wieder erreichte er Dissens statt Konsens. Was de Valera schon gegen Ende des Bür-

\footnotetext{
263 An POBLACHT, 3. Januar 1922, S. 2.

264 „Selfsacrifice“: AN POBLACHT, 29. März 1922, S. 4; 27. April 1922, S. 4; 22 . März 1922, S. 4; 10. Januar 1922, S. 2.

265 AN TOGLACH, 15. August 1922, S. 1 (Hervorhebung im Original).

266 An POBlaCHT, 20. April 1922, S. 4.

267 WORKER'S REPUBLIC, 6. Mai 1922, S. 3.

268 IRISH INDEPENDENT, 18. März 1922, S. 5.
} 
gerkrieges meisterlich beherrschte, "to cloak political compromise and ambiguity in the language of principle“, mißlang ihm diesmal völlig. ${ }^{269}$ Seine Rede war ein Propagandageschenk für die Vertragsbefürworter. Auch noch lange nach dem Bürgerkrieg lieferte die Thurlesrede propagandistische $\mathrm{Mu}-$ nition für de Valeras politische Gegner. ${ }^{270}$ Die Thurlesrede machte es der vertragsbefürwortenden Propaganda leicht, den faktisch machtlosen de Valera als eigentlichen Drahtzieher der Republikaner darzustellen. Sie verurteilte ihn als „Demagogen“, seine Rede als ,incitement to civil war“ und demontierte so die Popularität de Valeras als ehemaligem Präsidenten der Republik. 271

Nicht nur im Frühjahr 1922, sondern sein ganzes politisches Leben lang, versuchte de Valera sich für seine Thurlesrede zu rechtfertigen, beschwerte sich, vertragsbefürwortende Propaganda und Presse hätten ihn absichtlich mißinterpretiert. ${ }^{272}$ Und zu Recht: Thurles war kein Aufruf zum Bürgerkrieg. Dafür gab es eine andere klassische Rhetorik: Tod für "the Republic“, Geschichtsgesetz, Märtyrertradition. „Wading through blood“ war dagegen ein Horrorszenario, ein Alptraum, eine Warnung vor der „terrible nature of such conflict." 273

Doch unschuldig war de Valera an diesem Mißverständnis nicht. Er nahm in Kauf, ja kalkulierte, daß zumindest ein Teil seiner Zuhörer ihn mißverstand. Er hoffte, nach dem Scheitern von Document No. 2, durch eine radikale Rhetorik zumindest einen Teil seines Einflusses auf die IRA zurückzugewinnen. Seine Warnung war ambivalent und zugleich eine massive Drohung an die Adresse der Führung der Vertragsbefürworter: Nur im Rahmen von „the Republic“ sei ein Bürgerkrieg zu vermeiden. ${ }^{274}$ De Valeras Argumentation folgte der Lehre des republikanischen Geschichtsgesetzes und hatte, solange man die Republik als zwangsläufiges Ziel der irischen Geschichte akzeptierte, eine bestechende zirkuläre Logik:

Their tradition will never allow them to remain in subjection, and when they rise again in arms, as all our history teaches us they must rise, the Army of the people

269 HOPKINSON, Green, S. 71; MURRAY, Voices, S. 43, 44, 47, 49-51

270 Charakteristisch die Fehleinschätzungen von Historikern mit vertragsbefürwortenden Sympathien: VAliUlis, Mulcahy, S. 131; undifferenziert auch: LiTTON, Civil War, S. 43; YOUNGER, Civil War, S. 250.

271 Young IRELAND, 25. März 1922, S. 4; FreEMAN’s JournAL, 20. März 1922, S. 4; 23. März 1922, S. 4; O’HEGARTY, Victory, S. 120.

272 Poblacht, 22. März 1922, S. 4; LONGFORD und O’NeILl, De Valera, S. 185; MurraY, Voices, S. 38, $204 \mathrm{f}$.

273 AN POBlachT, 22. März 1922, S. 4; FLK, DeV, 231, de Valera, 22. März 1922.

274 CURran, Birth, S. 173-5. 
would have to face the Irish Free State troops as they had to face the Royal Irish Constabulary in the past. ${ }^{275}$

Der nächste Aufstand „mußte“ also zwangsläufig gegen eine irische Regierung gerichtet sein und damit ein Bürgerkrieg werden.

Hier klang gleichzeitig hindurch, daß de Valera die radikale IRA nicht mehr kontrollieren konnte, nicht verhindern konnte und wollte, daß sie das republikanische Geschichtsgesetz erfüllte. Die Abneigung gegen Gewalt, die Bereitschaft zur Gewalt, das Zersplittern des vertragsablehnenden Spektrums, der Wunsch nach „national unity“, die Unfähigkeit zu einem Kompromiß: all diese Widersprüche spiegelten sich in der Ambivalenz der Thurlesrede. Damit zeigte sich auch, wie handlungs- und kommunikationsunfähig die Republikaner vor dem Bürgerkrieg waren.

Auch die vertragsbefürwortende Propaganda und die Tagespresse warnten immer wieder vor einem Bürgerkrieg. Wenn die Tagespresse hin und wieder auf einen kommenden Angriff gegen die Republikaner anspielte, sprach sie abstrakt von „return to sanity and order“276, argumentierte im Sinne der „will of the people“-Rhetorik: „The people must assert themselves. "277 Die offizielle vertragsbefürwortende Rhetorik hielt sich demgegenüber mit Zweideutigkeiten oder unpopulären Kriegsdrohungen zurück. Sie baute „majority rule“ und „liberal rights“ zum Gegenpol der republikanischen Gewalt auf, propagierte im Sinne des antithetischen Weltbildes die Überlegenheit von „spirit“ über „force“, von „majority rule“ und „liberal rights“ über den Terror der IRA. ${ }^{278}$

Die vertragsbefürwortenden Politiker schrieben nicht nur über die Überlegenheit der „ballot box“ über „bullets“, sie inszenierten sie auch in ihren Wahlkampfveranstaltungen, gerade wenn sie von IRA und Cumman na mBan gestört und bedroht wurden. ${ }^{279}$ Am wirkungsvollsten gelang es Griffith im von der IRA kontrollierten Sligo, die Gewaltbereitschaft seiner politischen Gegner für seinen Auftritt zu instrumentalisieren.

Ohne Rücksprache mit der neugewählten IRA-Exekutive hatte die lokale IRA im April 1922 Griffith Veranstaltung in Sligo verboten. Dennoch erschien Griffith zusammen mit dem hochrangigen General und Guerillahelden Sean Mac Eoin in einem gepanzerten Fahrzeug und sprach schließlich

275 An POBLACHT, 22. März 1922, S. 4.

276 Freeman's Journal, 1. Mai 1922, S. 4; Irish Times, 1. Mai 1922, S. 4.

277 FREEMAN'S JOURNAL, 12. Mai 1922, S. 4.

278 Nationalist, 19. April 1922, S. 2; O’Hegarty, Victory, S. 141; TCD, Early Printed Books, Samuels Collection, Box 2/3, Collins, Arguments for the Treaty, S. $29 \mathrm{f}$.

279 Zur Theatermetapher: DeNNING, Mr. Bligh, passim; LÜSEBRINK, Transfer, S. 38. 
unter dem Schutz von Maschinengewehren. Die lokale IRA griff trotz aller Ankündigungen nicht ein. Damit inszenierte Griffith nicht nur seine Unerschrockenheit und, daß Redefreiheit stärker als „britische“ Gewalt sei. Die Anwesenheit Mac Eoins machte Kontinuität zur revolutionären Vergangenheit sichtbar. Die Maschinengewehre und der Panzerwagen, gemessen an der republikanischen Bewaffnung im Unabhängigkeitskrieg wahre Wunderwaffen, signalisierten Entschlossenheit: Die Vertragsbefürworter waren bereit, „majority rule“ und „liberal rights“ $\mathrm{zu}$ „verteidigen“. ${ }^{280}$ Das aktionistische Drohen der IRA garantierte in diesem Kontext einen Propagandasieg für die Vertragsbefürworter. Was als Demonstration republikanischer Stärke geplant war, wurde, wie es ein anglo-irischer Zeitgenosse formulierte, zu einem „severe moral defeat“. 281

\section{2. „NATIONAL UNITY“}

„National unity“, das war während des Unabhängigkeitskrieges für alle Revolutionäre ein hoher Wert. Beaslais oben ausgeführtes Loblied auf die schon brüchige Einheit der Nation war nur ein besonders illustratives Beispiel dafür.

Nach der Vertragsspaltung war „national unity“ nicht nur ein Wert, den man im Sinne von Kompromiß und Ausgleich verstehen mußte. Die Bürgerkriegsparteien wandten "national unity“ gegeneinander. Die Legitimationsstrategien beider Bürgerkriegsparteien ließen sich auch als Varianten von „national unity“ lesen. Für die Vertragsbefürworter bedeutete „majority rule" eine durch Wahl meß- und zählbare „unity“ mit der Mehrheit der „living nation“.282 Für die Republikaner garantierte „the Republic“ nicht nur die „unity“ der vertragsablehnenden Elite, sondern auch eine nicht quantifizierbare „unity“ der Revolutionäre mit dem „Willen“ der historischen Nation und ihren republikanischen Märtyrern.283

Auch wenn die Bürgerkriegsparteien „national unity“ gegen die jeweils andere Seite instrumentalisierten: Primär war und blieb „national unity“ ein Wert, der die Einheit der ganzen revolutionären Bewegung und der Bevölkerung implizierte. Nur die radikalen Blätter Plain People und die Worker's Republic mißtrauten prinzipiell jedem weiteren Kompromiß: „Truth is bet-

280 Free State, 22. April 1922, S. 4; Irish Independent, 17. April 1922, S. 4; Hopkinson, Green, S. $75 \mathrm{f}$.

281 The Round Table, XiI, 47, (Juni 1922), S. 521; Sligo Champion, 29. April 1922, S. 4.

282 YOUNG IRELAND, 18. Februar 1922, S. 4.

283 An Poblacht, 10. Januar 1922, S. 2; CATHOlic Bulletin, Januar 1923, S. 22. 
ter than unity! Unity is not strength!“ Doch sie repräsentierten nur eine kleine Minderheit. ${ }^{284}$

Ansonsten unterstützten fast alle Politiker und Militärs beider Lager jede Bemühung, um eine rhetorisch meist gegen England und Nordirland gerichtete „national unity“ wieder herzustellen.285 Ihre Versuche, einen Kompromiß zu finden, waren eine Gegenbewegung zu dem, was viele Historiker in unbewußter Nachfolge der vertragsbefürwortenden Propaganda implizit als Einbahnstraße, als allein durch die Übergriffe der IRA verursachten „drift towards civil war“, darstellten.286

Selbst die radikaleren IRA-Aktivisten waren lange nicht so aggressiv und kriegsbereit, wie es auf den ersten Blick scheint. ${ }^{287}$ Die Übergriffe der IRA sollten Entschlossenheit demonstrieren, „Zitierten“ den Bürgerkrieg, sollten den Gegner einschüchtern und die IRA finanzieren. Doch auch für die radikalen Militärs war es ein Alptraum „to wade through Irish blood.“ Der Gedanke, auf ehemalige Kameraden zu schießen, war für sie unerträglich und kaum vorstellbar.

Wenn es darauf ankam, setzten sie ihre Drohungen nicht um, zögerten, den ersten Schritt zu tun: während der Limerick Crisis griff die IRA genauso wenig an, wie sie Griffith' Rede in Sligo unterdrückte. Statt dessen zerstörte sie am folgenden Tag die Druckplatten des Sligo Champion, der über die Schlappe der lokalen IRA berichtet hatte. ${ }^{288}$ Abgesehen von solchen unkoordinierten Anschlägen hatte die IRA keine offensive Strategie. Sie nutzte ihre klare militärische Überlegenheit nach der Vertragsspaltung nicht, sondern wartete darauf, die Republik zu verteidigen - während die vertragsbefürwortende Armee, weiter unter dem offiziellen Etikett IRA, aufrüstete. ${ }^{289}$

Doch auch wenn die vertragsbefürwortende Armee aufrüstete, so schnell sie konnte, hieß das nicht, daß sie unbedingt eine militärische Lösung des Konflikts wollte. Im vertragsbefürwortenden Lager waren es die Zivilisten wie Griffith, die weder auf „national unity“ noch auf die „ballot box“, son-

284 Worker's Republic, 24. Dezember 1921, S. 5; vgl. Plain People, 7. Mai 1922, S. 2.

285 An Poblacht, 1. Mai 1922, S. 4; CATHOlic Bulletin, März 1922, S. 139; Hopkinson, Green, S. 93-104.

286 So: MARYANN GIALANELla VALIUlis, „The man they could never forgive“- The View of the Opposition: De Valera and the Civil War, in: MurPHY und O'CARroll (Hrsg.), De Valera, S. 92-100, hier: S. 93; LYONS, Three Essays, S. 253; LAFFAN, ,Labour must wait', S. 216; vgl. Freeman's Journal, 28. April 1922, S. 4: „deadly drift“.

287 In diesem Zusammenhang unkritisch: TOWNSHEND, Political Violence, S. 361-3.

288 Sligo Champion, 29. April 1922, S. 4; FreEMAN's Journal, 22. April 1922, S. 5.

289 O’Donoghue, No Other Law, S. 225, 230; ANDRews, Dublin Made Me, S. 218; LitTon, Civil War; S. 86; vgl. NeESON, Civil War, S. 88; HOPKINSON, Green, S. 102, 119. 
dern auf „bullets“ setzten. Ein Krieg mit den Vertragsgegnern, so Griffith, sei unvermeidbar, deshalb sollte ihn die Provisorische Regierung zügig hinter sich bringen. 290

Die offizielle Freistaatspropaganda, fast alle Provinzzeitungen und alle Tageszeitungen bis auf die unionistische Irish Times propagierten dagegen „national unity“.291 Das war nicht nur Propaganda. Gerade die militärische Führung der Vertragsbefürworter, Collins und Mulcahy, hofften auf einen Ausgleich mit ihren alten Kameraden. Wie viele prominente vertragsablehnende Militärs setzten auch sie auf „army unity“ und mißtrauten politischen Kompromissen. ${ }^{292}$ Immer wieder bemühten sich führende IRA- und IRB-Aktivisten, eine organisatorische Einheit der IRA wiederherzustellen. Doch ihre Kompromisse waren nicht tragfähig, weil sie inhaltlichen Fragen aus dem Weg gingen und von radikaleren vertragsablehnenden Aktivisten ignoriert wurden. 293

Auch auf der politischen Ebene versuchten sich vertragsbefürwortende und vertragsablehnende Aktivisten immer wieder zu einigen. ${ }^{294}$ Doch auch ihre Verhandlungen scheiterten, weil die Positionen beider Seiten prinzipiell unvereinbar waren. Nicht etwa, weil Republikaner und Freistaatler zu weit, sondern weil sie zu nahe beieinander lagen. Gab es eine Mitte zwischen „Republic“ und „treaty“? Auf diese Frage war de Valeras Document No. 2 eine geniale beziehungsweise genialische Antwort. Doch war es, wie die vertragsbefürwortende Propaganda immer wieder treffend feststellte, eine Antwort auf die falsche Frage. ${ }^{295}$ Die entscheidende Frage lautete: Akzeptierte die revolutionäre Elite den Vertrag? Beziehungsweise: Sollte sie für Nachverhandlungen einen Krieg mit Großbritannien riskieren? Diese Fra-

290 VALIULIS, Mulcahy, S. 131 f., 146; so auch rückblickend: BEASLAI, Collins, S. 397; LiTTON, Civil War, S. 43; HOPKINSON, Green, S. 64, 99.

291 Young IRELAND, 4. Februar 1922, S. 4; FrEEMAN'S Journal, 2. Mai 1922, S. 4; IRISH INDEPENDENT, 2. Mai 1922, S. 4; IRISH Homestead, 22. April 1922, S. 249 f.; Clare ChamPION, 4. März 1922, S. 3; Cork EXAMINER, 23. März 1922, S. 4; DroghedA IndePENDENT, 27. Mai 1922, S. 4; KeRry PeOPle, 14. Januar 1922, S. 3; Limerick LEADER, 20. Februar 1922, S. 3; MAYO NEWS, 20. Mai 1922, S. 2; NATIONALIST, 21. Januar 1922-4. Februar 1922, S. 5; MUNSTER News, 24. Mai 1922, S. 3.; WATERFORD News, 24. Februar 1922, S. 5; Western People, 8. April 1922, S. 5; Wexford People, 8. Februar 1922, S. 4; Ausnahmen waren die IRISH TIMES, 26. April 1922, S. 5 und die dezidiert vertragsbefürwortenden Blätter Dundalk Democrat, 27. Mai 1922, S. 4 und Galway ObSerVer, 13. Mai 1922, S. 2.

292 VALiUlis, Mulcahy, S. 137, 140 f., 143.

293 Catholic Bulletin, Juni 1922, S. 354-6; Hopkinson, Green, S. 92-5, 101-4; Valiulis, Mulcahy, S. 132f., 137, 140-5, 147, 150-2; O’DonOGHUE, No other Law, S. 197, $238-44$.

294 HOPKINSON, Green, S. 95-7.

295 Young Ireland, 22. April 1922, S. 4; Freeman's Journal, 20. Mai 1922, S. 4; UnITED IRISHMAN, 1. März 1923, S. 2. 
gen ließen sich sinnvoll nur mit ja oder nein beantworten. Ein Kompromiß war so strukturell unmöglich. Es exisitierte kaum Verhandlungsmasse.296

Trotz dieser Aussichtslosigkeit gaben beide Seiten lange Zeit das Verhandeln nicht auf: um einen Bürgerkrieg zu verhindern, um von der gegnerischen Propaganda nicht als Aggressor dargestellt zu werden, und die Vertragsbefürworter, weil jeder Tag ihre militärischen Chancen erhöhte. ${ }^{297}$

\section{Der Collins-De-VAlera-PAKT: Hoffen und TAKTIEREN}

Obwohl ein Kompromiß zwischen Vertragsbefürwortern und -gegnern theoretisch unmöglich war, solange nicht eine Seite prinzipiell nachgab, einigten sich Collins und de Valera am 20. Mai 1922 auf einen Wahlpakt.

Im Wahlpakt verpflichtete sich die Provisorische Regierung, den mit Großbritannien ausgehandelten Verfassungsentwurf vor der Wahl zu veröffentlichen und nach der Wahl eine Koalitionsregierung mit den Republikanern zu bilden: Neben fünf vertragsbefürwortenden Ministern sollte es vier vertragsablehnende Minister geben und einen direkt von der IRA gewählten Verteidigungsminister. De facto hieß das, daß die Vertragsgegner den Verteidigungsminister stellten und über ihn zumindest nominal die gesamte Truppe kontrollieren konnten.

Bei den Wahlen sollten Vertragsbefürworter und -gegner gemeinsam als Sinn Fein antreten. Beide Seiten sollten den Vertrag dabei nicht zum Thema der Wahl machen und ihre Wähler ermutigen, keinen Kandidaten wegen seiner Haltung in der Vertragsfrage zu bevorzugen. Jede Seite durfte so viele Kandidaten aufstellen, wie es ihrer momentanen Stärke in Dail Eireann entsprach. Nur in einem Punkt stellten die Vertragsbefürworter sicher, daß der von ihnen so vehement vertretene Wert „majority rule“ nicht völlig zu Gunsten der nationalen Frage ausgehebelt wurde: Auch „third issues“, also von Sinn Fein unabhängige Parteien, durften an der Wahl teilnehmen. Doch auch das änderte nicht viel an der Dominanz Sinn Feins: unter ihrem moralischen, manchmal auch gewalttätigen Druck stellten sich nur 54 Nicht-Sinn Fein-Kandidaten zur Wahl. Selbst wenn sie alle gewählt worden wären, waren bei insgesamt $128 \mathrm{zu}$ wählenden Abgeordneten der zukünftigen Sinn Fein-Koalition von vornherein 74 Abgeordnete sicher. ${ }^{298}$ Ob der Wahlpakt

296 NeW IRELAND, 22. April 1922, S. 308.

297 Irish InDEPENDENT, 2. Mai 1922, S. 4; 4. Mai 1922, S. 4; vgl. FLK, DeV, Pressestatement von de Valera, Januar 1. Mai 1922, HOPKINSON, Green, S. 103.

298 Michael Gallagher, The Pact Election of 1922, in: Irish Historical Studies, XXI, 84, (1979), S. 404-21, hier: S. 408. 
hielt, lag nun allein an den Sinn Fein-Wählern: Das irische Verhältniswahlrecht nach dem Prinzip des „single transferable vote“ erlaubte ihnen, am Pakt vorbei gezielt vertragsbefürwortende oder vertragsablehnende Kandidaten zu wählen. ${ }^{299}$

Das erstaunliche an diesem Pakt war, daß er keine inhaltlichen Fragen berührte. Er war ein reiner Formelkompromiß, der der Vertragsfrage systematisch aus dem Weg ging. ${ }^{300} \mathrm{Z}$ war unterstützen bis auf wenige Provinzblätter und die Irish Times alle Zeitungen den Wahlpakt. ${ }^{301}$ Doch auch sie wunderten sich, wie der Pakt funktionieren sollte, ohne die Vertragsfrage zu klären. Die meisten Blätter vermuteten, daß es geheime Absprachen gäbe. ${ }^{302}$ Für Irish Labour, vor allem aber für die ausgegrenzten Unionisten wirkte dabei diese neu definierte „national unity“ bedrohlich; 303 denn während republikanische und vertragsbefürwortende Propaganda der nationalen Labour Party noch ein historisches Existenzrecht einräumten, sahen sie keinen Grund, auf die Bedenken unionistischer „Clubsesselsitzer" Rücksicht zu nehmen. ${ }^{304}$ Für radikale Unionisten wie Bretherton schienen sich nun ihre düstersten Prophezeiungen zu erfüllen. Die „IRA in search of Irish traditions with which to adorn history [is planning] the real butchery [of] Loyalists." 305 Was Bretherton schon im April zynisch prophezeit hatte, was die Irish Times nur zwischen den Zeilen befürchtete und was die radikale IRA hoffte, sprach die Worker's Republic offen aus: Sie forderte einen „Northern Crusade." Auch die republikanischen Politiker spekulierten nicht nur auf eine „republikanische“ Verfassung, sondern vor allem auf eine gemeinsame Politik gegen Nordirland. 306

Für die Vertragsgegner hatte der Pakt nichts Doppelbödiges. Er war zwar auch für sie ein kalkulierter Zug, um nicht als Kriegstreiber zu gelten. Der Pakt selbst basierte jedoch auf den zentralen Werten der Republikaner. Er war in seiner schwammigen Art so lesbar, daß er „national unity“ gegen den

299 Das irische personalisierte Verhältniswahlrecht nach dem „single transferable vote“ ist in seinen Details reichlich kompliziert. Siehe dazu: Michael Gallagher, Irish Elections 1922-1944: Results and Analysis. Dublin 1993, S.X.

300 HOPKINSON, Green, S. 98 f.

301 Ausnahmen waren: SLIGo Champion, 27. Mai 1922, S. 4; bedingt: Galway ObSERVER, 17. Juni 1922, S. 2 und IRISH TIMES, 22. Mai 1922, S. 4.

302 Irish Homestead, 27. Mai 1922, S. 330; IRISH Times, 22. Mai 1922, S. 4; VolCe OF LABOUR, S. 4; WORKER'S REPUBLIC, 27. Mai 1922, S. 3.

303 IRISH TIMES, 22. Mai 1922, S. 4; VOICE OF LABOUR, 27. Mai 1922, S. 4.

304 AN Poblacht, 15. Juni 1922, S. 2; IRELAND Over ALL, 7. April 1922, S. 3.

305 NAI, D/T, S-1322, Telegramm, ca. 5. April 1922.

306 Worker's Republic, 27. Mai 1922, S. 3; Irish Times, 22. Mai 1922, S. 4; AN Poblacht, 1. Juni 1922, S. 4; 8. Juni 1922, S. 1; Plain PeOPle, 28. Mai 1922, S. 2; HopKinson, Green, S. $98-100$. 
„common enemy“ garantierte, ohne zuviel von „the Republic“ aufzugeben. 307

Neben der Hoffnung auf „national unity“ erreichte der Wahlpakt für die auf das Symbolische fixierten Republikaner einen greifbaren Erfolg: Es gab keine Wahl zum Vertrag, die Bevölkerung hatte keine Chance „[to vote for] the voluntary entry of the Irish people into the British Empire, for the first time in history. “308 Für die Republikaner war damit ein nationaler Alptraum verhindert. Der Wahlpakt blockierte, daß die Vertragsbefürworter ihre Politik ungebrochen demokratisch legitimieren konnten. Das inhomogene vertragsablehnende Lager von radikaler IRA bis zu gemäßigten Politikern stand deshalb fast geschlossen zu de Valeras Pakt. Einzig die kleine Gruppe um die kommunistische Worker's Republic wertete den Pakt als naive Zeitverschwendung und propagierte weiter den „inevitable clash“ mit dem Freistaat. 309

Auch die Vertragsbefürworter erwarteten sich vom Wahlpakt Vorteile. Er fügte sich in die zweigleisige Politik der Provisorischen Regierung: geheime Verfassungspolitik und aggressive Nordirlandpolitik auf der republikanischen Seite; Aufrüstung und vertragsbefürwortende Agitation auf der freistaatlichen Seite. Als Teil einer mit de Valera abgesprochenen „steppingstone“-Politik war der Wahlpakt ein Druckmittel gegenüber Großbritannien. Der Pakt signalisierte, wie entschlossen die Provisorische Regierung und wie geschlossen die nationalen Bewegung waren. Der Pakt sollte der Provisorischen Regierung helfen, eine möglichst republikanische Verfassung durchzusetzen - um wiederum den Pakt aufrecht erhalten zu können. ${ }^{310}$

Aber auch innerhalb der freistaatlichen Politik war der Pakt sinnvoll. Der Wahlpakt begrenzte das Chaos und die Übergriffe der IRA, erlaubte der Provisorischen Regierung zu regieren, es zumindest zu versuchen. Dazu verschaffte der Pakt der Provisorischen Regierung ein Stück demokratische Legitimation - wie unbefriedigend der Wahlmodus auch immer war. ${ }^{311}$ Einige Freistaatspolitiker - wie Darrel Figgis - brachen deshalb aus dem

307 AN POBLACHT, 25. Mai 1922, S. 4.

308 CATHOlic Bulletin, Februar 1922, S. 72.

309 WORKER'S REPUBLIC, 27. Mai 1922, S. 3.

310 FLK, DeV, 216, Memo de Valera für Joe McGarrity über Gespräch mit Collins, ca. Mai 1922; DONALD HARMAN AKENSON und J. F. FALlin, The Irish Civil War and the Drafting of the Irish Free State Constitution, in: Eire/Ireland, V, 1 (1970), S. 10-26, V, 3, (1970), S. 42-93, V, 4, (1970), S. 28-70, hier: no.1, S. 11 f., S. 22-4, no. 2, S. 44; no.4, S. 29, 34 f., 38.

311 Free STATE, 27. Mai 1922, S. 4 f.; Young Ireland, 27. Mai 1922, S. 4; Hopkinson, Green, S. 98-100. 
Pakt aus. Sie unterstützen eine gemeinsame Kampagne aller Dubliner Tageszeitungen für unabhängige Kandidaten, um so aus der Paktwahl doch noch eine Abstimmung über den Vertrag zu machen. ${ }^{312}$ Die republikanische Propaganda reagierte entsetzt auf den „Verrat“ von Figgis, einzelne IRA-Aktivisten rabiat. Sie entführten Figgis und entmannten ihn symbolisch: Sie nahmen ihm seinen roten Vollbart ab, der neben seinem Tirolerhut das Markenzeichen des eigenwilligen Aktivisten gewesen war. ${ }^{313}$ Doch auch wenn Figgis den Pakt unterlief und die IRA provozierte, so war er deshalb nicht weniger national als viele seiner Parteifreunde. Als Vorsitzender der Verfassungskommisson arbeitete er mit an der „republikanischen“ Variante der vertragsbefürwortenden Politik. ${ }^{314}$

Wie ein aufmerksamer anglo-irischer Beobachter kritisch formulierte, übten sich die Vertragsbefürworter, unter ihnen vor allem Collins, bis kurz vor dem Bürgerkrieg in der „rather dangerous facility for riding two horses simultaneously. “315 Collins probierte flexibel, welcher Feind leichter diplomatisch, notfalls militärisch zu besiegen war: Großbritannien oder die Republikaner. Solange sich die vertragsbefürwortende Führung nicht entscheiden mußte, gewann sie Zeit, um aufzurüsten. Sie wußte genauso wenig wie die verwirrten Republikaner und die irritierten Briten, auf was sie eigentlich hinaus wollte. ${ }^{316} \mathrm{Um}$ sich alle Handlungsmöglichkeiten offen $\mathrm{zu}$ halten, mußte die Provisorische Regierung auf eine klare Rhetorik verzichten, Ungereimtheiten verschweigen. Anders als die offen und häufig undiplomatisch argumentierenden Republikaner, mußten die vertragsbefürwortenden Propagagandisten ihre Gegner und die Bevölkerung in die Irre führen, manchmal auch anlügen. Sie hielten ihre zweigleisige Kalkulation nach außen geheim, kaschierten die Widersprüche zwischen „natonal unity“ und vertragsbefürwortender Rhetorik und legten sich in keiner Richtung fest. 317

\footnotetext{
312 Freeman's Journal, 10. Juni 1922, S. 4; IRISH IndePENDENT, 27. Mai 1922, S. 6; IRISH TIMES, 23. Mai 1922, S. 4; IRISH HOMESTEAD, 27. Mai 1922, S. 330.

313 WORKER'S REPUBLIC, 17. Juni 1922, S. 4: „Savage atrocity, horrible sacrilege, woeful desecration of Beauty"; vgl. AKENSON und FALLIN, Drafting, no.1, S. 13.

314 NAI, D/T, S-8952, Darrell Figgis an Griffith, 18. Januar 1922; Diarmuid O’Hegarty für Collins an Darrell Figgis, 27. Januar 1922; Darrell Figgis an Collins, 27. Januar 1922.

315 The Round TABLe, XII, 48, (September 1922), S. 789.

316 Thomas Towey, The Reaction of the British Government to the 1922 Collins-de Valera Pact, in: Irish Historical Studies, XXII, 85, (1980), S. 65-76, hier: S. 66-8.

317 Free State, 27. Mai 1922, S. 4; 3. Juni 1922, S. 4; Young IReland, 3. Juni 1922, S. 4; vgl. Evening Herald, 22. Mai 1922, S. 4.
} 


\section{TABUbruCh: DER AusbruCH DES BÜRGERKRIEgES}

Als am 15. Juni 1922 die irische Delegation in London damit scheiterte, eine quasi republikanische Verfassung durchzusetzen, geriet die Provisorische Regierung unter Zugzwang. Für eine Koalitionsregierung mit den Republikanern gab es keine Grundlage mehr. ${ }^{318}$

Nun setzten die Vertragsbefürworter alles auf ihre Freistaatspolitik. Während prominente Politiker wie Ernest Blythe, Eoin O'Duffy und Darrell Figgis schon zuvor den Wählern in ihrem Wahlkreis empfohlen hatten, lieber „unabhängig“ als vertragsablehnend zu stimmen, forderte zwei Tage vor der Wahl auch Collins seine Zuhörer bei einer Wahlkampfveranstaltung in Cork auf „to vote for the candidates you think best of “ .319 Damit hatte er den Wahlpakt ignoriert, wie die Republikaner - erst nach Ausbruch des Krieges - meinten, offen gebrochen. ${ }^{320}$ Fast alle Zeitungen publizierten Collins Rede, die so kurz vor den Wahlen in ganz Irland verbreitet wurde. Dennoch hielten sich die meisten Sinn Fein-Wähler, ob sie nun vertragsbefürwortend oder vertragsablehnend dachten, an den Pakt, was eine deutliche Wahlniederlage der Republikaner verhinderte. ${ }^{321}$ Auch in einem zweiten Punkt demontierten die Vertragsbefürworter den Pakt mit den Republikanern: Den Verfassungsentwurf veröffentlichten sie erst am Wahltag. ${ }^{322}$ Formal war das vor der Wahl, praktisch aber hatten die Republikaner und auch die irische Bevölkerung keine Chance, auf den Verfassungsentwurf zu reagieren.

Das Wahlergebnis brachte eine kleine Sensation: Neben 38,48 Prozent für vertragsbefürwortende Kandidaten und 21,26 Prozent für vertragsablehnende Kandidaten, stimmten 40,26 Prozent mit ihrer ersten Präferenz für Nicht-Sinn Fein-Kandidaten. Deutlich mehr als ein Drittel der Wähler hatten also ihrerseits Sinn Feins Definition von „national unity“ aufgekündigt, stimmten für ihr „sectional interest“ und gleichzeitig für den Vertrag. In Sitze umgerechnet, schlug sich das wesentlich weniger deutlich nieder: 58 Sitze für Vertragsbefürworter, 36 für Vertragsgegner, 17 für Labour, 10 für Unabhängige und 7 für Farmer. ${ }^{323}$ Aus der „national unity“ Sinn Feins aus-

318 Akenson und Fallin, Drafting, no.4, S. 64-9; Towey, Reaction, S. 71; Hopkinson, Green, S. 105-7, 111.

319 FREEMAN'S JOURNAL, 20. Juni 1922, S. 4.

320 Exemplarisch: CATHOLIC Bulletin, Juli 1922, S. 429; vgl. Oktober 1922, S. 634.

321 Michael Gallagher, Pact Election, S. 412f., 418f.; Hopkinson, Green, S. 109-11; BOYCE, Nationalism, S. 276.

322 IRISH INDEPENDENT, 16. Juni 1922, S. 5.

323 Michael GallagHer, Irish Elections, S. $14 \mathrm{f}$. 
gegrenzt zu sein, war für Labour, Farmer und Unabhängige von einer Bedrohung zu einem Vorteil geworden. ${ }^{324}$

Selbst de Valera wertete in einem ersten Interview den Ausgang der Wahlen als Niederlage für die Republikaner und als Erfolg der britischen Kriegsdrohung. ${ }^{325}$ Die Dubliner Tagespresse, die meisten Provinzzeitungen und die offizielle vertragsbefürwortende Propaganda begrüßten die Wahl als Plebiszit für den Vertrag. ${ }^{326}$ Mit dieser Rhetorik gab die Provisorische Regierung die ohnehin unrealistische Koalitionsregierung endgültig auf. ${ }^{327}$ Auch die britische Regierung betrachtete das Wahlergebnis als demokratische Legitimation für den Vertrag und erhöhte ihren Druck auf die Provisorische Regierung. ${ }^{328}$ Das war jedoch noch immer kein Automatismus Richtung Bürgerkrieg. Der Pakt sah für das Scheitern der Koalitionsregierung freie Neuwahlen nach einem aktualisierten Wahlregister vor. ${ }^{329} \mathrm{Ob}$ die radikale IRA das akzeptiert hätte, war eine andere Frage. Aber die Provisorische Regierung hätte weiter auf Zeit spielen können, solange die IRA nicht angriff.

Erst nachdem zwei radikale IRA-Aktivisten den prominenten Unionisten Sir Henry Wilson ermordet hatten, erst nachdem die britische Regierung die Four Courts-Besatzung als Drahtzieher des Mordes verdächtigt hatte und erst nach der ultimativen Drohung der britischen Regierung, die Four Courts notfalls selbst anzugreifen, mußte sich die Provisorische Regierung endgültig entscheiden. Die zweigleisige Politik des Freistaats war jetzt endgültig am Ende. ${ }^{330}$ Unter dem doppelten Druck von IRA und Großbritannien geriet die Führung der Vertragsbefürworter in einen Zugzwang, den sie nicht mehr kontrollieren konnte: Sie mußte sich entweder mit britischer Hilfe gegen die IRA wenden oder hoffen, daß die britische Regierung ihre Kriegsdrohung nicht wahr machte, sich dann notfalls mit Hilfe der IRA gegen Großbritannien wenden.

Wie im Dezember 1921 und wie bei den Verfasssungsverhandlungen ließ es die Führung der Vertragsbefürworter nicht darauf ankommen, auszupro-

324 Michael Gallagher, Pact Election, S. 416.

325 FLK, DeV, 236, Pressemitteilung de Valeras, 21. Juni 1922

326 IRISH InDEPENDENT, 20. Juni 1922, S. 4; IRISH TIMES, 20. Juni 1922, S. 4; DUNDALK Democrat, 24. Juni 1922, S. 4; Drogheda IndePENDENT, 24. Juni 1922, S. 4; GALWAY ObSERVER, 24. Juni 1922, S. 2; NATIONAlist, 21. Juni 1922, S. 5; RosCOMMON MESSANGER, 24. Juni 1922, S. 4.

327 Young Ireland, 1. Juli 1922, S. 4; Free State, 24. Juni 1922, S. 4; vgl. Hopkinson, Green, S. 102, 108, 111.

328 TOWEY, Reaction, S. 75.

329 HOPKINSON, Green, S. 98.

330 Vgl. bereits: NAI, D/T, S-1322a, Lloyd George an Collins, 22. Juni 1922. 
bieren, wie ernst es der britischen Regierung war. Jetzt entschied sich auch Collins für eine rein freistaatliche Politik. Die Provisorische Regierung wandte sich gegen den offenbar schwächeren Gegner: Sie stellte der IRA ein Ultimatum, die Four Courts zu räumen. 331

Seit Juni 1922 haben Historiker und Politiker darüber gestritten, ob die Freistaatsregierung auf britischen Druck handelte oder nicht. Bis heute reproduzieren sie dabei die Stereotypen der Bürgerkriegspropaganda; denn diese Frage impliziert eine moralische Aussage über die Provisorische Regierung und den Status des Freistaats. Nationalistische Historiker argumentierten in der Nachfolge der republikanischen Propaganda, der Freistaat habe als "Marionette“ auf Druck oder Befehl Englands gehandelt. ${ }^{332}$ Die Freistaatspropagandisten und die revisionistische Geschichtsschreibung versuchten dagegen, den Republikanern eines ihrer besten Argumente zu stehlen. Sie schrieben mehr oder weniger bewußt die Geschichte um und billigten dem Freistaat ein Stück Souveränität zu, das er nicht hatte. Sie argumentierten die Provisorische Regierung hätte die Four Courts nicht auf britischen Druck hin, sondern aus eigener Initiative angegriffen, etwa um einen Staatsstreich gegen die Demokratie zu verhindern. ${ }^{333}$

Bei allem Verständnis für den revisionistischen Feldzug gegen republikanische Mythen scheint das kaum glaubhaft: Die britische Drohung und das Ultimatum der Provisorischen Regierung hingen zeitlich und kausal direkt miteinander zusammen. Auch das schlecht vorbereitete Vorgehen der Vertragsbefürworter zu Beginn des Krieges spricht deutlich dafür, daß der britische Druck der entscheidende Impuls war, durch den die Vertragsbefürworter, insbesondere Collins, sich zu einem militärischen Schlag durchrangen. ${ }^{334} \mathrm{Ob}$ die Provisorische Regierung die Four Courts früher oder später angegriffen hätte, ob ein Teil der Provisorischen Regierung auch ohne britischen Druck gehandelt hätte, ist eine andere, rein spekulative Frage.

Jenseits dieser moralischen Fragen bleibt entscheidend: Die realpolitisch und flexibel denkenden Vertragsbefürworter blieben, auch in die Enge getrieben, handlungsfähig. Sie waren in der Lage, den Tabubruch zu denken und zu begehen, griffen ihre ehemaligen Kameraden in den Four Courts an,

331 Detailliert: HopkinSON, Green, S. 111-22, hier insbes.: S. 116-8.

332 MARgery Forester, Michael Collins: The Lost Leader. London 1971, S. 322; GrEAVES, Liam Mellows, S. 345 f.

333 Garvin, 1922, S. 31, übernimmt hier direkt die Propaganda von Freistaatsminister Ernest Blythe. Vgl. ebd., S. 53 f.; 127-9; VALIULIS, Mulcahy, S. 153; BOYCE, Nineteenth Century, S. 277; HOPKINSON, Green, S. 117 f.; LiTTON, Civil War, S. 69-70; vgl. YOUNGER, Civil War, S. 318f.; differenzierter: FOSTER, Modern Ireland, S. 512.

334 Hopkinson, Green, S. 117 f., zur Sonderrolle von Collins. 
um an der Macht zu bleiben, beziehungsweise, um überhaupt erst an die Macht zu gelangen.

Stolperten die Vertragsbefürworter auf britischen Druck in den Bürgerkrieg hinein, so waren die Republikaner völlig unvorbereitet, ohne offensive Strategie, untereinander zerstritten und in verschieden radikale politische und militärische Gruppen gespalten. Die Vertragsgegner saßen in einer kulturellen Falle: Die Verpflichtung auf „the Republic“ machte einen Ausgleich mit den Vertragsbefürwortern unmöglich, eine effiziente Kommandostruktur schwierig. Das Tabu des Brudermordens, das Denkverbot, ehemalige Kameraden anzugreifen, verhinderte, daß die IRA die militärische Initiative übernahm. ${ }^{335}$

Kurz vor dem Bürgerkrieg fand Tom Barry, als „Held von Cross Barry und Kilmichael“ schon zu Lebzeiten eine Guerillalegende, einen denkbaren Ausweg aus dieser Situation. Er erfand eine Methode, „republican unity“, „national unity“ und „Konfrontation“ so aufeinander zu beziehen, daß sich das Dilemma der republikanischen Handlungsunfähigkeit löste. Am 18. Juni 1922 stellte er der IRA in Dublin seinen Plan vor, innerhalb der nächsten vierundzwanzig Stunden die letzten in Irland verbleibenden britischen Truppen anzugreifen. Barry hoffte auf eine britische Vergeltung und auf eine neue „national unity“ gegen den „common enemy“.336 Er vertraute auf das republikanische Geschichtsgesetz, das ihm sagte, die Mehrheit der Bevölkerung werde einen Konflikt mit England als „Freiheitskrieg“ verstehen. Barry wollte einen neuen Unabhängigkeitskrieg erzwingen, um einen Bürgerkrieg zu vermeiden, - und das ging nur, solange der „common enemy" noch nicht völlig abgezogen war.

Auch wenn Barrys perfides Kalkül republikanischen Politikern, selbst vielen Guerilleros „,idiotisch“ vorkam, 337 aus der Perspektive eines intransigenten Republikaners hatte es seine eigene, nicht ganz unrealistische Logik. Auch die britische Regierung und führende britische Militärs fürchteten, die IRA könne einen Konflikt provozieren. Sie waren deshalb bereit, Übergriffe, selbst vereinzelte Morde an britischen Soldaten zu ignorieren. ${ }^{338}$

In einer turbulenten Sitzung stimmte erst eine knappe Mehrheit für Barrys Vorschlag, beim zweiten Nachzählen eine knappe Mehrheit dagegen.

335 O’Donoghue, No Other Law, S. 225, 230, $260 \mathrm{f}$.

336 Hopkinson, Green, S. 115; VAliulis, Mulcahy, S. 152; O’Donoghue, No Other Law, S. $245 \mathrm{f}$.

337 Andrews, Dublin Made Me, S. 226; vgl. Brennan, Allegiance, S. 338.

338 Zur Angst der britischen Regierung vor provokativen Angriffen der IRA auf ihre Truppen: Macready, Annals, Bd. 2, S. 627, 633, 652f.; The Round TABle, XII, 47, (Juni 1922), S. 535; HOPKINSON, Green, S. 53 f., 73. 
Auch um der Bevölkerung einen neuen Unabhängigkeitskrieg aufzuzwingen, war die IRA also zu defensiv. Barry erreichte genau das Gegenteil von „national unity“. Nach seinem Vorschlag löste sich die Versammlung auf, die IRA-Exekutive spaltete sich jetzt offen in zwei Lager: Die radikaleren Aktivisten folgten Barry in die Four Courts, die Munster IRA um Liam Lynch bezog ihr Quartier in einem Dubliner Hotel. Keines der beiden Lager beschloß eine konkrete Politik für die folgenden Wochen und Monate. Die handlungsunfähige und gespaltene IRA schien der Freistaatsführung so ein leichter Gegner, ein Bürgerkrieg vielleicht sogar auf einen kurzen Kampf um die Four Courts beschränkbar. ${ }^{339}$

Was läßt sich für die Zeit zwischen Vertragsspaltung und dem Ausbruch des Bürgerkrieges zusammenfassen? Die führenden Propagandisten des Unabhängigkeitskrieges bestimmten ab 1922 auch die Propaganda der konkurrierenden Lager. FitzGerald und Beaslai auf der Seite der Vertragsbefürworter, Childers, Brennan und Gallagher auf der Seite der Republikaner. Dabei waren die von FitzGerald zentral gesteuerten Propagandabehörden der republikanischen Publicity organisatorisch weit überlegen. Vor allem, daß die Dubliner Tagespresse und fast alle Provinzzeitungen den Vertrag unterstützen, wurde zum uneinholbaren propagandistischen Vorsprung des Freistaats.

Die nationale Legitimation des Vertragsbefürworter war ohne den direkten Zugriff auf „1916“ und „the Republic“ zunächst brüchig. Ihre republikanische „stepping-stone“-Politik ließ sich nur heimlich umsetzen. Sie ergab keine überzeugenden Propagandageschichten, sondern erzählte im Normalfall von Kompromissen und den Grenzen irischer Souveränität. Dazu war der Versuch, sich hinter einer republikanischen Fassade zu verstecken, wenig überzeugend. Den „nationalen“ Eigenschaften des Vertrages haftete das Stigma des Materialismus und des Verrats an der Republik an. Auf anti-englische Rhetorik konnte die Freistaatspropaganda nur noch mit Schwierigkeiten zurückgreifen. Ihre anti-nordirische Rhetorik unterschied sich kaum von der der Republikaner. Während die Freistaatsführung so in einer Legitimationskrise steckte, fanden die Republikaner auch mit Document No. 2 nicht aus ihrer Handlungskrise heraus. Auf die Vorgaben von „the Republic“ fixiert, waren sie weder gegenüber dem Freistaat noch gegenüber der britischen Regierung kompromißfähig.

Erst als die freistaatlichen Propagandisten „majority rule“ und „liberal rights“ ins Nationale wandten, gelang ihnen eine überzeugendere Form der

339 Ebd., S. 115, 118; VAliulis, Mulcahy, S. 152f.; O’DonOghue, No Other Law, S. 245 f. 
nationalen Legitimation. Dazu modifizierten sie das republikanische Geschichtsgesetz. Sie definierten den jahrhundertelangen irischen Freiheitskampf als einen Krieg für diese bisher als sekundär geltenden Werte. Dabei gingen sie genauso flexibel und selektiv mit Geschichte um wie ihre republikanischen Gegner. Wegen der zahllosen Übergriffe der IRA fiel es den Freistaatspropagandisten leicht, „majority rule“ und „liberal rights“ zu monopolisieren und dem gesamten republikanischen Lager „britische“ Eigenschaften zuzuschreiben. Dabei machten die republikanischen Politiker der vertragsbefürwortenden Propaganda die Arbeit noch leichter: De Valera und die meisten anderen prominenten Aktivisten distanzierten sich nicht von der IRA, sondern zeigten in ihren Reden selbst immer wieder ein ambivalentes Verhältnis zur Gewalt. So versuchten die republikanischen Politiker mit wenig Erfolg, die innere Einheit des brüchigen republikanischen Spektrums wenigstens nach außen hin zu wahren.

Doch trotz des sich schnell polarisierenden Verhältnisses zwischen beiden Lagern gab es keinen Automatismus Richtung Bürgerkrieg. Der von Beaslai Ende 1921 gepriesene Wert „national unity“ war auf beiden Seiten nach wie vor eine Kernvorstellung. Trotz ihrer permanenten Übergriffe, trotz ihrer Verachtung für die öffentliche Meinung war gerade die radikale IRA kulturell angriffsunfähig: Sie war nicht in der Lage, den Angriff gegen ehemalige Kameraden zu denken und umzusetzen. Dennoch scheiterten alle Versuche, einen Bürgerkrieg zu verhindern, weil es in der entscheidenden Frage keine Verhandlungsmasse gab, weil ein Kompromiß nur dann möglich gewesen wäre, wenn Großbritannien nachverhandelt hätte. So sah sich die Führung der Vertragsbefürworter unter dem zunehmenden Druck der britischen Regierung schließlich gezwungen, das Gewaltmonopol des von ihnen propagierten Freistaats militärisch durchzusetzen. 